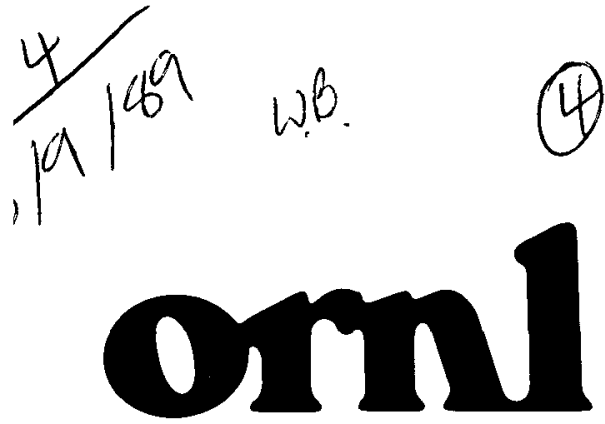

\section{OAK RIDGE NATIONAL LABORATORY}

MARTIN MARUETRA
DR $06 / 1-4$

ORNL/TM-10912

ISPO-293

\title{
Process Monitoring in International Safeguards for Reprocessing Plants- A Demonstration
}

M. H. Ehinger

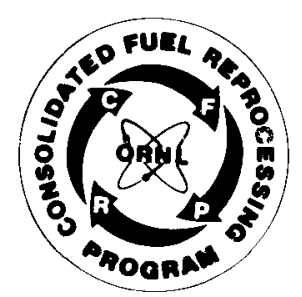

OPERATED BY

MARTIN MARIETTA ENERGY SYSTEMS, INC.

FOR THE UNITED STATES

DEPARTMENT OF ENERGY 


\section{Printed in the United States of America. Available from National Technical Information Service \\ U.S. Department of Commerce \\ 5285 Port Royal Road, Springfield, Virginia 22161 \\ NTIS price codes-Printed Copy: A05 Microfiche A01}

This report was prepared as an account of work sponsored by an agency of the United States Government. Neither the U nited States Government nor any agency thereof, nor any of their employees, makes any warranty, express or implied, or assumes any legal liability or responsibility for the accuracy, completeness, or usefulness of any information, apparatus, product, or process disclosed, or represents that its use would not infringe privately owned rights. Reference herein to any specific commercial product, process, or service by trade name, trademark, manufacturer, or otherwise, does not necessarily constitute or imply its endorsement, recommendation, or favoring by the United States Government or any agency thereof. The views and opinions of authors expressed herein do not necessarily state or reflect those of the United States Government or any agency thereof. 


\section{DISCLAIMER}

This report was prepared as an account of work sponsored by an agency of the United States Government. Neither the United States Government nor any agency Thereof, nor any of their employees, makes any warranty, express or implied, or assumes any legal liability or responsibility for the accuracy, completeness, or usefulness of any information, apparatus, product, or process disclosed, or represents that its use would not infringe privately owned rights. Reference herein to any specific commercial product, process, or service by trade name, trademark, manufacturer, or otherwise does not necessarily constitute or imply its endorsement, recommendation, or favoring by the United States Government or any agency thereof. The views and opinions of authors expressed herein do not necessarily state or reflect those of the United States Government or any agency thereof. 


\section{DISCLAIMER}

Portions of this document may be illegible in electronic image products. Images are produced from the best available original document. 


\title{
PROCESS MONITORING IN INTERNATIONAL SAFEGUARDS FOR REPROCESSING PLANTS - A DEMONSTRATION
}

\author{
JANUARY 1989
}

UNITED STATES PROGRAM FOR TECHNICAL ASSISTANCE TO IAEA SAFEGUARDS

\section{POTAS}

\section{H. EHINGER \\ FUEL RECYCLE DIVISION}

\author{
OAK RIDGE NATIONAL LABORATORY \\ Oak Ridge, Tennessee 37831 \\ operated by \\ MARTIN MARIETTA ENERGY SYSTEMS, INC. \\ for the \\ U.S. DEPARTMENT OF ENERGY \\ under Contract No. DE-AC05-84OR21400
}

INTERNATIONAL SAFEGUARDS PROJECT OFFICE

BROOKHAVEN NATIONAL LABORATORY

UPTON, LONG ISLAND, NEW YORK 11973 


\title{
DISCLAIMER
}

This report was prepared as an account of work sponsored by an agency of the United States Government. Neither the United States Government nor any agency thereof, nor any of their employees, makes any warranty, express or implied, or assumes any legal liability or responsibility for the accuracy, completeness, or usefulness of any information, apparatus, product, or process disclosed, or represents that its use would not infringe privately owned rights. Reference herein to any specific commercial product, process, or service by trade name, trademark, manufacturer, or otherwise does not necessarily constitute or imply its endorsement, recommendation, or favoring by the United States Government or any agency thereof. The views and opinions of authors expressed herein do not necessarily state or reflect those of the United States Government or any agency thereof.
ORNL/TM-10912

ISPO-293

Dist. Category UC-526

Consolidated Fuel Reprocessing Program

\section{PROCESS MONITORING IN INTERNATIONAL SAFEGUARDS FOR REPROCESSING PLANTS-A DEMONSTRATION}

M. H. Ehinger

Fuel Recycle Division

Date Published-January 1989

\author{
Prepared for the \\ Omice of Facillites, Fuel Cycle, \\ and Test Programs \\ Prepared by the \\ OAK RIDGE NATIONAL LABORATORY \\ Oak Ridge, Tennessee 37831 \\ operated by \\ MARTIN MARIETTA ENERGY SYSTEMS, INC. \\ for the \\ U.S. DEPARTMENT OF ENERGY \\ under contract DE-AC05-840R21400
}





\section{CONTENTS}

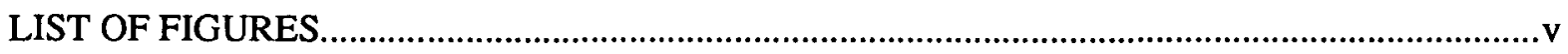

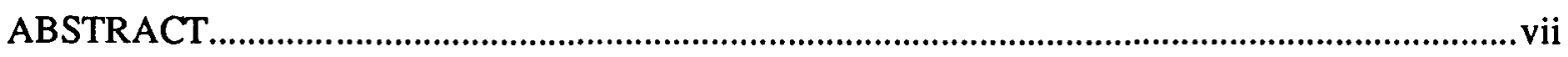

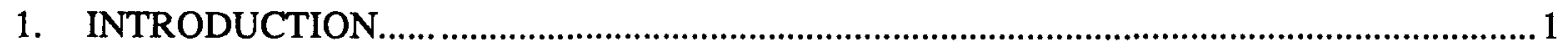

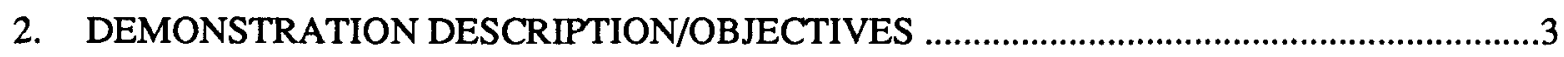

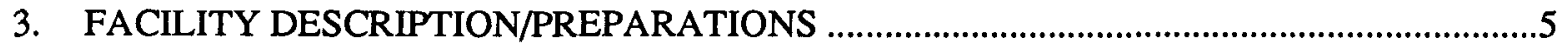

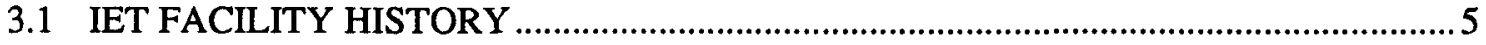

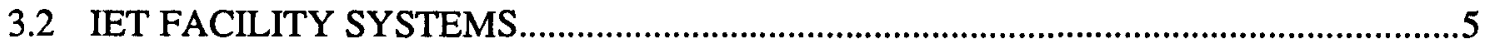

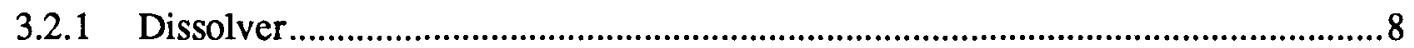

3.2.2 Accountability/Feed Preparation ............................................................. 8

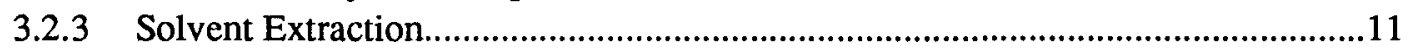

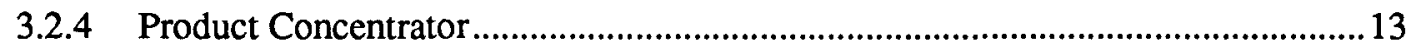

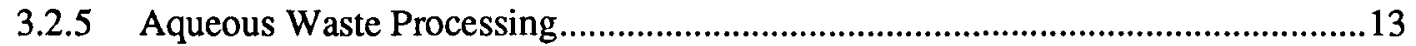

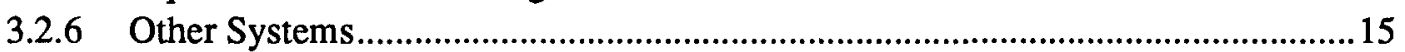

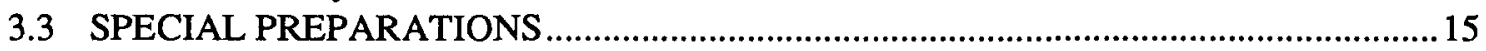

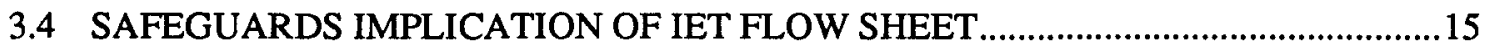

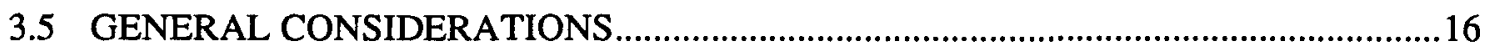

4. INSTRUMENT AND COMPUTER SYSTEM DESCRIPTION ..........................................

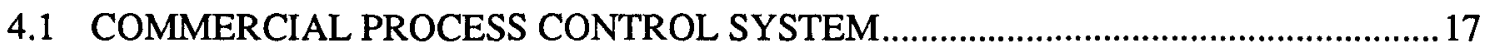

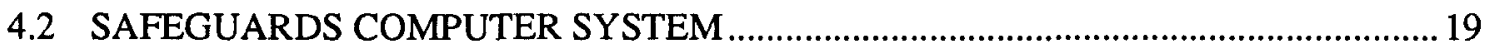

4.3 INTRODUCTION TO COMPUTER USE .............................................................. 19

5. PROCESS MONITORING ROLE IN SAFEGUARDS METHODOLOGIES ........................21

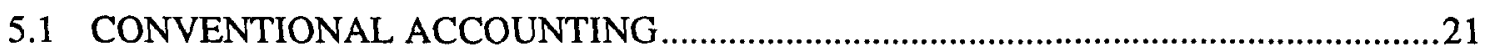

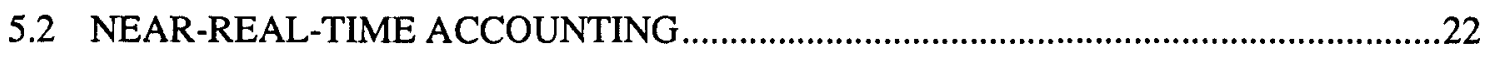

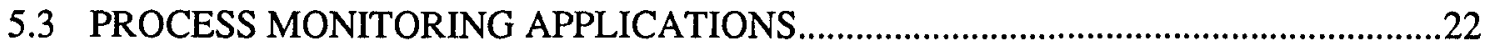

5.4 PROCESS MONITORING FOR THE DEMONSTRATION ........................................22

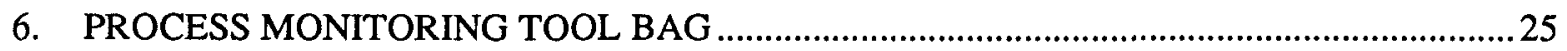

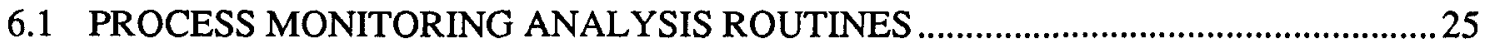

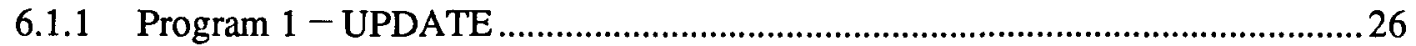

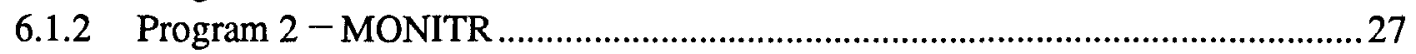

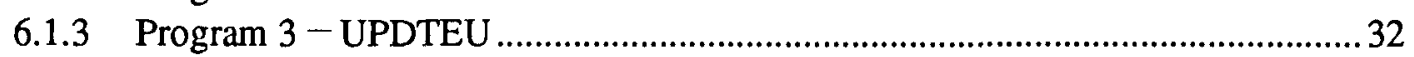

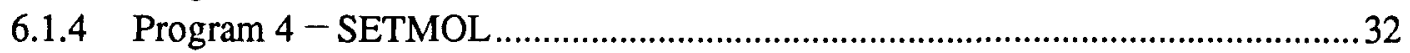




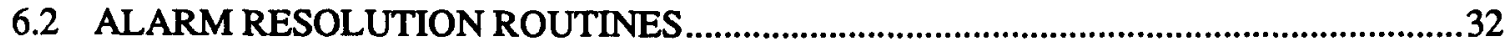

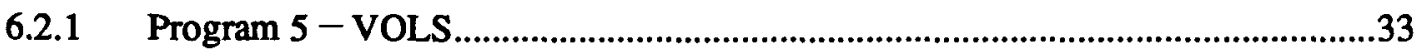

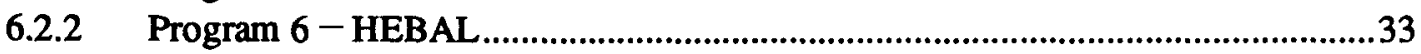

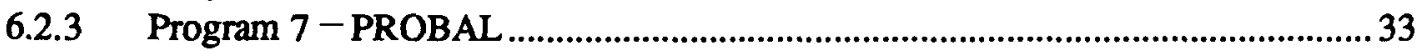

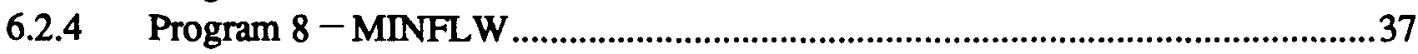

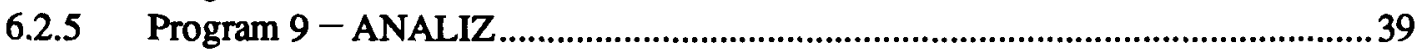

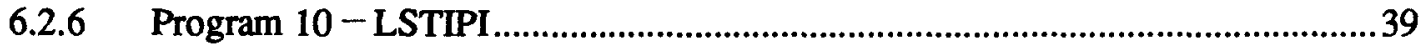

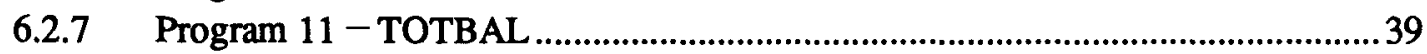

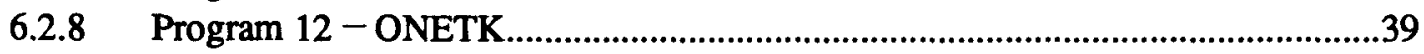

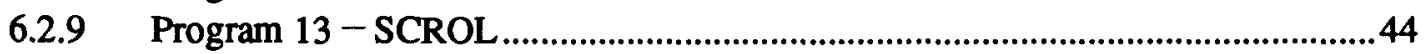

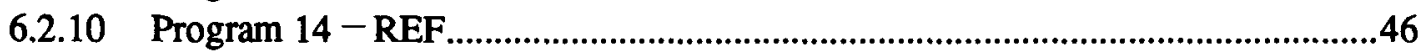

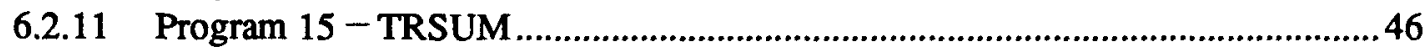

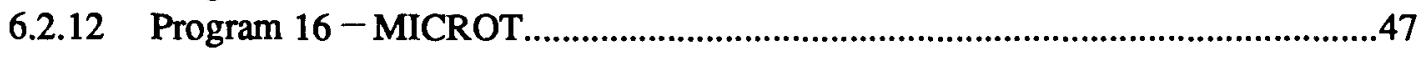

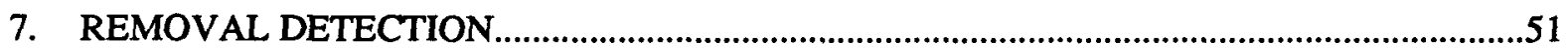

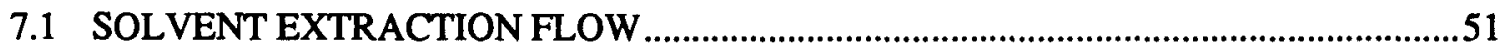

7.2 PRODUCT TANK MEASUREMENT BIAS DETECTION .........................................54

7.3 INPUT ACCOUNTABILITY MEASUREMENT ALARMS ...........................................58

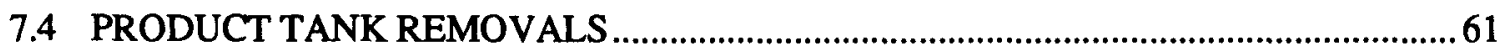

7.5 REMOVAL FROM SOLVENT EXTRACTION FEED TANK .....................................65

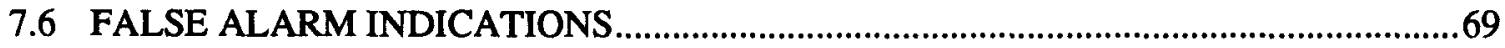

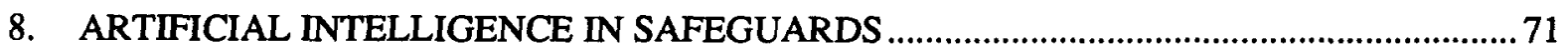

9. PROCESS MONITORING FOR INTERNATIONAL SAFEGUARDS .................................73

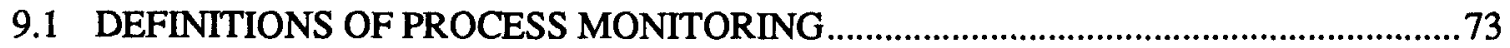

9.2 PROCESS MONITORING, THE BROAD RANGE OF TOOLS.....................................74

9.3 THE ROLE OF PROCESS MONITORING FOR

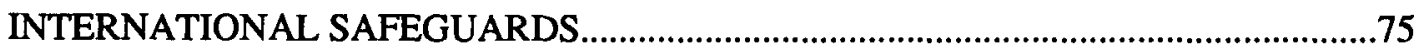

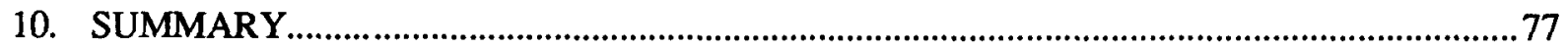

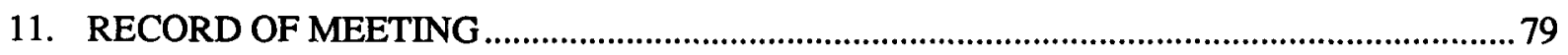

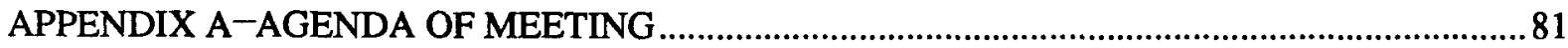




\section{LIST OF FIGURES}

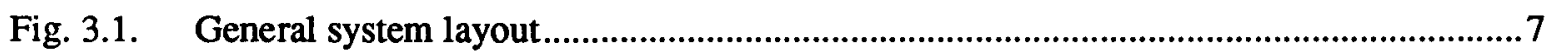

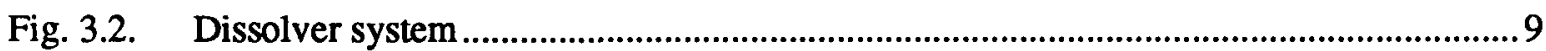

Fig. 3.3. Accountability and feed preparation area.............................................................10

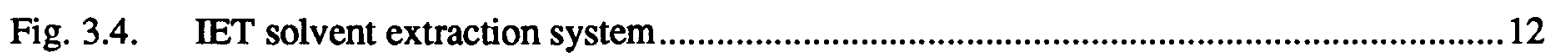

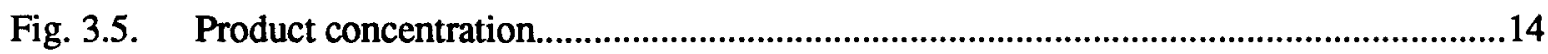

Fig. 4.1. The data acquisition system hardware configuration..............................................18

Fig. 6.1. Menu screen - available software routines........................................................26

Fig. 6.2. UPDATE routine - to record IPI data...............................................................28

Fig. 6.3. Selection of MONITR from menu (for periods 1961-87).........................................29

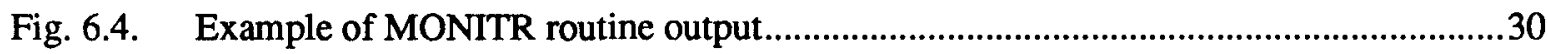

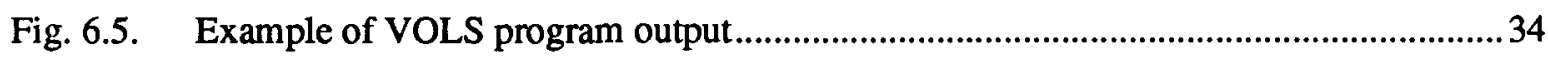

Fig. 6.6. Example of HEBAL program output (input area balance) ........................................... 35

Fig. 6.7. Example of PROBAL program output (product area balance)...................................36

Fig. 6.8. Example of MINFLW program (solvent extraction balance)...................................... 38

Fig. 6.9. Example of output from ANALIZ program...............................................................40

Fig. 6.10. In-process inventory summary from LSTIPI program ........................................41

Fig. 6.11. NRTA balance summary - TOTBAL program ....................................................42

Fig. 6.12. Single tank data summary - ONETK program........................................................43

Fig. 6.13. Procedure to initiate SCROL program (data summary) ...............................................44

Fig. 6.14. Example of SCROL program (HA feed tank summary)...........................................45

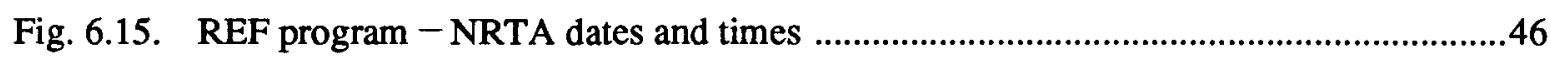

Fig. 6.16. TRSUM program - event-logging summary .........................................................48

Fig. 6.17. Initiation of MICROT program - tank transfer summary ......................................48

Fig. 6.18. MICROT program output - tank transfer summary ................................................49

Fig. 7.1. Alarm summary with HEBAL program..............................................................52

Fig. 7.2. MINFLW summary to confirm flow bypass.......................................................53

Fig. 7.3. MONITR program output showing product transfer................................................55

Fig. 7.4. Detail summary of product transfer from MICROT program.....................................57

Fig. 7.5. MONITR program - detection of accountability tank bypass..................................60

Fig. 7.6. MONITR program - detection of product tank removals ......................................61

Fig. 7.7. Confirmation of product tank removals with SCROL program.................................63 
Fig. 7.8. MONITR program alarm on feed adjust tank (11F03) .......................................66

Fig. 7.9. Confirmation of instrument failure with SCROL program....................................67

Fig. 7.10. Removal detection with HEBAL program.............................................................68

Fig. 7.11. Confirmation of removal with MINFLW program...................................................70 


\begin{abstract}
In the period 1985-87, the Oak Ridge National Laboratory investigated the possible role of process monitoring for international safeguards applications in fuel reprocessing plants. This activity was conducted under Task C.59, "Review of Process Monitoring Safeguards Technology for Reprocessing Facilities" of the U.S. program of Technical Assistance to the International Atomic Energy Agency (IAEA) Safeguards program. The final phase was a demonstration of process monitoring applied in a prototypical reprocessing plant test facility at ORNL. This report documents the demonstration and test results.
\end{abstract}




\section{INTRODUCTION}

In 1985 the U.S. Program for Technical Support to IAEA Safeguards (POTAS) undertook to sponsor Task C.59, "Review of Process Monitoring Safeguards Technology for Reprocessing Facilities." The objective of the task was to assist IAEA in assessing the potential safeguards value of employment of process monitoring in the chemical processing areas of a reprocessing facility. Task C.59 was administered by the International Safeguards Project Office (ISPO) at Brookhaven National Laboratory, and it became part of the Consolidated Fuel Reprocessing Program (CFRP) at the Oak Ridge National Laboratory (ORNL).

The task started with a literature survey for information on applications of process monitoring for safeguards. The results of this survey were published as ISPO-255, ORNL/TM-1015, Process Monitoring For Reprocessing Plant Safeguards - A Summary Review. The next phase of the task involved selection and development of specific applications of process monitoring with a role in international safeguards. These applications were reported in ISPO-275, ORNL/TM-10458, Process Monitoring in Support of International Atomic Energy Safeguards. The final phase of Task C.59, which is documented in this report, was to demonstrate these selected applications during a test run in the Integrated Equipment Test (IET) facility at ORNL.

The IET facility is a reprocessing plant equipment development facility. It includes prototypical examples of advanced reprocessing equipment in an integrated processing arrangement that includes feed, solvent extraction, product concentration, waste handling, and chemical recovery. While the IET facility is a test facility, limited to operations with depleted uranium, it is a full size, integrated processing plant. Process equipment is sized to process $0.5 \mathrm{MTU} / \mathrm{d}$ to simulate operation of an advanced breeder fuel reprocessing plant. Part of the installed advanced plant equipment is a computerized process control and data acquisition system. The system is interfaced to all plant process control instruments and control equipment.

Depleted uranium feed solutions are processed as a surrogate for the plutonium-bearing irradiated fuel feed material of an operating plant. Limiting process operations to depleted uranium solutions allows access to plant equipment, permitting easy exchange of equipment and variations in flow sheets for testing purposes. Depleted uranium as feed allows operation with no regulatory or production constraints. Safeguards applications can be tested under a variety of operating and upset conditions not generally available in operating plants.

The test campaign and safeguards demonstration for the final phase of Task C.59 was held at ORNL during the week of December 14-17, 1987. Five IAEA staff members and an International Safeguards Project Office representative participated in the three-day demonstration. Acting as inspectors, they used installed computer hardware and process monitoring software and were able to detect activities conducted to bypass the input accountancy tank. They were also able to detect several removals of material from the operating plant. Process monitoring was also used in an accountancy event-logging role and in a role to qualify process data, perhaps for near-real-time-accounting data verification. It was concluded that process monitoring shows 
sufficient potential for safeguards to justify further development, but this must be prioritized with other needs of IAEA and safeguards. The demonstration was conducted to allow attendees to use computer hardware and installed safeguards software and gain hands-on experience with process monitoring applications using data generated while the facility was in operation.

This document reports on the process monitoring demonstration conducted as part of Task C.59. Topics are arranged in the order that they were presented. Presentations and discussions among the demonstration participants are summarized. Also, examples are presented showing the operations staff efforts to implement safeguards removal scenarios, along with detection methods used. 


\section{DEMONSTRATION DESCRIPTION/OBJECTIVES}

The purpose of the demonstration was to provide an opportunity for personnel from IAEA and ISPO to experience the capabilities and problems of safeguards process monitoring applications in an operating plant environment. Planning for the demonstration assumed that participants would have a general knowledge of reprocessing plant operations.

An agenda (included as Appendix A) was developed to provide instruction on the specifics of the IET facility design and operation and the safeguards system. The agenda was developed considering that the participants would act as inspectors with the responsibility of inspecting the IET facility. Participants were presented with an introduction to the facility design and operation and the computer systems. Participants toured the facility to view operating process equipment, instruments, and the control system. Process monitoring with applications for intemational safeguards was discussed.

As a modern definition offered during the demonstration, process monitoring for safeguards is the use of a broad range of process data and analysis tools to make timely and sensitive judgments on the location and movement of nuclear materials throughout the processing plant and to make timely and sensitive judgments on the status and performance of equipment and instruments used for nuclear material accounting measurements.

During the discussions, the IET facility operations group initiated several special tests. These involved movements of process solutions, or actual removals, according to scenarios identified as concerns for international safeguards. The participants were able to use the installed safeguards system to detect, isolate, and quantify these activities. They were able to achieve this ability after only limited instruction on the specifics of the IET design, computer system use, and discussions on the analysis routines installed. The safeguards removal scenarios implemented during the test provided real events to be detected. The inspectors also needed to recognize actual removals among false alarm signals that are inherent in the use of process data for safeguards.

One objective of the demonstration was to call attention to the level of capabilities that the inspectors could achieve after only three days of exposure to the plant and the computerized safeguards procedures. Many of the more conventional safeguards capabilities are not implemented in the IET facility safeguards system. High accuracy conventional accounting measurements are not provided, and there is very limited analytical laboratory capabilities. However, by the end of the test, participants were able to recognize alarms and to resolve false indications using only the process monitoring system. The inspectors recognized, isolated, and quantified several of the removal scenarios implemented. These removals and some not discussed during the Demonstration due to time constraints, are discussed in Sect. 7.

Another objective was to show methods that could allow regular IAEA inspectors to effectively use safeguards methods that rely on a broad knowledge of reprocessing. Participants in the demonstration had the benefit of considerable knowledge of reprocessing plant activities: They also had the advantage of direct interaction with the personnel who designed and developed the system for the IET facility. The inspector assigned to a reprocessing plant must deal with 
specific plant information and operating conditions in the field. The IAEA training program ensures that the inspectors have a general knowledge but cannot give the details of plant operations necessary to make detailed safeguards judgments from process monitoring data. This situation is further complicated by continual tumover in inspector assignments.

A small part of the discussion was devoted to artificial intelligence (AI) applications in safeguards. This is a very important topic in relation to process monitoring for intemational safeguards. Artificial intelligence is a science that tries to capture the knowledge of experts in computer logic. Artificial intelligence, and more specifically expert systems, was presented as having the potential to bring the knowledge of the few experts at the IAEA headquarters to the use of inspectors in the field. Applications were discussed in helping the inspector make effective use of the variety of process monitoring tests that are available. This is probably the newest aspect of safeguards process monitoring. Further development has only recently been started.

This demonstration presented the entire topic of process monitoring and allowed participation in the demonstration run over a three-day period. The specifics of the IET facility and computer system were presented during the first day. This prepared the participants for later discussions on the specific process monitoring tests and analysis of data recorded during the test campaign conducted during the demonstration. Definitions and descriptions of process monitoring became the central topics during the second day. Historical data, recorded during earlier test runs in the IET facility, were used as examples and for practice with the analysis routines after the facility information was presented. The final day of the demonstration was devoted to analysis of current data from the facility for the participants to actually identify the removals or other safeguards related scenarios involving material. 


\section{FACILITY DESCRIPTION/PREPARATIONS}

Process monitoring and most safeguards activities require a general knowledge of plant processes on the part of the inspector. Since participants would play the role of inspectors in the IET facility, the demonstration at ORNL began with a description of the facility.

\subsection{IET FACILITY HISTORY}

The CFRP has focused on advancement of the technology of breeder fuel reprocessing. The IET was constructed as part of CFRP to provide a test-bed for advanced equipment and flow sheet demonstration. The facility was constructed and became available for testing in 1984. After a series of cold chemical checkout activities, the first integrated process runs involving depleted uranium as feed were conducted in December 1985.

The facility was initially designed for demonstration of prototype equipment for a 0.5-MTHM/d plant capable of handling fuels ranging from light-water reactor (LWR) to fast breeder reactor (FBR) types. As the mission and goals of CFRP changed, the facility has been modified to accommodate a wider range of test activities. Many of these changes are discussed later in this section. It has been recognized that many future reprocessing facilities are being designed for remote maintenance. This makes it possible to change plant configurations after initial design verification and checkout. Process monitoring has been shown to be effective for verifying changes in the plant design. Participants were shown some of these changes and how process monitoring verifies actual plant conditions.

One significant process change involved the solvent extraction system. As the focus of attention within CFRP changed to smaller plants dedicated to FBR reprocessing, development of solvent extraction equipment moved to smaller systems. Centrifugal contactors for solvent extraction continue in development. The initial IET design used 12-cm units. With studies on smaller throughput facilities, 5.5-cm units were developed. A second solvent extraction line was installed in IET to use these smaller units in a 0.1-MTHM/d flow sheet.

Testing under a number of different flow sheet and throughput conditions has continued since the initial runs in 1985. Development of advanced safeguards techniques has been an integral part of most of these test runs.

It has been recognized that there is little contribution that this test facility can make in the area of conventional accounting. Therefore, the safeguards testing and development in the IET facility have concentrated on process monitoring and certain applications related to NRTA, particularly in-process inventory measurement development.

\subsection{IET FACILITY SYSTEMS}

The IET facility is a full-scale integrated test facility. It includes equipment for continuous processing of depleted uranium feed to simulate actual plant operations. Figure 3.1 shows the general system layout of the facility. The IET facility is well suited for safeguards development, particularly in the areas of process monitoring and NRTA. Even though the IET facility uses prototypical equipment, the process systems interact like those of an actual operating plant. 



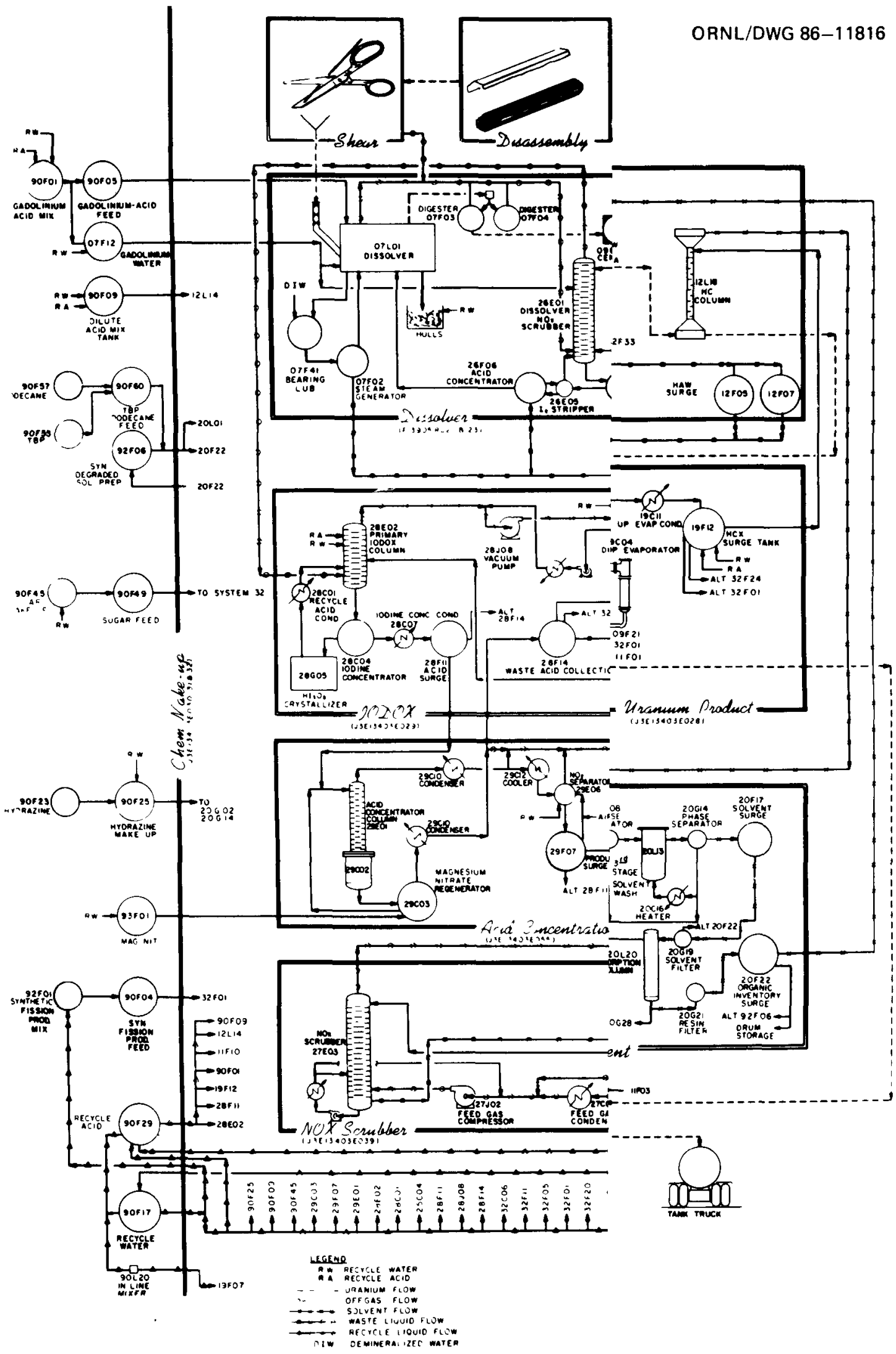


Applications of process monitoring for safeguards require a knowledge of basic plant layout. One of the first sessions in the demonstration discussed the specific IET facility design.

There was a discussion of many of the equipment changes that have been made in the IET system since the initial design. Process monitoring, using a minimum set of available process data, can be valuable in a design verification role. The layout shown in Fig. 3.1 is the initial IET design. The following discussions point out some of the changes as well as normal operating conditions. The discussions on design and changes helped to emphasize the role of process monitoring for design verification.

\subsubsection{Dissolver}

Among the prototype advanced equipment installed in the IET facility is a rotary dissolver for feed preparation. Dummy assemblies containing depleted uranium can be sheared into feed. Altematively, simulated shear product, consisting of hulls, wires, and uranium oxide powder, can be fed to the dissolver.

Figure 3.2 is a diagram of the dissolver system showing equipment and measurement data available to the safeguards system. It shows two digestor tanks (07F03 and 07F04) that receive dissolver product. It also shows transfer from the digestors in the dissolver area to a clarified feed solution surge tank (09F21). Figure 3.1 shows this transfer as made through a feed clarification centrifuge. Figure 3.2 shows the centrifuge in the transfer from the surge tank to the accountability tank. The relocation of the centrifuge is one of the modifications to the IET facility that has been made since startup. The transfer to the centrifuge is made by a fluidic pump with gravity flow to the accountability tank.

In order to avoid costs of fresh feed and disposal fees, an altemate to preparation of fresh feed material in the dissolver is provided. Contents of the product accountability tank can be recycled to the dissolver solution surge tank, as shown in Fig. 3.2.

\subsubsection{Accountability/Feed Preparation}

The accountability/feed preparation of the IET facility is similar in design and function to a typical reprocessing plant. The IET facility configuration used for the demonstrations is shown in Fig. 3.3. The dissolver system delivers solutions, rather low in acid concentration, for solvent extraction. Acid additions are required to bring solutions to flow sheet specifications.

In the IET facility, the input accountability tank (09F23) is provided as the primary input measurement vessel. Solutions are batch type received from tank 09F21. The design of the accountability tank includes several important features relative to safeguards.

The accountability tank has a narrow diameter neck area in the upper region. It was designed to permit operation in a batch type, constant volume delivery mode. The neck area has two overflow weirs; the lower weir can be closed. Constant volume delivery operations involve filling the upper weir, mixing and sampling, and then draining back to the lower constant volume delivery weir.

Operation of the accountability tank in the constant volume delivery mode was discussed during the demonstration. A constant volume delivery tank would seem to offer safeguards advantages. This mode was tried during some early IET facility tests. There were problems with operation in this mode. Mixing had to be carefully controlled to prevent overflow back to the surge tank. This mode also required sufficient extra material in the surge tank to keep the accountability tank filled. Due to the operational problems with the constant volume delivery mode, the tank is now used in a conventional batch delivery mode. It was noted in the discussions 
ORNL-DWG 88-5707

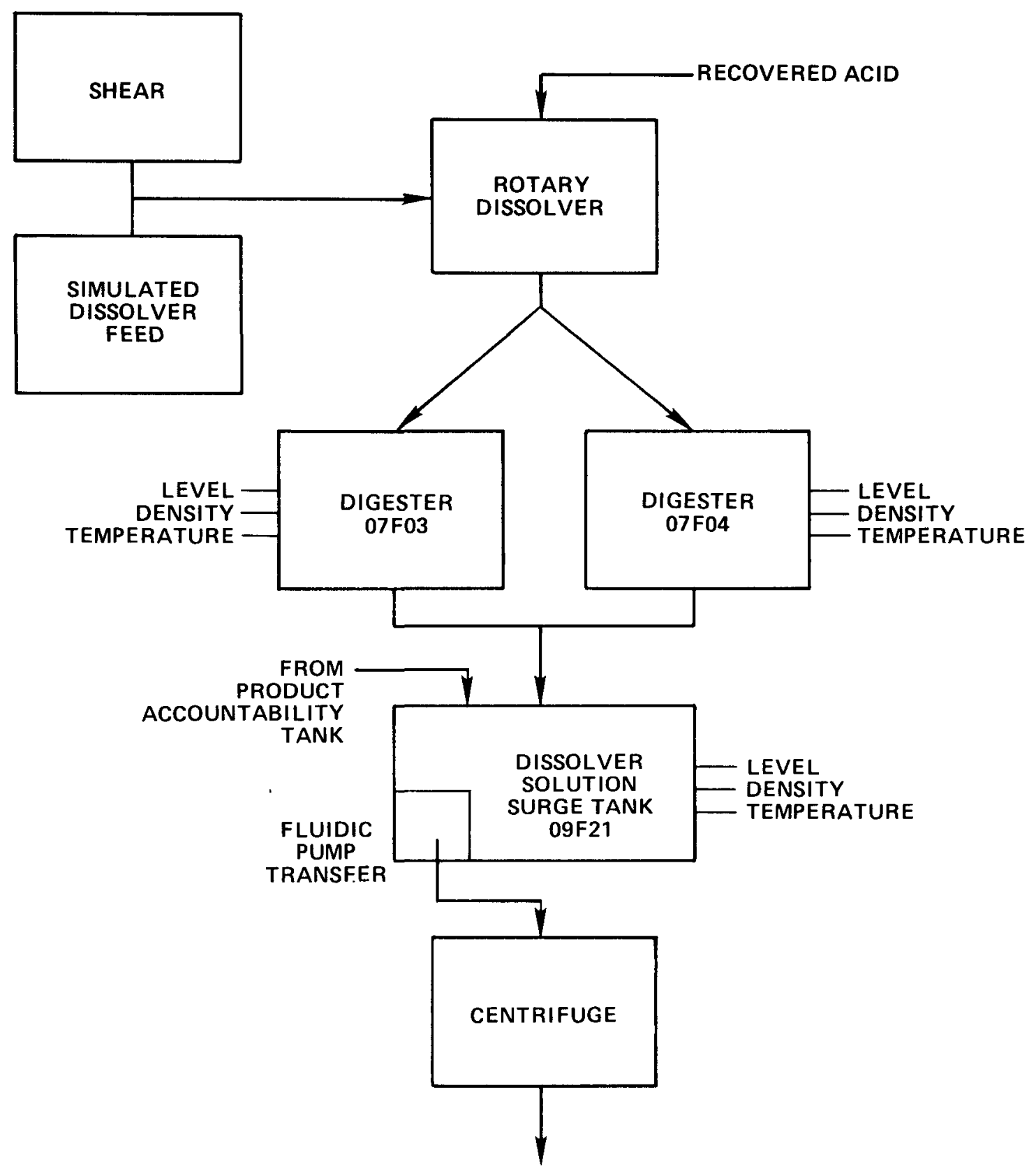

TO INPUT ACCOUNTABILITY

Fig. 3.2. Dissolver system.

that there is an advantage to the design of an accountability tank with a small diameter neck area, but advantages of a constant delivery system do not justify operational difficulties.

The transport mechanism between tanks 09F21 and 09F23 is a fluidic pump. This is believed to be a transport mechanism that may see applications in future facilities. In most other applications in this area, steam jets are used. As the process monitoring applications were discussed, the safeguards implications of transport mechanisms were explored. 


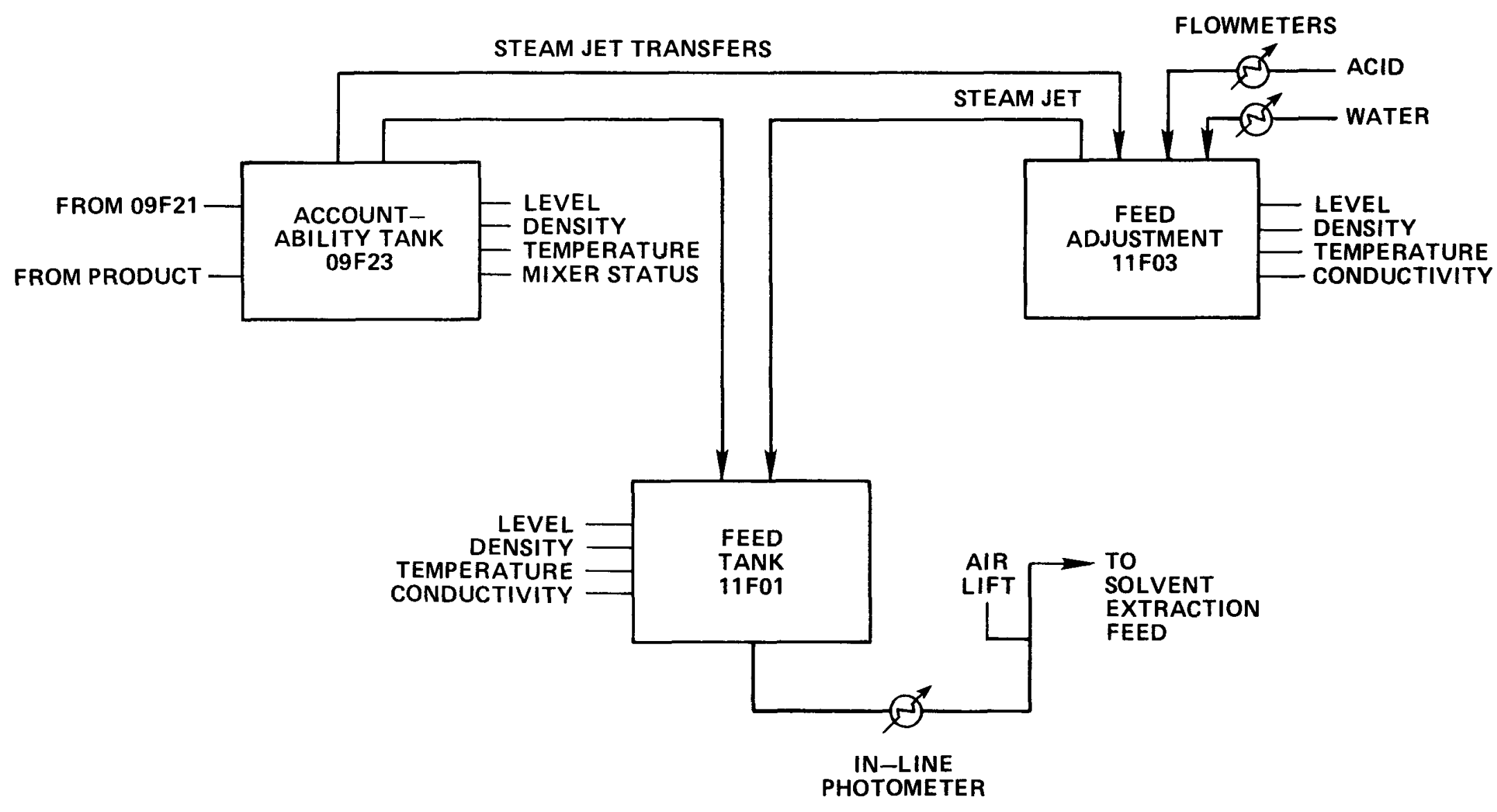

Fig. 3.3. Accountability and feed preparation area. 
As noted in the previous section, product material can be recycled to tank 09F21. In addition, product can be recycled directly to the accountability tank, as shown in Fig. 3.3. In this case, the recycled material bypasses the clarification step.

The accountability tank has typical process control measurement instruments, as well as an indicator on the air sparge supply, as shown in Fig. 3.3. These process control instruments are used for accountability measurements. After accountability measurement, solutions are typically transferred by steam jet to the feed adjustment tank (11F03). An alternate route is provided directly to the feed tank (11F01).

The careful reader will notice a difference between the systems shown in Figs. 3.1 and 3.3. Another recent system modification was made to switch the functions of tanks 11F01 and 11F03. This was discussed with participants to show a role for process monitoring in verification of design information.

The feed adjustment tank (11F03) has typical level density and temperature instruments. Additionally, a conductivity instrument is installed. Conductivity and density information is used to calculate acid and heavy metal concentrations. These data are used to calculate acid additions needed to adjust solutions to flow sheet conditions. Acid additions are measured by in-line, integrating flowmeters. For the demonstration run, target feed conditions were $175 \mathrm{~g} \mathrm{U} / \mathrm{L}$ and $3.5 M$ acid.

Feed requirements for this test run were typically met by product recycle. Preadjustment conditions were typically $300 \mathrm{~g} \mathrm{U} / \mathrm{L}$ and about $1 \mathrm{M}$ acid. Acid additions were from the chemical recovery system and monitored by in-line, integrating flowmeters. These are typical process control instruments.

After adjustment, feed solutions are transferred by steam jet to the solvent extraction feed tank (11F01). The tank can feed either the 0.5 -MTU/d process system or the $0.1-\mathrm{MTU} / \mathrm{d}$ system with minor piping changes. The feed system to the $0.5-\mathrm{MTU} / \mathrm{d}$ process involves a two-stage airlift system that is typical of operating plants. The system to feed the 0.1-MTU/d system involves an airlift to a waterwheel flow controller.

Measurements available to the safeguards system again include level density and temperature. Additionally, an in-line measurement of feed concentration is provided. The device used is a spectrophotometer. The airlift flow rate is also measured and provides an indication of feed to the solvent extraction system.

\subsubsection{Solvent Extraction}

It has been noted that two separate solvent extraction systems exist in the IET facility. Both systems are based on centrifugal contactors for the solvent extraction process. Both systems are designed to simulate operation of the codecontamination step of a typical operating reprocessing plant.

For the 0.5-MTU/d plant, the extraction and scrub steps are each accomplished with 8-unit banks of 12-cm contactors. In this system, strip is accomplished in a pulsed-column contactor. In the 0.1-MTU/d system, extraction scrub and strip are all accomplished with multi-unit banks of $5.5-\mathrm{cm}$ centrifugal contactors.

For safeguards purposes, the systems are essentially the same. Figure 3.4 shows the solvent extraction system and measurements available for safeguards process monitoring tests. The figure is representative of either solvent extraction system in the IET facility and is typical of any reprocessing plant solvent extraction system.

In the IET system, feed flow rate is measured. For the system used during the demonstration, flow is measured by the rotation speed of a feed delivery wheel system. The 
ORNL-DWG 88-5709

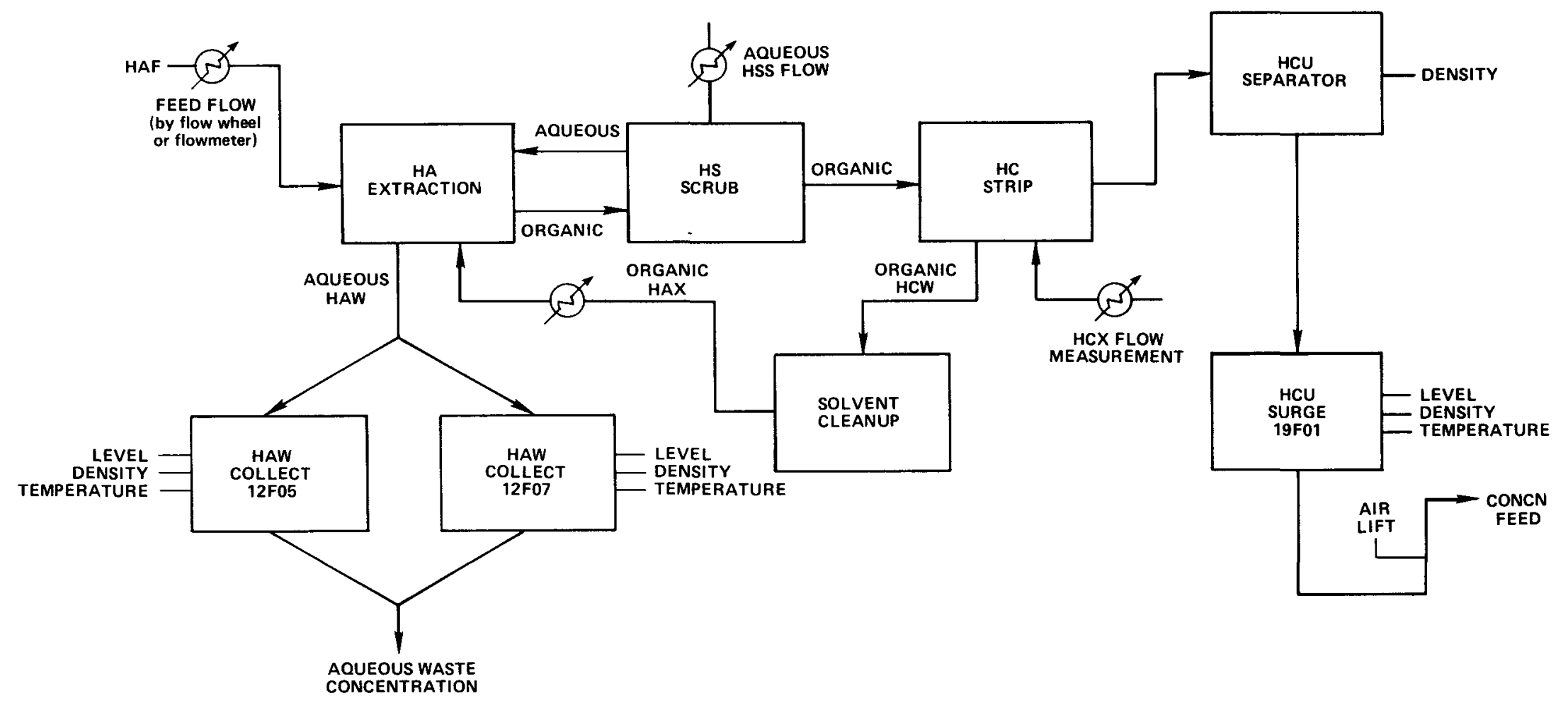

Fig. 3.4. IET solvent extraction system. 
aqueous scrub stream, HSS, is measured by a flowmeter. It is important to safeguards process monitoring applications to recognize the implications of all measurements. The HAF flow measurement can be periodically related (calibrated) to the depletion rate of the feed tank. The HAF and HSS, after extraction of the nuclear material, combine in the HAW. The HAW rate can be periodically calibrated to increases in the receiver tanks. This calibration is indirectly a calibration on the HSS flow measurement.

In either system, the solvent extraction product stream is airlifted to a separator pot prior to being collected in an intercycle surge tank (19F01). A density measurement in the separator pot can be related to concentration of the product. This product is typically $40-60 \mathrm{~g} \mathrm{U} / \mathrm{L}$ in concentration. The surge tank has a capacity of about $400 \mathrm{~L}$ and typically operates about half full. The tank continually receives solvent extraction system product and simultaneously feeds the product concentrator. Concentrator feed is delivered by a monitored airlift.

The aqueous waste stream, simulating HAW in the traditional PUREX flow sheet, is received in one of two collection tanks (12F05 or 12F07). Flow of HAW to these tanks is controlled to fill one of the tanks while the other is being emptied to the waste concentration system.

Organic for solvent extraction is supplied from the organic inventory supply tank. The organic waste stream from solvent extraction, simulating $\mathrm{HCW}$, is returned to the organic treatment area and passed through a solvent cleanup system.

\subsubsection{Product Concentrator}

The product concentrator and accountability system is shown in Fig. 3.5. The IET facility product concentrator is a continuous operating, thermosyphon device. Concentrator feed from the intercycle surge tank (19F01) is airlifted to a separator pot and flows by gravity to the concentrator. Feed enters at the top tray of the evaporator. In normal operation, steam supply to the reboiler leg is controlled to maintain a constant density in the evaporator bottoms. Product takeoff is by overflow of the bottoms and gravity transfer to the product collection tank (19F05). A water addition capability is available to backwash the demister trays as required.

Overheads from the product concentrator are collected in a surge tank (19F12) and recycled as strip solution (HCX) to solvent extraction. The acid concentration of the solution is monitored in the surge tank. Periodic adjustments are made. Excess condensate is periodically transferred to the waste concentration area.

Concentrator product is continually collected in tank 19F05. As the collection tank fills, product is batch type transferred by airlift to the product accountability tank (19F07). This accountability tank is similar in design to the input accountability tank. It is capable of operating in a constant volume delivery mode. Like the input accountability tank, the constant volume mode presents more operational problems than it offers in improved measurement capabilities. It is routinely operated in the more conventional batch mode.

Product from the accountability tank can be recycled to the dissolver surge tank (09F21) or the input accountability tank (09F23). Since the test material is depleted uranium, the possibility of transfer for disposal also exists.

\subsubsection{Aqueous Waste Processing}

The IET facility includes equipment for aqueous waste processing that simulates high level waste processing (HAW) of a typical plant. The waste concentrator feed tank (32F01) receives the solvent extraction waste stream from either of the two collection tanks (12F05 or 12F07). Additionally, excess condensate from the concentrator overheads may be added. 
ORNL-DWG 88-5710

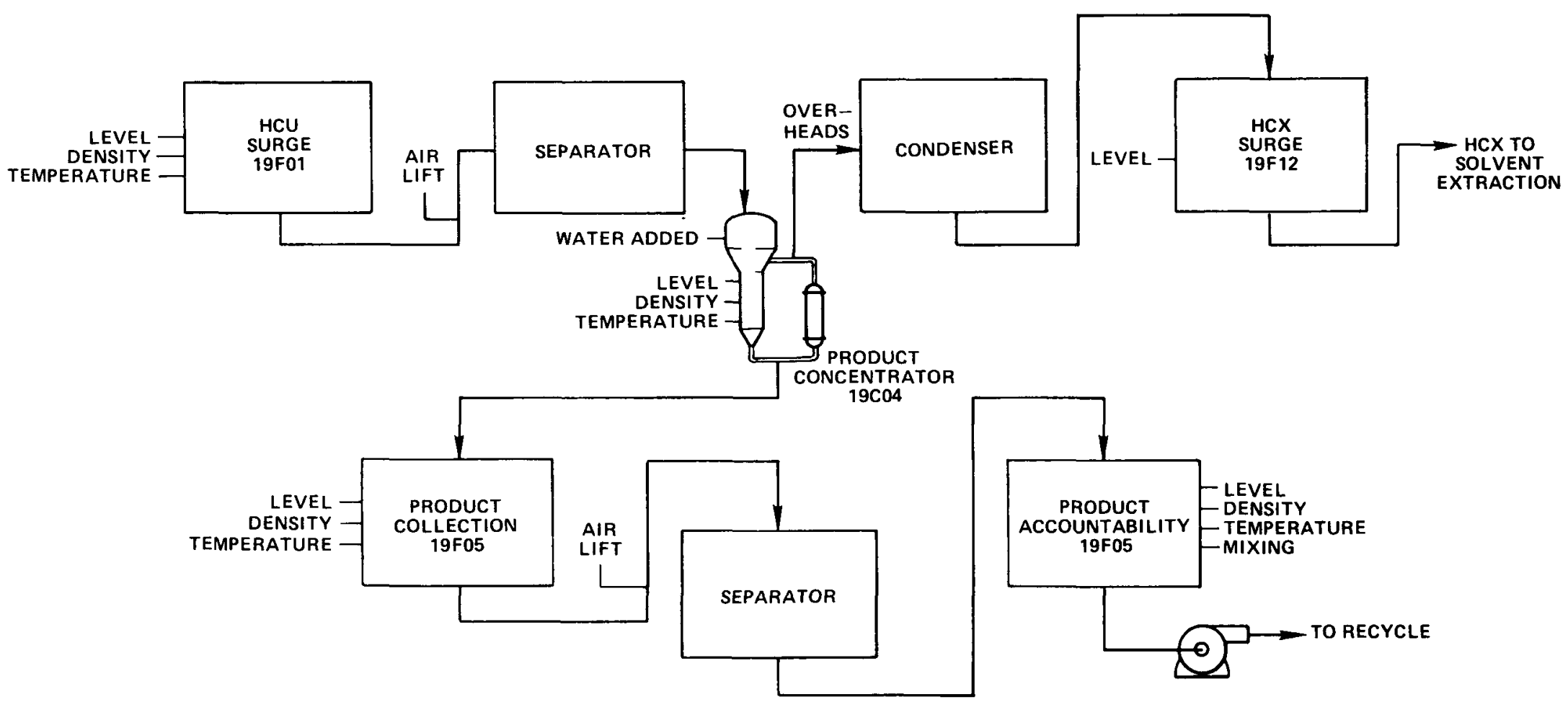

Fig. 3.5. Product concentration. 
Continuous feed is provided to the concentrator. Overheads from the waste concentrator feed the acid fractionator system to provide recycle acid and water to meet process needs. Concentrator bottoms are continuously collected in the catch tank and periodically transferred batch type to the waste accountability measurement tank (32F11). Measured waste is transferred for disposal.

\subsubsection{Other Systems}

Figure 3.1 shows additional systems included in the IET facility. The $\mathrm{NO}_{\mathrm{x}}$ scrubber system is used for development and demonstration of off-gas handling processes. The IODOX system is a development system for iodine removal. The acid concentration system shown in Fig. 3.1 is support for the IODOX system. These additional systems do not relate to safeguards and were not discussed in detail.

\subsection{SPECIAL PREPARATIONS}

It has been noted that two separate solvent extraction systems are in place. Either can be operated with minor piping changes.

The 0.5-MTHM/d system using the 12-cm centrifugal contactor system was the focus of earlier studies in CFRP. More recent attention has been focused on the 0.1-MTHM/d flow sheet using the $5.5-\mathrm{cm}$ units to support current research and design efforts in CFRP.

For the test conducted in conjunction with the demonstration run, it was decided to continue use of the smaller units. However, the rest of the IET facility is still sized for $0.5-\mathrm{MTHM} / \mathrm{d}$ processing. This means that the rest of the facility only operates at $20 \%$ capacity to support the smaller system. The safeguards demonstrations are focused more on activities and batch transfers in the feed and product areas than within solvent extraction. The lower flow rate means fewer events associated with the support equipment. For example, batch transfers for the feed and product tanks occur on 24-h cycles at the lower flow sheet.

The demonstration was planned for three days. With the smaller capacity flow sheet, there would not be enough activities to study safeguards techniques applied to the facility. In order to meet all objectives of the test run (CFRP operational and ISPO Task C.59 objectives), the solvent extraction feed system was modified. An additional transfer line was added to bypass solvent extraction with feed material directly to the intercycle surge tank that feeds the product concentrator. Solvent extraction was operated at the lower flow rate, and additional feed material was transferred through the bypass to bring apparent flows to $0.5 \mathrm{MTHM} / \mathrm{d}$ and allow the rest of the IET facility to operate at capacity.

\subsection{SAFEGUARDS IMPLICATION OF IET FLOW SHEET}

The IET facility is a demonstration facility for breeder fuel reprocessing development. The system operates on depleted uranium solutions as surrogate for actual feed. Flow sheets are specified to meet total heavy metal throughput, substituting depleted uranium for uranium and plutonium.

Safeguards development considers the surrogate feed to be plant feed as if it actually contained plutonium. For solutions in the dissolver system through the accountability and feed preparation areas, solutions are considered to contain $20-30 \%$ plutonium. Thus, where feed concentrations for IET tests are $175 \mathrm{~g} \mathrm{U} / \mathrm{L}$, safeguards test applications treat these solutions as if they contained $35-50 \mathrm{~g} \mathrm{Pu} / \mathrm{L}$. Tests consider that a kilogram of plutonium is contained in $20-30 \mathrm{~L}$ of highly radioactive process solution. 
Solutions in the product area of IET, from the concentrator feed tank through the product accountability tank, are considered as if they were plutonium product in an operating facility. In this analysis, a kilogram of plutonium is contained in 3-5 L of concentrated product. Safeguards tests and procedures that are developed and demonstrated in IET treat the depleted uranium process solutions as if they were plutonium in product concentrations.

Process monitoring for safeguards was also applied to the solvent extraction process. In many cases, safeguards applications within the operational solvent extraction system can be very sensitive by looking at total heavy metal content. As a general characteristic, solvent extraction process streams will be on the order of $20-70 \mathrm{~g}$ heavy metal per liter. The mix of heavy metals depends on the stream location. In the plutonium purification areas, heavy metal is $100 \%$ plutonium.

An important consideration for safeguards is that the total plutonium content of any stream, at any location throughout the plant, will be related to throughput. Thus, for a $0.5-\mathrm{MTHM} / \mathrm{d}$ plant with breeder fuel, the stream flows and concentrations always have to equate to a $2-\mathrm{kg} / \mathrm{h}$ plutonium rate. A kilogram of plutonium will involve $50 \%$ of any stream for an hour, $25 \%$ for two, or some lower fraction over a longer time. Any removal will have to take total heavy metal content.

For the IET facility, the solvent extraction system relates to the codecontamination cycle. However, for safeguards development, this stream is considered to have the throughput equivalent of plutonium. Most tests react to heavy metal content.

\subsection{GENERAL CONSIDERATIONS}

The IET facility processes only depleted uranium. There is no plutonium or high level activity in process solutions. Measurements and solution handling activities are simpler than in an actual operating plant. However, process equipment and measurement instruments, particularly process control instruments, are exactly the same as those applied in operating plants. Pneumatic, dip-tube measurement systems, using differential pressure measurement devices and remote thermocouples, are used for volume and solution weight measurements. Steam jets, airlifts, and fluidic pumps are used for solution motivation. Mixing and sampling systems are typical. While on-line analysis techniques that are installed and tested react to depleted uranium, every consideration for deployment in an operating plant reacting to plutonium solutions is given before considering safeguards applicability. 


\section{INSTRUMENT AND COMPUTER SYSTEM DESCRIPTION}

Safeguards process monitoring is the use of operators' process control data to make safeguards judgments and decisions. Process monitoring uses large quantities of data and necessitates the use of computers to collect and process the data. For process monitoring to gain acceptance as a safeguards tool, plant operators and regulators must understand the capabilities that exist with modern process control computer systems and recognize methods to interface those systems to regulatory agencies.

As the IET facility was being designed and built, one of the major focuses of attention was the demonstration of an advanced instrument and computer control system. The IET design came at a time when commercial, computerized process control systems were first becoming available. Such a commercial system was purchased and incorporated in the design. The installed computer system is now central to safeguards development in the IET facility.

The IET facility system represents computer control system technology of the late 1970 s. The installed computerized capabilities are representative of what can be expected in future large-scale reprocessing plants. While technology of computers has improved considerably, the costs of these systems are considerably lower now than when the IET system was purchased. However, performance is similar to currently available commercial systems. Participants in the demonstration were introduced to the commercial process control system and how it has been adapted for the safeguards effort.

\subsection{COMMERCIAL PROCESS CONTROL SYSTEM}

The IET facility control system was procured from and installed by a commercial vendor. It was delivered with the basic software tools to enable IET staff to customize the control system to the needs of the facility.

Process control instruments were interfaced with control devices. The flexibility of this system has allowed IET personnel to develop extensive control logic and extend the system from basic process control to a system of automated facility operations.

The system uses a number of process control modules (PCMs) that are dedicated microprocessors. The PCMs include analog and digital input/output capabilities for communication with process instruments and control equipment. Each PCM shares measurement information with other PCMs console display devices and a host computer along a data highway.

The console devices serve as the interface to the operator. The consoles allow entry of control information from the operator and pass the information to the PCMs along the data highway. Operator information is presented in graphics form. Graphics for the operator displays are received from the host.

The host computer is a DEC PDP11/70. As noted, the host also communicates on the data highway to obtain process information. In addition to providing operator display graphics to the consoles, the host functions include limited data archival and data base management. Program development and compilation for the PCMs occur in the host, and PCM software is downloaded 
from the host along the data highway. As control schemes have evolved toward automation, the host has played a larger role in higher level control logic implementation. The host also carries the functions of alarm analysis, notification, and event logging.

The system architecture for the operational process control system is shown in the upper portion of Fig. 4.1

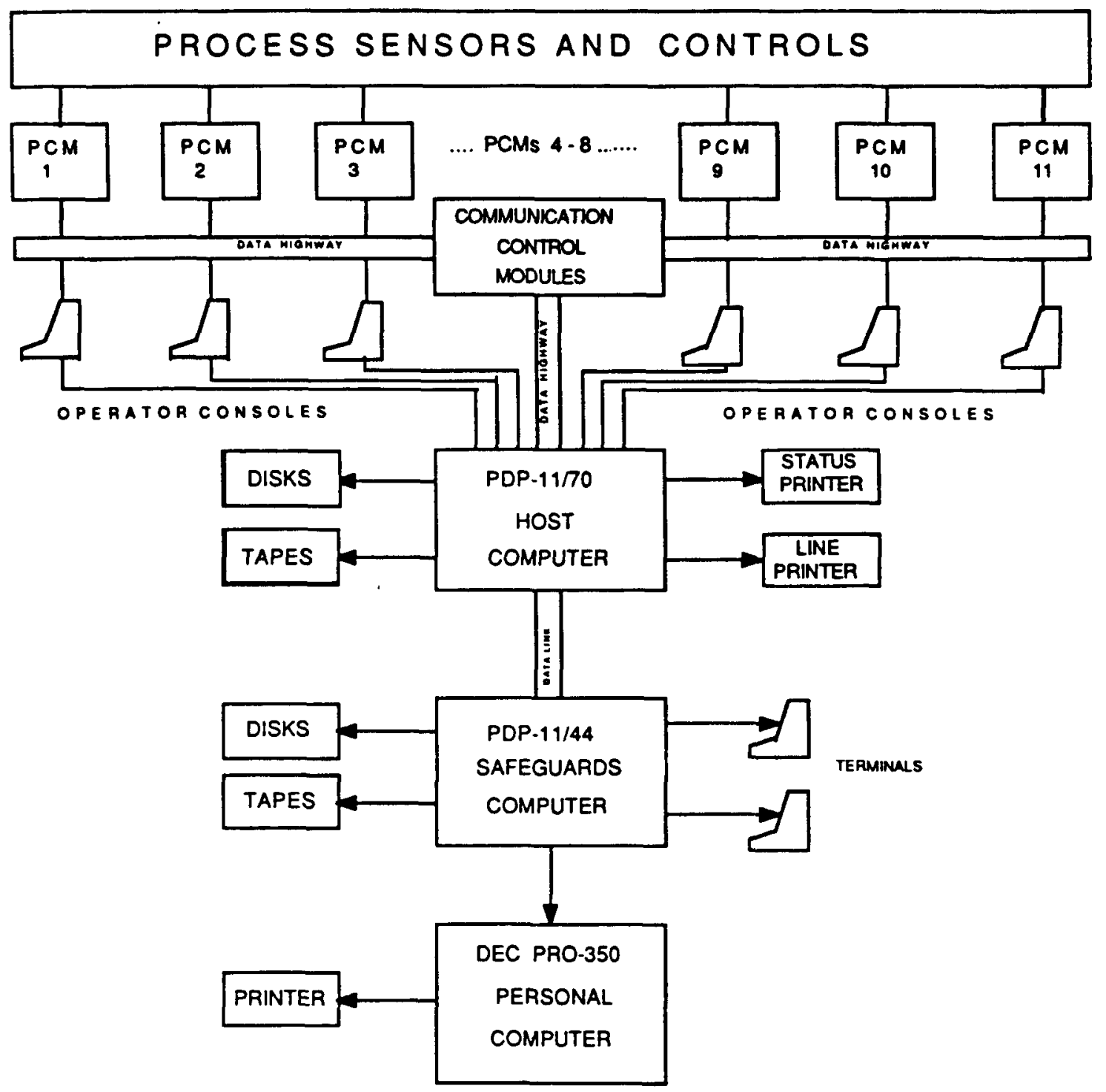

Fig. 4.1. The data acquisition system hardware configuration. 


\subsection{SAFEGUARDS COMPUTER SYSTEM}

The safeguards computer system has evolved as a stand-alone computer system that communicates with the process control system on a dedicated communication link. The system architecture in relation to the process control system is shown in the lower part of Fig. 4.1. This arrangement was selected to represent an approach that the agency could use to interface to a facility process control system. The safeguards computer system is based on a DEC PDP 11/44 computer. In terms of computer power, the DEC system used is comparable to current personal computers on the market in 1988.

An important part of the safeguards system is the data link into the process control system. A valid concern in applications of process monitoring is intrusiveness. In the IET system, the structure of this link only allows passage of an established list of measurement data into the safeguards computer. This is a method to limit the agency monitoring activities to only a list of previously negotiated data points. In the IET facility, some 600 measurement points are transmitted by the communications link, including many that are archived for operational reasons only. The actual safeguards related data that are collected amount to about 100 data points.

The data link involves a data collection and sending task in the process control computer and a receiving task in the safeguards computer. At a specified interval, the receiving task in the safeguards computer sends a request message to the sending task in the process control computer. The sending task polls the PCMs on the data highway to collect the appropriate set of data. It then transfers the set along the data link to the receiving program in the safeguards computer.

In the IET system test runs, the interval between data sets requested is typically set at $4 \mathrm{~min}$. This interval was chosen based on typical process event times. As an example, it is typical to size solution transfer equipment to accomplish a batch transfer in 15-30 min. A 4-min data cycle provides data points to evaluate transfer/receive rates.

In the IET safeguards system, the receiving task maintains an active file of the data sets for the previous eight hours. At intervals of about eight hours, the receiving program makes an archival copy of the active file and continues to add information to the active file by overwriting the oldest data.

\subsection{INTRODUCTION TO COMPUTER USE}

As noted, a major part of the ISPO demonstration was to allow participants access to the active data sets and the archived data to gain an understanding of the logistics involved in collection and analysis of process data for safeguards.

The demonstration was intended to be a working session for participants. The group was split into three teams. Each team had a terminal and was given the log-in procedure, passwords, and accounts for access into the safeguards computer system.

Participants in the demonstration generally had good computer backgrounds. For this particular session of the demonstration, they only needed general introduction to some of the basic system commands to make effective use of the DEC system. These were primarily specifics of the keyboard and terminal use, such as screen scroll and hold commands.

The point to be made in this part of the demonstration is that personnel from the agency (participants) with a minimum of instruction could make use of the installed system in the IET facility. 



\section{PROCESS MONITORING ROLE IN SAFEGUARDS METHODOLOGIES}

The specifics of process monitoring applications that have been implemented in the IET safeguards system were discussed next during the demonstration. A contemporary definition of process monitoring is the broad use of process data to make judgments about the location and movement of nuclear material in the facility. As such, process monitoring utilizes a variety of analysis tools that can be directed at specific concerns or removal scenarios, or can be directed at improving measurements or verification of other safeguards activities such as conventional accounting and NRTA.

This definition was presented as an introduction to the system developed and in place in the IET facility. Remember that the demonstration was to allow participants to use the system and gain experience with a process monitoring application. Section 9 will present some of the discussions and ideas on the definitions and role as they evolved during the demonstration. The initial discussions focused on the definition and roles investigated as the IET facility system was developed.

Safeguards development in the IET facility has concentrated on process monitoring. Some elements of conventional accounting and NRTA have also been implemented. Process monitoring is being investigated for its role in conventional accounting and NRTA. The relation of process monitoring to these other methodologies was discussed during the demonstration and is summarized in this section.

\subsection{CONVENTIONAL ACCOUNTING}

Process monitoring can play a role in the measurement control and quality assurance of conventional accounting measurements. As noted in the facility description sections, the IET facility has input and output accountability tanks. These tanks are routinely used to make accountability measurements. However, conventional accounting is not required nor fully implemented for testing in the IET facility.

Other facilities, including those operating facilities around the world, have done an exceptional job of development in the conventional accounting area. The procedures and equipment necessary for accountability measurements are well understood. However, expensive measurement equipment like electromanometers and a well equipped laboratory are necessary. The IET facility cannot handle actual reprocessing plant solutions. Thus, analytical method development for accountability is not a part of IET activities, although other ORNL divisions are involved in this area. In the area of solution measurements, the IET activities have concentrated on process monitoring in measurement control and automation of accountability procedures.

Accountability measurements in the IET facility are made with the routine process control differential pressure instruments. The data recording aspects of accountability measurements have been automated in the IET facility. Process monitoring has been used to detect measurement instrument problems or biases in conventional accounting. 


\subsection{NEAR-REAL-TIME ACCOUNTING}

NRTA is under development and demonstration at facilities throughout the world, and it has one aspect that is the same as conventional accounting - to provide accurate determination of the input and output quantities. NRTA has the additional requirement over conventional accounting to measure in-process inventory without plant shutdown. To date, most of the NRTA development programs have involved manual data collection and special samples with material balance intervals on the order of a week.

Future large-scale reprocessing plants are likely to have substantial in-process inventory quantities. Throughput and nominal inventory, coupled to timeliness and sensitivity requirements, will dictate the frequency of NRTA material balance closures. The NRTA for future facilities may require more frequent closures and considerably more effort for in-process inventory measurement. In addition to the need for more data, questions are already being asked about methods for verification of NRTA measurements.

NRTA has been implemented in the IET facility to investigate the roles of process monitoring in collection/qualification of NRTA in-process inventory data and verification. The in-process inventory data collection activity has been automated. The efforts are primarily directed at the volume measurement activities, but there is an effort to use on-line nondestructive analysis (NDA) techniques for concentration determinations. Process monitoring plays a significant role in qualification/verification of on-line measurements in support of NRTA.

\subsection{PROCESS MONITORING APPLICATIONS}

For purposes of safeguards process monitoring applications, the IET facility can be considered as three separate areas: (1) feed preparation, (2) solvent extraction, and (3) product concentration. Process monitoring has been considered by CFRP as a safeguards tool for the facility operator as well as a tool for use in the regulatory structure. While the focus of attention for the ISPO task has been process monitoring for international safeguards applications, the demonstration was an opportunity for participants to experience the broad range of applications and powers of process monitoring.

In terms of intemational safeguards, the document prepared as the second part of Task C.59 (ISPO-275, ORNL/TM-10458, Process Monitoring in Support of International Atomic Energy Safeguards), presented two specific applications. The first was an event-logging role, and the second involved solvent extraction mass flow measurements and balances. These applications, demonstrated during the demonstration, were selected based upon concerns and material removal scenarios developed as discussed in STR-140, "An Advanced Approach for a Model 200 T/A Reprocessing Plant." Eight criteria were established as necessary to complete a process monitoring application. These criteria, in relation to the IET facility and the selected applications, were discussed in the report issued as the second phase of Task C.59 (ISPO-275). These two applications of process monitoring were demonstrated during the demonstration.

In addition to the two specific applications, the demonstration included other aspects of process monitoring, which are not as fully developed. Process monitoring includes a broad range of analysis tools that can respond to a wide range of concerns.

\subsection{PROCESS MONITORING FOR THE DEMONSTRATION}

The computer system available in the IET facility was described in Sect. 4. A data link between the process control computer and the safeguards computer passes a structured set of data that is a snapshot of plant conditions at the time of the request. These data sets are time stamped and stored. During test runs, the data sets are recorded at 4-min intervals. 
The recorded data sets are the process monitoring data base. The large volume of information available to the safeguards analyst over a period of time can well be imagined. If the analyst is to make use of the data, summaries and indicators must be available to help locate problems and resolve alarms.

Process monitoring, as developed for the IET facility, is closely tied to the NRTA applications. For test purposes in the IET, NRTA material balances are closed hourly. Process monitoring is used in this procedure, and the NRTA balances serve as references into the data base. To make this a little clearer, recognize that the computer is doing the job of the on-site safeguards representative. The 4-min data sets represent a library of volumes of process monitoring data. Each page of the volume holds all data for each time period. Each volume holds 120 pages, or about $8 \mathrm{~h}$ of information.

One aspect of the process monitoring routine simulates the on-site representative as he pages through the library volumes. This particular routine establishes the NRTA in-process inventory measurements. With the 4-min data sets in the library volume, he stops at every 15th page to record the in-process inventory data. These in-process inventory data are transferred to a volume of NRTA data. Each NRTA data set includes a reference pointer to the original data base. It should be recognized that the computerized system maintains the original process information data base along with NRTA in-process inventory data. These data have been recorded automatically by update routines within the computerized safeguards system.

The next aspect of the process monitoring routine available within the IET facility safeguards system is one that scans the data base to accomplish several important functions: (1) qualify all data for errors, (2) recalculate inventory quantities based on qualified data, (3) scan the data base to log any transfer and processing activities, (4) generate alarm messages about abnormal conditions that can signal safeguards problems, and (5) calculate cumulative flow quantities associated with key measurement points. The process monitoring routine successively accesses each data set, performing these functions on the interval between data sets.

As the process monitoring routine reaches a data set corresponding to an NRTA data set, recalculated and updated in-process inventory data and cumulative flow measurements for key measurement points are written to the NRTA data base. This is the IET facility implementation for investigation of the role of process monitoring in NRTA. Process monitoring automates the NRTA activity.

The IET facility is operated using on-line methods of determining concentration data to minimize sampling and analytical laboratory requirements. These process control methods are used for NRTA in the IET facility and qualified by process monitoring tests.

The basic process monitoring routine generates alarm and information messages for the safeguards analyst or inspector. As the monitoring routines are implemented in the IET facility for use during the demonstration, these are general information messages and often suggest further investigation or evaluation. The process monitoring system offers the inspector a series of tools for additional analysis. 



\section{PROCESS MONITORING TOOL BAG}

Process monitoring for safeguards employs a collection of software programs that allow the analyst or inspector to detect anomalies that are indicative of safeguards problems. Process data is the source of information for process monitoring.

Unlike other safeguards techniques, there is no single statistic like Inventory Difference (ID) for analysis. Process data are characterized by anomalies and spurious signals. Process monitoring involves a number of tests and analyses. A process monitoring application must include a series of routines that allow for data analysis and investigation of anomalies for resolution of false alarms or confirmation of indicated problems.

For the ISPO demonstration of process monitoring, these tests were collected as a menu driven set of programs for easy use by participants. This collection of test and analysis procedures can be considered as the safeguards analyst's tool bag.

As noted in Sect. 4.3, the participants in the demonstration were divided into three teams, and each team was given an account and password for access into the safeguards computer. After gaining access to the computer, a simple command file (in the DEC operating system context) was used to set up the menu. Figure 6.1 shows the menu of available routines.

The programs available can be divided in two broad categories. The first group of four, shown in Fig. 6.1, are the basic routines associated with process monitoring analysis. These software routines set up the data bases and are discussed in Sect. 6.1. The second group, which is discussed in Sect. 6.2, is directed more at alarm resolution or confirmation.

As an introduction to this section, it should be noted that the second phase of Task C.59 proposed two specific process monitoring applications for international safeguards: event logging and mass flow while monitoring. These specific process monitoring applications are described in this section, along with several others. The TRSUM program described in Sect. 6.2.11 contains the basics of the event logging application. The mass flow monitoring application is described in Sect. 6.2.4 as the MINFLW program. The application for the event-logging routine are apparent. The mass flow monitoring application has a number of uses. It plays a role in some of the removal detections described in Sect. 7.

\subsection{PROCESS MONITORING ANALYSIS ROUTINES}

Process monitoring safeguards routines have been used for a number of test runs in the IET facility. They have proven most effective when the basic process monitoring program is used to indicate that problems and alarms are resolved with the series of analysis routines. The programs discussed in this section provide that basic analysis and establish the data base for additional analyses. 


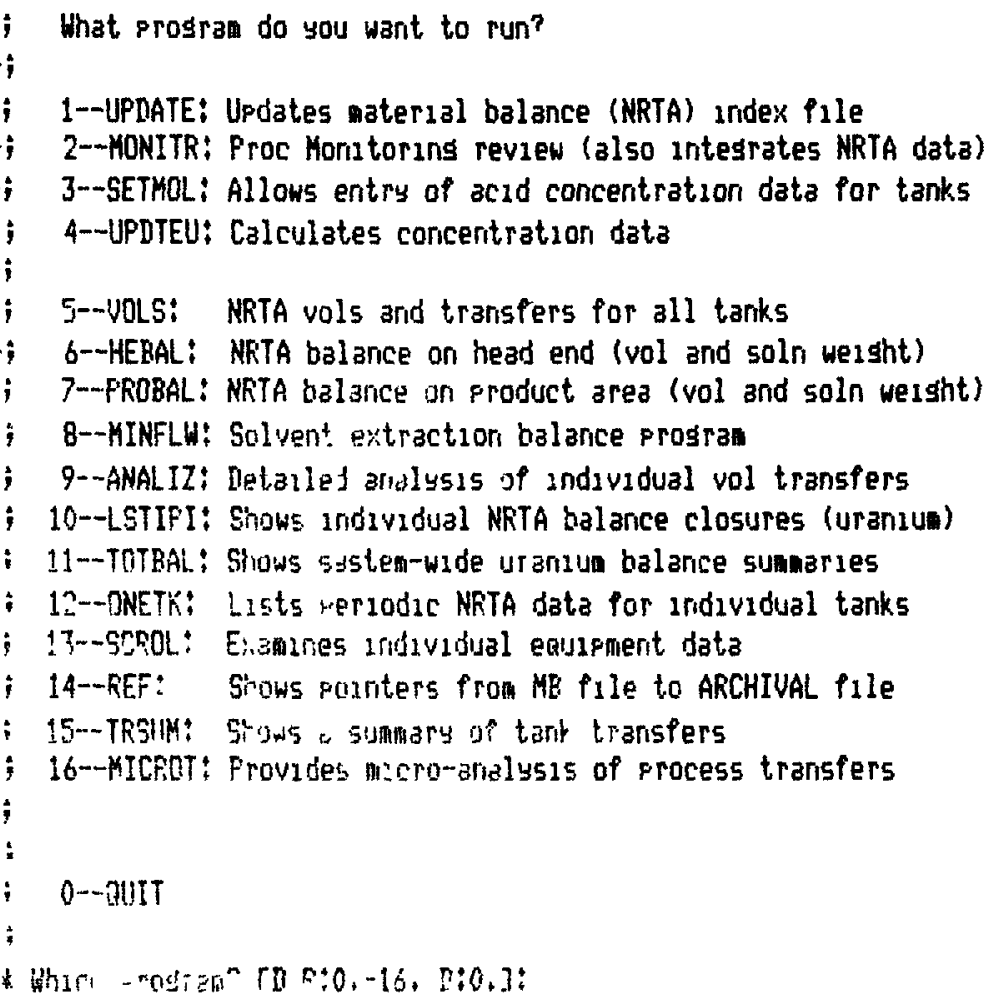

Fig. 6.1. Menu screen - available software routines.

\subsubsection{Program 1 - UPDATE}

Development of the safeguards system for the IET facility has involved a discussion concerning the appropriate way to implement process monitoring for safeguards. Timeliness of analysis is one part of this discussion. Another involves the way alarms are generated. Does the safeguards analysis proceed automatically, generating immediate messages whether or not someone is in attendance, or should the inspector initiate the analysis when he arrives on site and scan a block of information covering the period since his last visit? The system has been implemented in both ways in the IET facility. In one application, only the messages are written to a chronological file and only the messages are reviewed. In the other application, the inspector, or participants in the case of the demonstration, sit down to a terminal and replay plant activities watching the process monitoring routine being applied and generating information messages.

The merits of one approach over the other were not discussed at length, but the latter approach was selected for the demonstration. Since there was limited time for participants to gain experience, they were given the opportunity to review data from the ongoing test as well as previous IET facility runs. The approach that involves review of selected blocks of data better served the purpose of the demonstrations.

Section 5.4 noted that NRTA data files provide the reference points for analysis of data. The first program available from the menu shown in Fig. 6.1 is UPDATE. The purpose of this program is to establish and update the NRTA file. 
For the demonstration and other IET tests, hourly NRTA material balances are closed. With data sets collected and stored at 4-min intervals from the process control computer, every 15th data set is the basis for an NRTA closure. When run, the UPDATE program opens the NRTA data file and reads the last data set. This data set contains a reference to the original data on the process monitoring data base. Update opens the original data set as a starting point. The program allows the inspector (participant) to select the NRTA balance interval by selecting the number of process monitoring data sets between balances.

Figure 6.2 shows an example run of the UPDATE program. After initiation, the program presents the inspector with a list of reference numbers. In the IET system, the process monitoring data set contains about 600 pieces of information in an ordered list (including those related to safeguards). These reference numbers indicate which pieces of information will be transferred to the NRTA data base for the in-process inventory determination.

The example in Fig. 6.2 shows that the inspector has selected an interval of 15 . The routine then pages through the process monitoring data sets and stops at every 15th page, which corresponds to hourly. The routine pulls the appropriate data according to the list and records the in-process inventory information in the NRTA data file.

The routine also writes a reference to the process monitoring data base in the NRTA data record to allow cross reference back to the original data.

\subsubsection{Program 2-MONITR}

MONITR is the basic process monitoring software program. It contains all of the logic to sort through the process monitoring data base, evaluate data, make judgments about location and movement of process solutions, and integrate flow measurements for NRTA and process monitoring analysis. In addition to the process monitoring functions, it is also important to NRTA and data base update routines.

The MONITR program operates based on the NRTA reference numbers. The user selects the interval to be analyzed. In the update procedure, the inspector (participant) selects an interval that starts with the last updated NRTA data set and ends with the last recorded data set. As an example, the update session as shown in Fig. 6.2 records material balance data sets 61-87. Figure 6.3 shows the inspector selecting the MONITR routine from the menu and selecting that same interval for analysis.

Figure 6.4 is the output from a short segment of this analysis. The first line of information below the heading shows the particular process monitoring data file open and being used as the source of information for the analysis. The data in Fig. 6.4 are grouped by time segment. The arrangement of the data in each time segment follows the pattem of the heading. Level, density, and volume are presented for each of the major uranium-bearing tanks in the facility. On the first row, data are shown for the dissolver surge tank (09F21), accountability tank (09F23), feed adjustment tank (11F03), and feed tank (11F01). At the end of the first line is the feed rate (in liters per minute) over the time interval since the last data set. On the second row are data for the HCU (intercycle) surge tank (19F01), the product collection tank (19F05), and the product accountability tank (19F07). The product collection rate over the interval since the previous data set is given at the end of the second line.

As each data set is read by the MONITR program, the first step is to qualify the data. This program deals primarily with measurements and calculations of volumes and solution weights. Differential pressures in pneumatic, dip-tube measurement systems are used. Measurement errors are common due to restricted or plugged probes, or when solution levels are below density 
reference numbers into archival files:

\begin{tabular}{|c|c|c|c|c|c|}
\hline tant & level & dens & tenp & extra & volume \\
\hline-- & - & -- & $-\cdots$ & $\cdots$ & $-\cdots$ \\
\hline $09 F 21$ & 122 & 120 & 123 & 0 & 156 \\
\hline $09 F 23$ & 118 & 115 & 124 & 0 & 157 \\
\hline $11 \mathrm{FOI}$ & 131 & 129 & 139 & 0 & 158 \\
\hline $11 F 03$ & 135 & 133 & 136 & 0 & 159 \\
\hline $19 F 01$ & 253 & 251 & 271 & 0 & 254 \\
\hline $19 C 04$ & 258 & 255 & 272 & 0 & 0 \\
\hline $19 F 05$ & 265 & 263 & 274 & 0 & 284 \\
\hline $19 F 07$ & 268 & 266 & 276 & 0 & 285 \\
\hline $\begin{array}{l}\text { sFare } \\
32 F 11\end{array}$ & $\begin{array}{l}128 \\
415\end{array}$ & $\begin{array}{l}126 \\
413\end{array}$ & $\begin{array}{l}125 \\
416\end{array}$ & $\begin{array}{l}0 \\
0\end{array}$ & $\begin{array}{l}160 \\
419\end{array}$ \\
\hline $12 F 05$ & 152 & 150 & 148 & 0 & $16:$ \\
\hline $12 \mathrm{FO}$ & 155 & 153 & 149 & 0 & 162 \\
\hline $19 F 12$ & 279 & 0 & 282 & 0 & 280 \\
\hline $32 \mathrm{FO1}$ & 387 & 384 & 388 & 0 & 389 \\
\hline extra & 50 & 48 & 0 & ( & 0 \\
\hline extra & 137 & 202 & 167 & 230 & 0 \\
\hline ex & 51 & 49 & 0 & 0 & 0 \\
\hline
\end{tabular}

The last aterial balance record was: 60 Recorded at $06: 55: 53$ on 12-16-87

It cane fron DU: $[40,100]$ ISPO 0 CFY

; 95, record $\$ 61$

How wany records between balances? 15

Set to read fron file DU: [40,100]15FO.CFY

enter $a$ 'cr' to continue, anything else will abort:

Write $4 B$ rec 62 from archival rec 91 at $08: 56: 00$ on 12-16-97

Write $M B$ rec 63 from archival rec 106 at $09: 57: 26$ on 12-16-87

Write rec 64 from archival rec 121 at 11:00:47 on 12-16-87

Set to read fron fle DU:[40,100]ISPO.CFY ;140 started at 00:47:23 on 12-17-87

Write $\mathrm{HB}$ rec 65 from archival rec 16 at $12: 00: 27$ or 12-16-8?

Write $M B$ rec 66 from irchival rec 31 at 13:00:24 on 12-16-8?

Write $A B$ rec 67 proa archival rec 46 at $14: 00: 12$ on $12-16-87$

Write $A B$ rec 68 Pron archival rec 61 at $15: 00: 16$ on 12-16-87

Write HB rec 69 frow archival rec 76 at $15: 59: 54$ or 12-16-87

Write $M B$ rec 70 frol archival rec 91 at $18: 17: 44$ ar $12-16-87$

Write $A B$ rec 71 from archuval rec 105 at $20: 47: 32$ on $12-16-87$

Write rec 72 fron archival rec 121 at $23: 17: 23$ or 12-16-8;

Set to read from ple IU: $[40,100] 15 F 0$. CPY ;141 started at 20:46:18 on 12-17-87

Write $A B$ rec 73 from archival rec 16 at $01: 47: 20$ on 12-17-87

Write $4 B$ rec 74 frol archival rec 31 at $04: 17: 06$ on $12-17-87$

Write $M E$ rec 75 from archival iec 46 at $06: 47: 00$ on 12-17-37

Write $M E$ rec 76 from archival rec 61 at $07: 16: 58$ on $12-17-37$

Write 4 rec 77 fron archival rec $7 t$ at $11: 46: 40$ on $12-17-87$

Write $A B$ rec 78 fro archival rec 91 at $14: 16: 41$ on 12-17-87

Write ME rec 79 from archival rec $10 t$ at $16: 46: 30$ on 12-17-97

Write $A B$ rec 80 from archival rec 121 at 19:16:27 or 12-17-87

Set to read froa file DU:[40,100]1SF0.CFY i142 started at $15:: 6: 15$ or 12-13-87

Write AB rec 81 fron archival rec 16 at $21: 46: 18$ or $12-17-87$

Write MB rec 82 Prou archival rec 31 at $00: 16: 12$ on 12-18-e7

Write MB rec 83 from archival rec 46 at $02: 46: 08$ on $12-18-87$

Write $\mathrm{KB}$ rec 84 from 3rchival rec 61 3t $05: 16: 00$ on 12-18-87

Write $H B$ rec 85 from archival rec 76 at $07: 45: 42$ an 12-18-97

Write $M B$ rec 86 Prom archival rec 91 at $10 \div 15 \div 35$ on 12-19-87

Write MB rec 87 from 3rchival rec 106 at $12: 45: 28$ on 12-18-07

Fig. 6.2. UPDATE routine - to record IPI data. 


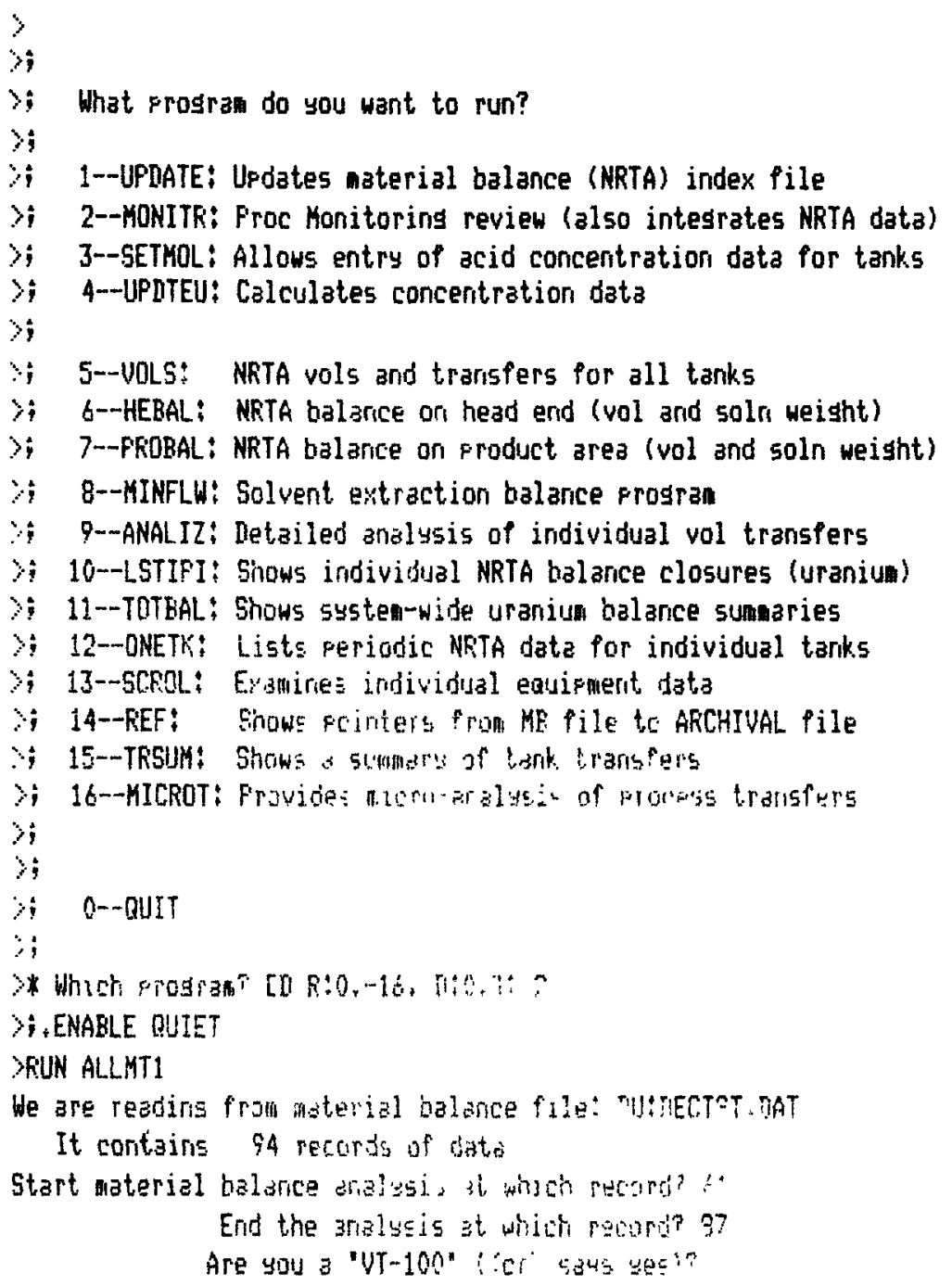

Fig. 6.3. Selection of MONITR from menu (for periods 1961-87).

measurement probes. These errors are often apparent to an experienced operator, but a less experienced person may often record bad data. Logic in the MONITR routine recognizes these problems and makes corrections. The correction part of this effort involves a logic structure to find the estimate or alternative measurement.

The program analyzes for inventory changes throughout the system. Logic is included to recognize normal batch transfers or inventory changes associated with routine operations. These routine operations include solvent extraction feed, concentrator feed, and product collection.

The logic associated with recognition of routine activities can be involved. Using the case of solvent extraction feed calculation as an example, the program makes a number of checks. As noted in Sect. 3.2.3, IET facility operations can use the $12-\mathrm{cm}$ contactor system or the smaller $5.5-\mathrm{cm}$ system. The monitor checks on both systems. It first looks for measured HAX flow, the organic extractant. If this is on, it looks for aqueous scrub and strip streams. With positive indications, the routine concludes that solvent extraction "MAY" be operating. 
Suenary of IET process tank activities



Fig. 6.4. Example of MONITR routine output. 
Both solvent extraction systems involve a common airlift to deliver solution from the feed tank. If the routine in the MONITR program finds that solvent extraction is operating, it looks to the airlift indicator. If this shows a positive indication, the routine looks to other indicators to determine which system is operating. For the $12-\mathrm{cm}$ system, this involves a level in the second stage airlift feed pot. For the smaller system using the waterwheel feed device, this is an rpm meter. Without final indicators, the routine concludes that solvent extraction is operating on cold streams only and prints a message. Otherwise, it concludes that solvent extraction is operating and goes on to compute flow rates and cumulative flow quantities.

The analysis on solvent extraction feed recognizes that the feed rate computed based on tank depletion rates is the most accurate. However, periodically, the tank is refilled and the depletion rate is an invalid measure. During the tank fill periods, the logic defaults to a backup calculation before doing rate checks and material flow calculations.

The analyses in Fig. 6.4 show continuous alarm on the feed tank (possible loss or unauthorized removal from 11F01). Each step described in the previous paragraph is implemented, and the logic concludes that solvent extraction is not running. The logic still finds depletion in the feed tank and presents the alarm. This particular segment was chosen as an example. As noted in Sect. 3.3, a solvent extraction bypass line was installed. This segment represents a period when the solvent extraction line was shut down but the bypass route was still in use. More will be presented on solvent extraction monitoring in later sections.

Solvent extraction feed and the feed tank monitoring of the MONITR routine is a complex logic structure implemented to compute and check solvent extraction feed calculations. It is presented in detail here to show the extent to which the knowledge and logic of an experienced operator has been included in the routine to benefit the inspector in application of the safeguards process monitoring routine. A similar logic structure is in place to calculate the rate of product delivery from the product concentrator. This logic involves concentrator feed rate indicators, temperatures, and measurements in the collection tank. Logic is also in place to recognize and interpret all other significant batch transfers throughout the system.

The MONITR routine maintains cumulative quantities for transfers in progress. It prints information messages about cumulative quantities and transferred-received comparisons. At the completion of a transfer, the MONITR program calculates the cumulative transferred and received quantities and informs the inspector if differences are excessive. These comparisons are made for any intemal process transfer. Examples of these analyses will also be used in later sections.

After analyzing and processing information on routine plant activities, the MONITR program analyzes any remaining, unexplained inventory changes. Some additional logic is applied. As an example of the adaptability of the routine, there have been periods of unresolved alarms in the solvent extraction feed tank (11F01). Closer examination found that these alarms occurred during periods when the tank was used to concentrate feed by heating. The alarms were attributable to volume changes during heating and boil-off of water. Logic was added to resolve alarms when volume increases or decreases were consistent with temperature change or when solution weight and volume loss were consistent with water loss in boil-off.

As noted in the previous section, the MONITR routine updates the NRTA balance files. Information on cumulative transfer quantities is maintained by the MONITR program for all internal transfers and accountability tank transfers. As the MONITR routine reaches a data set associated with one of the NRTA in-process inventory determinations, the routine writes the corrected inventory measurements and quantities to the file and enters the cumulative transfer data. 


\subsubsection{Program 3-UPDTEU}

Process monitoring applications that have been developed and implemented in the IET facility do not generally rely on concentration information. The NRTA applications do make use of some concentrations that are derived from on-line measurements, although this has not been a major part of the safeguards development program. The UPDTEU program contains the routines that are used to provide the concentration data used by various routines. A specific example of the use of this routine is not included. The inspectors simply select the routine from the menu and select the range of NRTA data files in which he desires the calculation to be applied.

As noted in Sect. 3, the IET facility is an experimental facility that does not have extensive laboratory capabilities. Instead, the facility control system is being developed to make extensive use of on-line measurements. There are only a few process control samples routinely taken. Measurements for control of solvent extraction are made using an on-line photometer device that is under development. Most other process control measurements use relationships between acid concentration, uranium concentration, and density. These relationships have been tested and demonstrated as effective on uranium solutions. They show some promise for plutonium solutions but have not been demonstrated. Safeguards process monitoring program development in the IET facility has made use of these on-line concentration estimation techniques. There has been some effort to use available process control samples and results to verify the performance of these on-line techniques. There is a relationship between process measurements, on-line analyzers, and process control samples (or specially requested agency samples that can be used to verify data for process monitoring and NRTA). These relationships and methods of application are being explored but need additional development.

\subsubsection{Program 4 - SETMOL}

The concentrator predictor methods used in the IET facility safeguards programs can use acid concentration information from laboratory analysis or those derived from on-line conductivity instruments. Acid concentration becomes less important in the equation as the uranium concentration increases. Density is the most important measurement in the relations used to predict concentration.

The estimators for the major uranium-bearing tanks generally use a laboratory result or process estimate for acid concentration. The UPDATE routine enters acid concentration values as the NRTA data files are being written. The SETMOL routine allows the inspector (participants) to update the NRTA files based on laboratory sample results and to change the values entered by the UPDATE routine.

A specific example of this routine is not included in this report. The routine prompts the user for which tank he will update and where to start. It then progresses through the NRTA data file showing the tank volume and prompting the user to indicate acid concentrations based on process control data.

\subsection{ALARM RESOLUTION ROUTINES}

The second group of programs available from the menu shown in Fig. 6.1 focus on the detailed analysis of problems indicated by the initial analysis of the MONITR routine. During the demonstration, participants were encouraged to use the MONITR routine and note the specific alarm messages. Depending on the alarm messages, there are specific routines from the second part of the menu that are used to resolve alarms as false or confirm the indication. 


\subsubsection{Program 5 - VOLS}

The VOLS program is a simple listing of the volumes and integrated flows associated with each of the major uranium-bearing tanks. The program is keyed to the NRTA balance numbers. The inspector selects the range of balance numbers to review. The program returns the data as shown in the example in Fig. 6.5.

This program is useful as a first step after the MONITR program is used. It quickly focuses attention on the major process events, such as batch transfers. It is a quick summary of the process events with references to the NRTA balance numbers. The integrated flow quantities offer a quick check on batch transfer comparisons.

\subsubsection{Program 6-HEBAL}

Process monitoring routines can be effective without the benefit of analytical information. The combined analysis of volume and solution weight balance data can be sensitive to material loss scenarios that involve removal or removal with substitution. The HEBAL routine examines the volume and solution weight balance on the process control unit from the accountability tank to the solvent extraction feed tank.

Figure 6.6 is an example of output from the HEBAL routine. This program also uses the NRTA balance number references to start and end. It uses cumulative flow quantities generated by the process monitoring routines. The balance equation considers input as transfers from the input accountability tank. Since the routine looks at a solution balance, input quantities also come from acid and water additions for feed adjustment and volume increases due to steam jet transfers. The output quantity is an integration of solvent extraction feed measurements. Inventory measurements are made in the feed adjustment tank (11F03) and the feed tank (11F01).

The HEBAL routine calculates an inventory difference statistic for both the volume and solution weight. The routine alarms if there is an apparent loss or gain of $25 \mathrm{~L}$ or $25 \mathrm{~kg}$ of solution. For feed solutions in an FBR reprocessing plant, this quantity corresponds to about a kilogram of plutonium. For an LWR facility, the quantity corresponds to about $50 \mathrm{~g}$. When the routine is run on a video terminal, each balance period that is in alarm blinks on the display to draw attention. The printed output includes an alarm summary.

The IDs for each period shown in Fig. 6.6 exceed the alarm limit set within the analysis routine. Each period generates an alarm. The causes of these alarms will be discussed in Sect. 7 .

\subsubsection{Program 7 - PROBAL}

The PROBAL program is very similar to the HEBAL program. It provides a volume and solution weight balance for a control unit around product tanks. An example is shown in Fig. 6.7.

The PROBAL program uses an integration of the measurement of product solution delivered to the collection tank (19F05) from the concentrator as the input to the control unit. Calculation of the input quantity is provided by the process monitoring routine and included in the NRTA balance file. Product from the control unit is calculated as the batch transfers.

Like the HEBAL program, the calculated IDs are evaluated. In the case of the product control unit, the alarm threshold is set at $8 \mathrm{~L}$ or $8 \mathrm{~kg}$ of solution. Individual IDs that exceed the limits are alarmed. In the data shown in Fig. 6.7, there are three alarm periods. The alarm summary for this set of data is also shown in Fig. 6.7. Causes of the alarms and resolution techniques will be discussed later. 


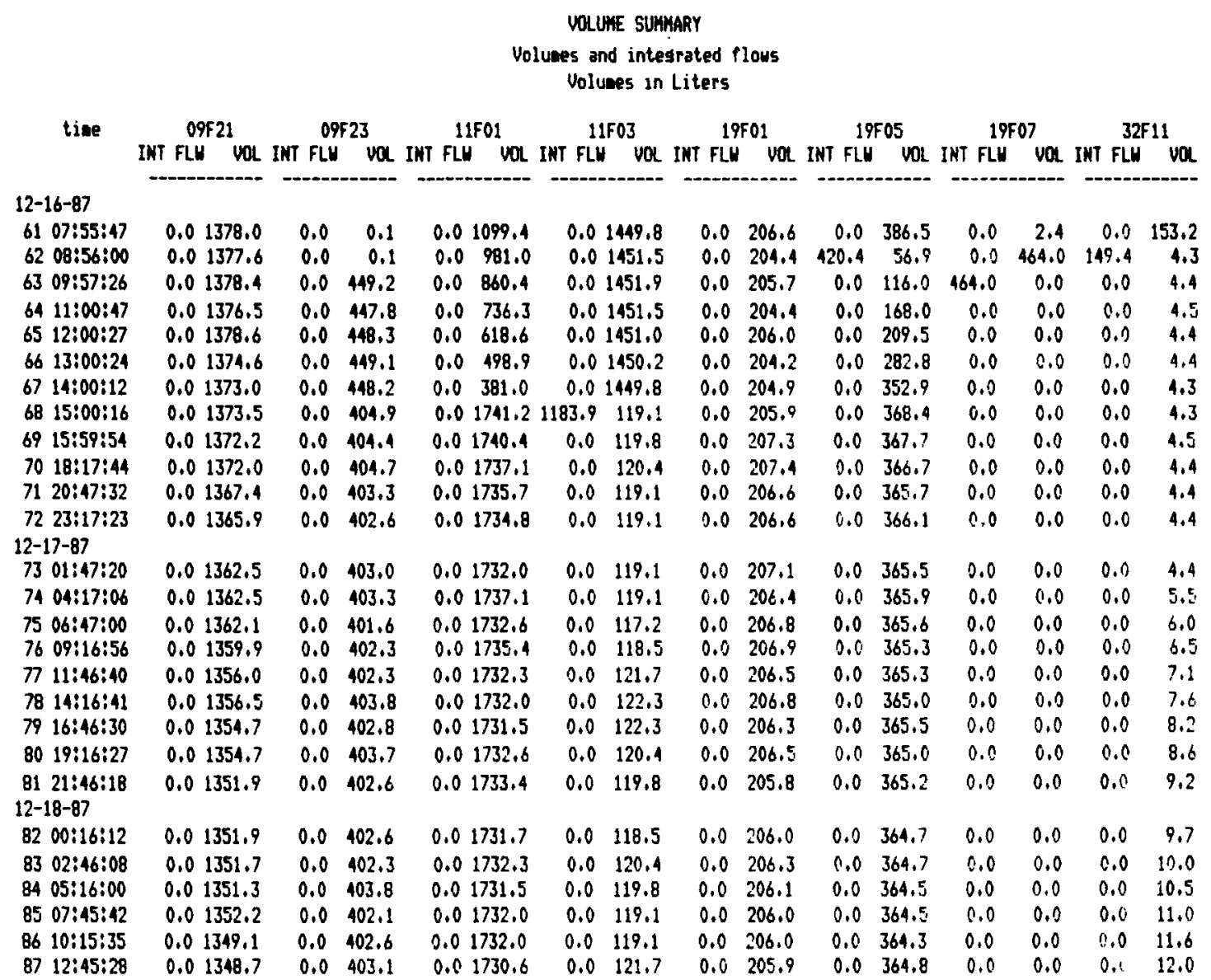

Fig. 6.5. Example of VOLS program output. 
HEAD END TANK VOLUME AND UEIGHT BALANCE

Solution weisht is volume $X$ density

infuts are 09F23, acid adods, 3nd jet dilution effects

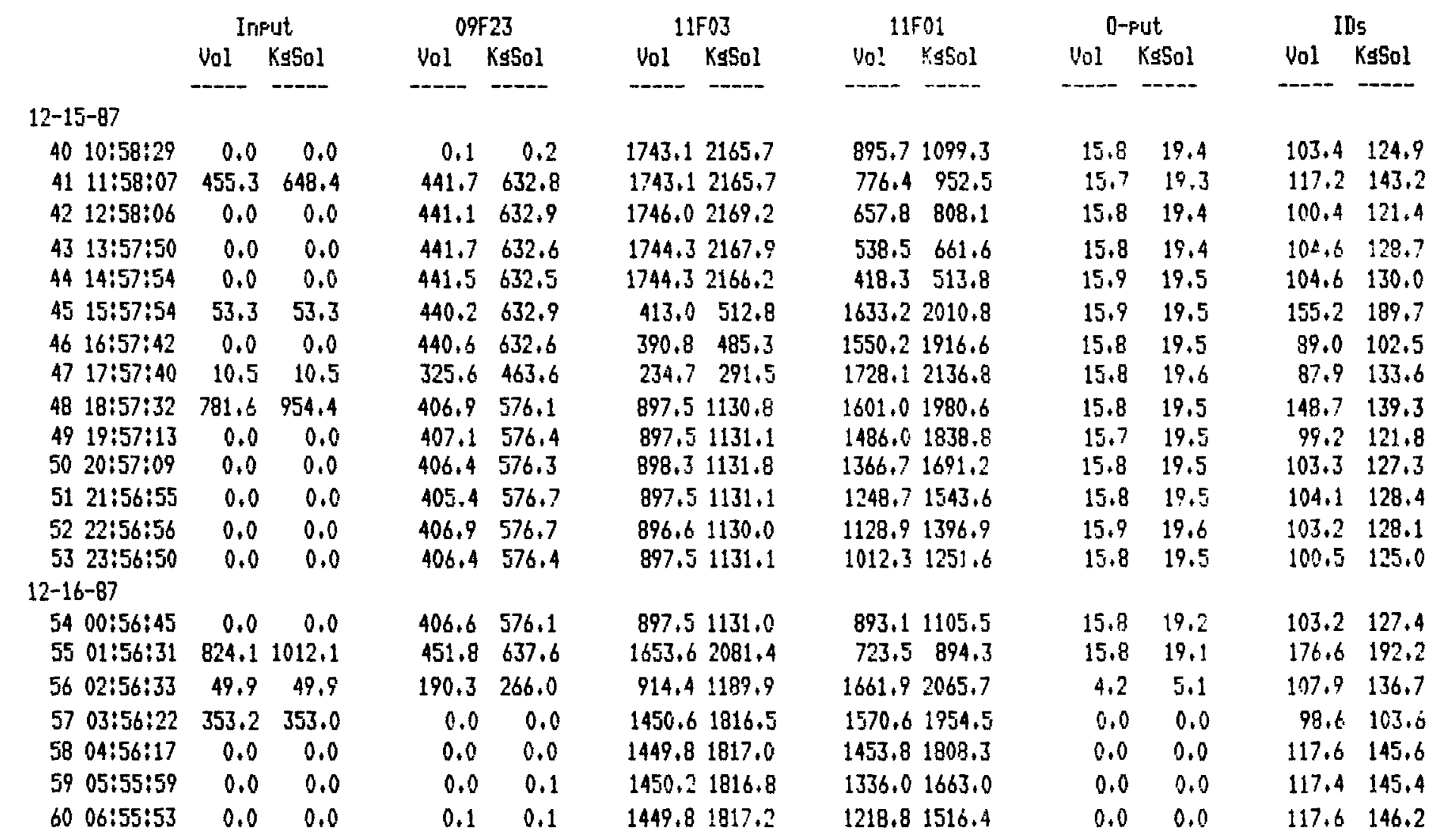

Fig. 6.6. Example of HEBAL program output (input area balance). 
FRORUCT TANK VOLURE AND WEIGHT BALANCE

Solution wersht is volume $X$ density input is auantity received from the concentrator

ID = Besin Iriv + Iniput - Ouput, - Erió Inv

\begin{tabular}{|c|c|c|c|c|c|c|c|c|c|c|c|c|}
\hline & \multicolumn{2}{|c|}{ Input } & \multicolumn{2}{|c|}{$19 F 05$} & \multicolumn{2}{|c|}{19597} & \multicolumn{2}{|c|}{$n-p \mid j t$} & \multicolumn{2}{|c|}{ Iriv } & \multicolumn{2}{|c|}{ IDs } \\
\hline & Vol & $\mathrm{K}_{\mathrm{SSOl}}$ & Vol & KsSOl & Vol & Ks5o! & Vol & $v_{\Phi 5 n !}$ & $y_{01}$ & KS5ol & Vol & KsSol \\
\hline & ---- & $-\cdots$ & ---- & ---- & $\cdots--$ & $\cdots$ & $\cdots$ & $\cdots$ & $-\cdots$ & $\cdots$ & & \\
\hline \multicolumn{13}{|l|}{$12-15-87$} \\
\hline $4010: 58: 29$ & 86.2 & 123.2 & 118.2 & 163.0 & 454.8 & 648.2 & 0.0 & 0.0 & 573.0 & 811.1 & -91.9 & -122.6 \\
\hline $4111: 58: 07$ & 27.1 & 37.7 & 145.3 & 203.8 & 0.0 & 0.0 & 455.3 & 648.4 & 145.3 & 207.8 & $-r .5$ & -3.4 \\
\hline $\begin{array}{ll}42 & 12: 58: 06 \\
43 & 13: 57: 50\end{array}$ & $\begin{array}{l}60.2 \\
43.1\end{array}$ & $\begin{array}{l}84.2 \\
60.5\end{array}$ & $\begin{array}{l}205.5 \\
248.6\end{array}$ & $\begin{array}{l}288.6 \\
348.8\end{array}$ & $\begin{array}{l}0.0 \\
0.0\end{array}$ & $\begin{array}{l}0.0 \\
0.0\end{array}$ & $\begin{array}{l}0.0 \\
0.0\end{array}$ & $\begin{array}{l}0.0 \\
0.0\end{array}$ & $\begin{array}{l}205.5 \\
248.6\end{array}$ & $\begin{array}{l}288.6 \\
348.8\end{array}$ & $\begin{array}{l}0.0 \\
0.0\end{array}$ & $\begin{array}{r}-0.6 \\
0.4\end{array}$ \\
\hline $4414: 57: 54$ & 83.3 & 117.3 & 331.9 & 467.6 & 0.0 & 0.0 & 0.0 & 0.0 & 331.9 & 467.6 & 0.0 & -1.6 \\
\hline $45 \quad 15: 57: 54$ & 31,3 & 44.0 & 363.1 & 510.4 & 0.0 & 0.0 & 0.0 & 0.0 & 363.1 & 510.4 & 0.0 & 1.1 \\
\hline $46 \quad 16: 57: 42$ & 71.8 & 101.3 & 98.5 & 138.7 & 300.3 & 423.3 & 0.0 & 0.0 & 398.8 & 562.0 & 36.1 & 49.7 \\
\hline $47 \quad 17: 57: 40$ & 120.1 & 169.1 & 100.7 & 141.8 & 419.6 & 591.7 & 0.0 & 0.0 & 520.3 & 733.5 & -1.3 & -2.3 \\
\hline $\begin{array}{ll}48 & 18: 57: 32 \\
49 & 19: 57: 13\end{array}$ & $\begin{array}{l}57.2 \\
24.8\end{array}$ & $\begin{array}{l}79.3 \\
34.4\end{array}$ & $\begin{array}{l}157.9 \\
182.7\end{array}$ & $\begin{array}{l}218.5 \\
254.6\end{array}$ & $\begin{array}{l}0.0 \\
0.0\end{array}$ & $\begin{array}{l}0.0 \\
0.0\end{array}$ & $\begin{array}{r}419.8 \\
0.0\end{array}$ & $\begin{array}{r}592.7 \\
0.0\end{array}$ & $\begin{array}{l}157.9 \\
182.7\end{array}$ & $\begin{array}{l}218.5 \\
254.6\end{array}$ & $\begin{array}{r}-0.2 \\
0.0\end{array}$ & $\begin{array}{r}1.6 \\
-1.7\end{array}$ \\
\hline $50 \quad 20: 57: 09$ & 73.3 & 102,4 & 256.0 & 358.3 & 0.0 & 0.0 & 0.0 & 0.0 & 256.0 & 358.3 & 0.0 & -1.4 \\
\hline $5121: 56: 55$ & 57,3 & 80.4 & 313.3 & 441.3 & 0.0 & 0.0 & 0.0 & 0.0 & 313.3 & 441.3 & 0.0 & -2.6 \\
\hline $52 \quad 22: 56: 56$ & 59.6 & 84.0 & 373.0 & 525.0 & 0.0 & 0.0 & 0.0 & 0.0 & 373.0 & 525.0 & 0.0 & 0.3 \\
\hline $5323: 56: 50$ & 48.5 & 68.2 & 0.0 & 0.0 & 466.9 & 656.8 & 0.0 & 0.0 & 166.9 & 656.8 & -45.5 & -63.6 \\
\hline \multicolumn{13}{|l|}{$12-16-87$} \\
\hline $5400: 56: 45$ & 60.0 & 84.1 & 60.0 & 84,1 & 467.8 & 656.1 & 0.0 & 0.0 & 527.9 & 740.1 & -0.9 & 0.7 \\
\hline $5501: 56: 31$ & 66.0 & 92.0 & 126.0 & 173.3 & 2.3 & 3.2 & 465.5 & 653.4 & 128.3 & 176.5 & 0.0 & 2.3 \\
\hline $\begin{array}{ll}56 & 02: 56: 33 \\
57 & 03: 56: 22\end{array}$ & $\begin{array}{l}24,8 \\
64,8\end{array}$ & $\begin{array}{l}34 . ! \\
89.8\end{array}$ & $\begin{array}{l}150.8 \\
215.6\end{array}$ & $\begin{array}{l}208.3 \\
295.5\end{array}$ & $\begin{array}{l}2.3 \\
2.2\end{array}$ & $\begin{array}{l}3.2 \\
3.1\end{array}$ & $\begin{array}{l}0.0 \\
0.6\end{array}$ & $\begin{array}{l}0 . \hat{1} \\
0.0\end{array}$ & $\begin{array}{l}153.1 \\
21^{7.8}\end{array}$ & $\begin{array}{l}211.5 \\
298.6\end{array}$ & $\begin{array}{l}0.0 \\
0.1\end{array}$ & $\begin{array}{l}0.8 \\
2.6\end{array}$ \\
\hline $58 \quad 04: 56: 17$ & 4.5 & 6.1 & 220.1 & 305,4 & 2.5 & 3.6 & 0.0 & 0.0 & 222.6 & 309.0 & -0.4 & -4.2 \\
\hline $\begin{array}{ll}59 & 05: 55: 59 \\
60 & 06: 55: 53\end{array}$ & $\begin{array}{l}81.1 \\
36.5\end{array}$ & $\begin{array}{r}112.6 \\
51.1\end{array}$ & $\begin{array}{l}301.1 \\
337.7\end{array}$ & $\begin{array}{l}419.2 \\
473.1\end{array}$ & $\begin{array}{l}2.1 \\
2.6\end{array}$ & $\begin{array}{l}3.0 \\
3.0\end{array}$ & $\begin{array}{l}0.0 \\
6.0\end{array}$ & $\begin{array}{l}0.0 \\
0.0\end{array}$ & $\begin{array}{l}303.3 \\
340.2\end{array}$ & $\begin{array}{l}422 .: \\
476.7\end{array}$ & $\begin{array}{r}6.4 \\
-9.4\end{array}$ & $\begin{array}{l}-0.6 \\
-3.4\end{array}$ \\
\hline
\end{tabular}

the followns periods exceed our 1rivestisation heuristic:

Puther investigation 15 reeded!

(1) Por period 40 voluae Il 15 - 91.9 and the solution weisht it $15-122.6$

(2) Por period is voluae In $15 \quad 36.1$ and the sclution weight Ifl is 49.7

(3) Por period 53 volue III 15 - 45.5 and the solutior weisit III $1=-53.6$

Fig. 6.7. Example of PROBAL program output (product area balance). 


\subsubsection{Program 8-MINFLW}

The MINFLW program is the control unit balance program for the solvent extraction system. This program also uses the NRTA material balance numbers as reference. The program monitors total heavy metal mass flows, calculating parameters for each of the 4-min data sets. Process monitoring routines maintain cumulative totals for each of the NRTA balance periods. This is a program that not only calculates a balance on cumulative mass flows, but also presents a number of redundant process measurements in order to make judgments on measurement performance. Data can be presented in summary form or in detail for study of the various measurements involved.

Figure 6.8 is an example of the MINFLW program detailed output. The intent of the routine is to compare the cumulative mass flow of the solvent extraction feed to the cumulative mass flow of solvent extraction product, measured as it leaves solvent extraction. This product is collected in the surge tank (19F01).

The MINFLW program is an elementary attempt to use decision logic to choose the best alternative from among several redundant process control measurements. For the feed flow measurement, the tank dropout rate is continuously shown in comparison to the rate calculated from the rpm counter in the waterwheel feed device. The comparison is used to develop the calibration factor for the wheel device.

Three determinations of the feed (HAF) concentration are shown. The "calc" concentration is a calculation based on measured tank density and an assumption on the adjusted acid concentrations. The "photo" calculation is the concentration as measured by an in-line, spectrophotometer device installed on the feed line. The "DDACS" concentration is also from the photometer device but is made between stages within the solvent extraction systems. This measurement can be related to the feed and serves as a check on solvent extraction performance.

The photometer device is more accurate than the calculated quantity, but less reliable. The calculated quantity is sensitive to a bias in the density measurement, but is a stable indicator of concentration. Together these measurements can provide an accurate determination of feed concentration. The photometer reading is used to develop a correction factor to be applied to the density measurement. The adjusted concentration tends to be accurate and is used with the flow calculated from the feed wheel measurement for input mass (uranium) flow. Total mass flow for each interval is shown in the column labeled "kg." The column labeled "cum kg" is cumulative total mass flow.

Figure 6.8 also shows the output for this control unit as the HCU stream. The "flow" column under "HCU" measurements is actually the HCX flow measurement. Flow of the HCU product is directly related to the HCX. The HCX is the aqueous strip stream which eventually becomes the HCU after stripping product from the organic stream in solvent extraction. Since the aqueous strip stream is a clean, cold chemical stream, it is easier to measure than HCU, and the measurement is traditionally available for process control. This measurement can be assumed to be the same as the HCU flow.

The concentration in the HCU stream is calculated based on a process control density measurement made in the separator pot as the product is airlifted to the surge tank. Again, this measurement is traditionally available as a process control signal on performance of the solvent extraction system. The strip solution is low acid concentration, and the density measurement accurately reflects heavy metal (uranium) concentration with an assumption of acid content. The assumption of acid content is confirmed by periodic samples and an in-line conductivity measurement on the strip solution. Sample results are not shown. The DDAC measurement 
HA FLOW MEASUREMENT STUUY

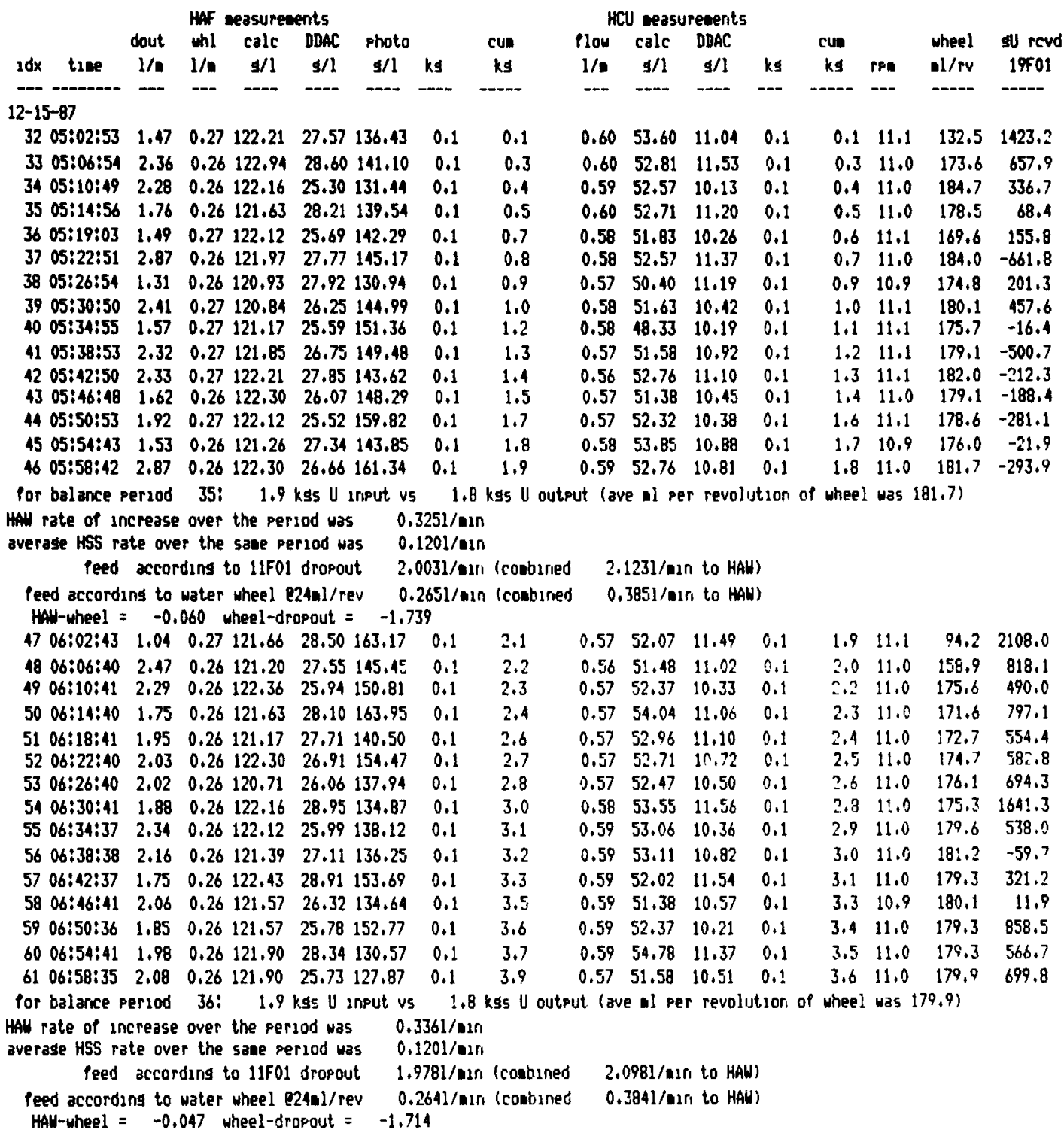

Fig. 6.8. Example of MINFLW program (solvent extraction balance). 
shown in Fig. 6.8 is measured by the photometer on an intermediate stream within the strip contactors of solvent extraction. The actual HCU concentration is confirmed by periodic samples and measurements in the HCU surge tank (19F01).

As the analyses in the MINFLW routine reach an NRTA balance data set, additional summary calculations are made. As shown in Fig. 6.8, the comparison of total mass flow is shown for HAF and HCU over the balance period. For this particular analysis, the actual quantities in HAW are considered negligible. A summary of cumulative dropout compared to wheel measured feed is given to confirm these calculations.

Solvent extraction operations have additional characteristics that help confirm the accuracy of process control measurements. The aqueous component of feed and additions of scrub solutions (HSS), all aqueous solutions, eventually combine in the HAW system. With the dual tank mode of HAW collection in the IET facility, HAW volume increases are an additional confirmation on feed measurements. Comparisons of HAW to feed measurements add additional confirmation to feed measurements.

As noted, the MINFLW program can be operated in a summary mode. In this mode, the analyses between NRTA balance periods are omitted from the program output. Only the summary comparisons are then presented.

The discussion on the MINFLW program is rather detailed. These details were presented to participants in the demonstration. The program is an example of a process monitoring routine that analyzes a balance statistic for potential removal, but also shows the relationships of process measurements to confirm or verify key measurements.

\subsubsection{Program 9-ANALIZ}

The ANALIZ program allows the inspector to review the process monitoring data for each of the major uranium-bearing tanks in the IET facility. The program is keyed to the NRTA balance file number. The inspector can select a summary of all level measurements, all density measurements, temperature, volume, or volume changes. The program presents data from the 4-min process monitoring data for two hours before and one hour after the selected NRTA data set.

Figure 6.9 is an example of the output from the ANALIZ program. A listing of tank level measurements was selected for this example.

\subsubsection{Program 10 - LSTIPI}

The NRTA, and the role of process monitoring in collection and qualification of automated in-process inventory measurements, is an integral part of the IET facility safeguards system. The program LSTIPI simply provides a detailed listing of in-process inventory for a single NRTA balance, along with inventory change information and a calculated inventory difference. Total uranium inventory in the IET facility is the basis for the inventory difference calculation. An example is shown in Fig. 6.10.

\subsubsection{Program 11 - TOTBAL}

The TOTBAL program is a summary of a series of NRTA balance determinations. An example of the output for a series of balances is provided in Fig. 6.11.

\subsubsection{Program 12 - ONETK}

The program ONETK is a tool for the inspector to view a summary of the NRTA in-process inventory data for an individual tank. The same data shown in the LSTIPI program are shown, but for a series in NRTA balances rather than all tanks in an individual IPI. The example in Fig. 6.12 shows a series of measurements for the feed adjustment tank (11F03). 
DATA FROH SAFEGUARDS 4-HINUTE ROUND FILES

For two hours before and an hour after RECCRD 35

LEVEL recorded for each of the 10 tanks

RF

\begin{tabular}{|c|c|c|c|c|c|c|c|c|c|c|}
\hline IDX TIHE & $09 F 21$ & $09 F 23$ & $11 F 01$ & $11 F 03$ & $19 F 01$ & 19004 & $19 F 05$ & 19507 & $11 F 10$ & $32 F 11$ \\
\hline \multicolumn{11}{|l|}{ on $12-15-87$} \\
\hline $\begin{array}{ll}16 & 03: 59: 00 \\
17 & 04: 03: 00 \\
18 & 04: 07: 06\end{array}$ & $\begin{array}{l}1.557 \\
1.560 \\
1.567\end{array}$ & $\begin{array}{l}0.580 \\
0.313 \\
0.000\end{array}$ & $\begin{array}{l}1.595 \\
1.583 \\
1.584\end{array}$ & $\begin{array}{l}1.066 \\
1.198 \\
1.265\end{array}$ & $\begin{array}{l}0.604 \\
0.605 \\
0.607\end{array}$ & $\begin{array}{l}0.718 \\
0.734 \\
0.729\end{array}$ & $\begin{array}{l}0.344 \\
0.343 \\
0.341\end{array}$ & $\begin{array}{l}0.000 \\
0.000 \\
0.000\end{array}$ & $\begin{array}{l}0.344 \\
0.347 \\
0.352\end{array}$ & $\begin{array}{l}0.921 \\
1.166 \\
0.878\end{array}$ \\
\hline $\begin{array}{l}1904: 11: 04 \\
20 \quad 04: 15: 02\end{array}$ & $\begin{array}{l}1.566 \\
1.567\end{array}$ & $\begin{array}{l}0.005 \\
0.006\end{array}$ & $\begin{array}{l}1.577 \\
1.571\end{array}$ & $\begin{array}{l}1.266 \\
1.267\end{array}$ & $\begin{array}{l}0.602 \\
0.603\end{array}$ & $\begin{array}{l}0.731 \\
0.749\end{array}$ & $\begin{array}{l}0.341 \\
0.342\end{array}$ & $\begin{array}{l}0.000 \\
0.000\end{array}$ & $\begin{array}{l}0.352 \\
0.352\end{array}$ & $\begin{array}{l}1.291 \\
1.330\end{array}$ \\
\hline $\begin{array}{ll}21 & 04: 19: 03 \\
22 & 04: 23: 05 \\
23 & 04: 27: 00\end{array}$ & $\begin{array}{l}1.568 \\
1.566 \\
1.564\end{array}$ & $\begin{array}{l}0.005 \\
0.007 \\
0.007\end{array}$ & $\begin{array}{l}1.565 \\
1.559 \\
1.551\end{array}$ & $\begin{array}{l}1.267 \\
1.267 \\
1.267\end{array}$ & $\begin{array}{l}0.603 \\
0.605 \\
0.601\end{array}$ & $\begin{array}{l}0.751 \\
0.761 \\
0.764\end{array}$ & $\begin{array}{l}0.342 \\
0.345 \\
0.348\end{array}$ & $\begin{array}{l}0.000 \\
0.000 \\
0.000\end{array}$ & $\begin{array}{l}0.351 \\
0.353 \\
0.353\end{array}$ & $\begin{array}{l}1.145 \\
0.737 \\
0.390\end{array}$ \\
\hline $\begin{array}{ll}24 & 04: 31: 04 \\
25 & 04: 35: 00 \\
26 & 04: 38: 59\end{array}$ & $\begin{array}{l}1.568 \\
1.569 \\
1.566\end{array}$ & $\begin{array}{l}0.008 \\
0.008 \\
0.006\end{array}$ & $\begin{array}{l}1.543 \\
1.540 \\
1.516\end{array}$ & $\begin{array}{l}1.269 \\
1.350 \\
1.446\end{array}$ & $\begin{array}{l}0.606 \\
0.601 \\
0.607\end{array}$ & $\begin{array}{l}0.759 \\
0.771 \\
0.757\end{array}$ & $\begin{array}{l}0.350 \\
0.353 \\
0.356\end{array}$ & $\begin{array}{l}0.000 \\
0.000 \\
0.000\end{array}$ & $\begin{array}{l}0.353 \\
0.353 \\
0.391\end{array}$ & $\begin{array}{l}0.006 \\
0.002 \\
0.004\end{array}$ \\
\hline $2704: 42: 56$ & 1.568 & 0.008 & 1.492 & 1.520 & 0.599 & 0.770 & 0.366 & 0.000 & 0.443 & 0.003 \\
\hline $\begin{array}{ll}28 & 04: 46: 58 \\
29 & 04: 50: 53\end{array}$ & $\begin{array}{l}1.568 \\
1.568\end{array}$ & $\begin{array}{l}0.007 \\
0.008\end{array}$ & $\begin{array}{l}1.485 \\
1.477\end{array}$ & $\begin{array}{l}1.521 \\
1.521\end{array}$ & $\begin{array}{l}0.603 \\
0.605\end{array}$ & $\begin{array}{l}0.768 \\
0.768\end{array}$ & $\begin{array}{l}0.382 \\
0.396\end{array}$ & $\begin{array}{l}0.000 \\
0.000\end{array}$ & $\begin{array}{l}0.443 \\
0.444\end{array}$ & $\begin{array}{l}0.002 \\
0.003\end{array}$ \\
\hline $30 \quad 04: 54: 55$ & 1,566 & 0,007 & 1.472 & 1.522 & 0.607 & 0.769 & 0.408 & 0,000 & 0.444 & 0.000 \\
\hline $\begin{array}{ll}31 & 04: 58: 53 \\
32 & 05: 02: 53 \\
33 & 05: 06: 54\end{array}$ & $\begin{array}{l}1.569 \\
1.565 \\
1.567\end{array}$ & $\begin{array}{l}0.008 \\
0.008 \\
0.008\end{array}$ & $\begin{array}{l}1.463 \\
1.458 \\
1.449\end{array}$ & $\begin{array}{l}1.521 \\
1.524 \\
1.523\end{array}$ & $\begin{array}{l}0.609 \\
0.608 \\
0.606\end{array}$ & $\begin{array}{l}0.770 \\
0.775 \\
0.772\end{array}$ & $\begin{array}{l}0.421 \\
0.436 \\
0.452\end{array}$ & $\begin{array}{l}0.000 \\
0.000 \\
0.000\end{array}$ & $\begin{array}{l}0.444 \\
0.444 \\
0.445\end{array}$ & $\begin{array}{l}0.000 \\
0.001 \\
0.001\end{array}$ \\
\hline $\begin{array}{l}3405: 10: 49 \\
3505: 14: 56\end{array}$ & $\begin{array}{l}1.564 \\
1.565\end{array}$ & $\begin{array}{l}0.008 \\
0.007\end{array}$ & $\begin{array}{l}1.442 \\
1.435\end{array}$ & $\begin{array}{l}1.524 \\
1.521\end{array}$ & $\begin{array}{l}0.602 \\
0.601\end{array}$ & $\begin{array}{l}0.764 \\
0.768\end{array}$ & $\begin{array}{l}0.467 \\
0.473\end{array}$ & $\begin{array}{l}0.000 \\
0.000\end{array}$ & $\begin{array}{l}0.444 \\
0.445\end{array}$ & $\begin{array}{l}0.002 \\
0.004\end{array}$ \\
\hline $3605: 19: 03$ & 1.565 & 0.009 & 1.430 & 1.523 & 0.604 & 0.764 & 0.479 & 0.000 & 0.444 & 0.000 \\
\hline $\begin{array}{ll}37 & 05: 22: 51 \\
38 & 05: 26: 54\end{array}$ & $\begin{array}{l}1.566 \\
1.565\end{array}$ & $\begin{array}{l}0.008 \\
0.008\end{array}$ & $\begin{array}{l}1.420 \\
1.416\end{array}$ & $\begin{array}{l}1.523 \\
1.521\end{array}$ & $\begin{array}{l}0.607 \\
0.609\end{array}$ & $\begin{array}{l}0.750 \\
0.766\end{array}$ & $\begin{array}{l}0.487 \\
0.493\end{array}$ & $\begin{array}{l}0.000 \\
0.000\end{array}$ & $\begin{array}{l}0.443 \\
0.443\end{array}$ & $\begin{array}{l}0.002 \\
0.004\end{array}$ \\
\hline $3905: 30: 50$ & 1.566 & 0.009 & 1.407 & 1.524 & 0.604 & 0.772 & 0.504 & 0.000 & 0.444 & 0.005 \\
\hline $40 \quad 05: 34: 55$ & 1.566 & 0.008 & 1.402 & 1.524 & 0.607 & 0.771 & 0.520 & 0.000 & 0.441 & 0.003 \\
\hline $4105: 38: 53$ & 1.563 & 0.010 & 1.394 & 1.522 & 0.599 & 0.771 & 0.537 & 0.000 & 0.445 & 0.055 \\
\hline $4205: 42: 50$ & 1.563 & 0.009 & 1.386 & 1.522 & 0.601 & 0.769 & 0.549 & 0.000 & 0.445 & 0.349 \\
\hline $4305: 46: 48$ & 1.566 & 0.007 & 1.380 & 1.521 & 0.605 & 0.753 & 0.570 & 0.000 & 0.444 & 0.780 \\
\hline $4405: 50: 53$ & 1.566 & 0.009 & 1.373 & 1.523 & 0.605 & 0.762 & 0.578 & 0.000 & 0.445 & 1.138 \\
\hline $4505: 54: 43$ & 1.566 & 0.008 & 1.368 & 1.522 & 0.603 & 0.756 & 0.593 & 0.000 & 0.444 & 0.960 \\
\hline \multicolumn{11}{|c|}{ The data for RECORD 35 are: } \\
\hline $4605: 58: 42$ & 1.564 & 0.008 & 1.358 & 1.521 & 0.607 & 0.731 & 0.592 & 0.000 & 0.443 & 1.330 \\
\hline $4706: 02: 43$ & 1.564 & 0.008 & 1.354 & 1.523 & 0.604 & 0.717 & 0.594 & 0.000 & 0.444 & 1.161 \\
\hline $\begin{array}{l}4806: 06: 40 \\
4906: 10: 41\end{array}$ & $\begin{array}{l}1.564 \\
1.564\end{array}$ & $\begin{array}{l}0.008 \\
0.009\end{array}$ & $\begin{array}{l}1.346 \\
1.338\end{array}$ & $\begin{array}{l}1.521 \\
1.523\end{array}$ & $\begin{array}{l}0.607 \\
0.600\end{array}$ & $\begin{array}{l}0.696 \\
0.707\end{array}$ & $\begin{array}{l}0.592 \\
0.594\end{array}$ & $\begin{array}{l}0.000 \\
0.000\end{array}$ & $\begin{array}{l}0.444 \\
0.442\end{array}$ & $\begin{array}{l}0.992 \\
0.718\end{array}$ \\
\hline $50 \quad 06: 14: 40$ & 1.565 & 0.008 & 1.332 & 1.523 & 0.596 & 0.745 & 0.593 & 0.000 & 0.443 & 0.424 \\
\hline $\begin{array}{ll}51 & 06: 18: 41 \\
52 & 06: 22: 40\end{array}$ & $\begin{array}{l}1.568 \\
1.569\end{array}$ & $\begin{array}{l}0.009 \\
0.011\end{array}$ & $\begin{array}{l}1.325 \\
1.318\end{array}$ & $\begin{array}{l}1.521 \\
1.522\end{array}$ & $\begin{array}{l}0.605 \\
0.606\end{array}$ & $\begin{array}{l}0.766 \\
0.772\end{array}$ & $\begin{array}{l}0.593 \\
0.603\end{array}$ & $\begin{array}{l}0.000 \\
0.000\end{array}$ & $\begin{array}{l}0.444 \\
0.443\end{array}$ & $\begin{array}{l}0.140 \\
0.005\end{array}$ \\
\hline $5306: 26: 40$ & 1.564 & 0.010 & 1.311 & 1.523 & 0.607 & 0.759 & 0.616 & 0.000 & 0.443 & 0.085 \\
\hline $\begin{array}{ll}54 & 06: 30: 41 \\
55 & 06: 34: 37\end{array}$ & $\begin{array}{l}1.564 \\
1.562\end{array}$ & $\begin{array}{l}0.011 \\
0.009\end{array}$ & $\begin{array}{l}1.304 \\
1.296\end{array}$ & $\begin{array}{l}1.522 \\
1.522\end{array}$ & $\begin{array}{l}0.606 \\
0.603\end{array}$ & $\begin{array}{l}0.769 \\
0.770\end{array}$ & $\begin{array}{l}0.631 \\
0.656\end{array}$ & $\begin{array}{l}0.000 \\
0.000\end{array}$ & $\begin{array}{l}0.442 \\
0.444\end{array}$ & $\begin{array}{l}0.161 \\
0.255\end{array}$ \\
\hline $5606: 38: 38$ & 1.566 & 0.010 & 1.288 & 1.521 & 0.594 & 0.768 & 0.680 & 0.000 & 0.443 & 0.271 \\
\hline $\begin{array}{ll}57 & 06: 42: 37 \\
58 & 06: 46: 41\end{array}$ & $\begin{array}{l}1.563 \\
1.565\end{array}$ & $\begin{array}{l}0.011 \\
0.009\end{array}$ & $\begin{array}{l}1.282 \\
1.275\end{array}$ & $\begin{array}{l}1.524 \\
1.522\end{array}$ & $\begin{array}{l}0.605 \\
0.607\end{array}$ & $\begin{array}{l}0.750 \\
0.726\end{array}$ & $\begin{array}{l}0.688 \\
0.691\end{array}$ & $\begin{array}{l}0.000 \\
0.000\end{array}$ & $\begin{array}{l}0.443 \\
0.444\end{array}$ & $\begin{array}{l}0.351 \\
0.443\end{array}$ \\
\hline $5906: 50: 36$ & 1.565 & 0.010 & 1.269 & 1.521 & 0.603 & 0.726 & 0.689 & 0.000 & 0.442 & 0.503 \\
\hline $\begin{array}{ll}60 & 06: 54: 41 \\
61 & 06: 58: 35\end{array}$ & $\begin{array}{l}1.565 \\
1.562\end{array}$ & $\begin{array}{l}0.010 \\
0.011\end{array}$ & $\begin{array}{l}1.262 \\
1.255\end{array}$ & $\begin{array}{l}1.522 \\
1.523\end{array}$ & $\begin{array}{l}0.606 \\
0.607\end{array}$ & $\begin{array}{l}0.730 \\
0.767\end{array}$ & $\begin{array}{l}0.689 \\
0.689\end{array}$ & $\begin{array}{l}0.000 \\
0.000\end{array}$ & $\begin{array}{l}0.442 \\
0.443\end{array}$ & $\begin{array}{l}0.582 \\
0.656\end{array}$ \\
\hline
\end{tabular}

Fig. 6.9. Example of output from ANALIZ program. 
IN-PROCESS INUENTORY SUMMARY (for bolance period

data recorded at $01: 59: 18$ on $12-15-87$

Previous IPI data at $00: 59: 22$ on 12-15-87

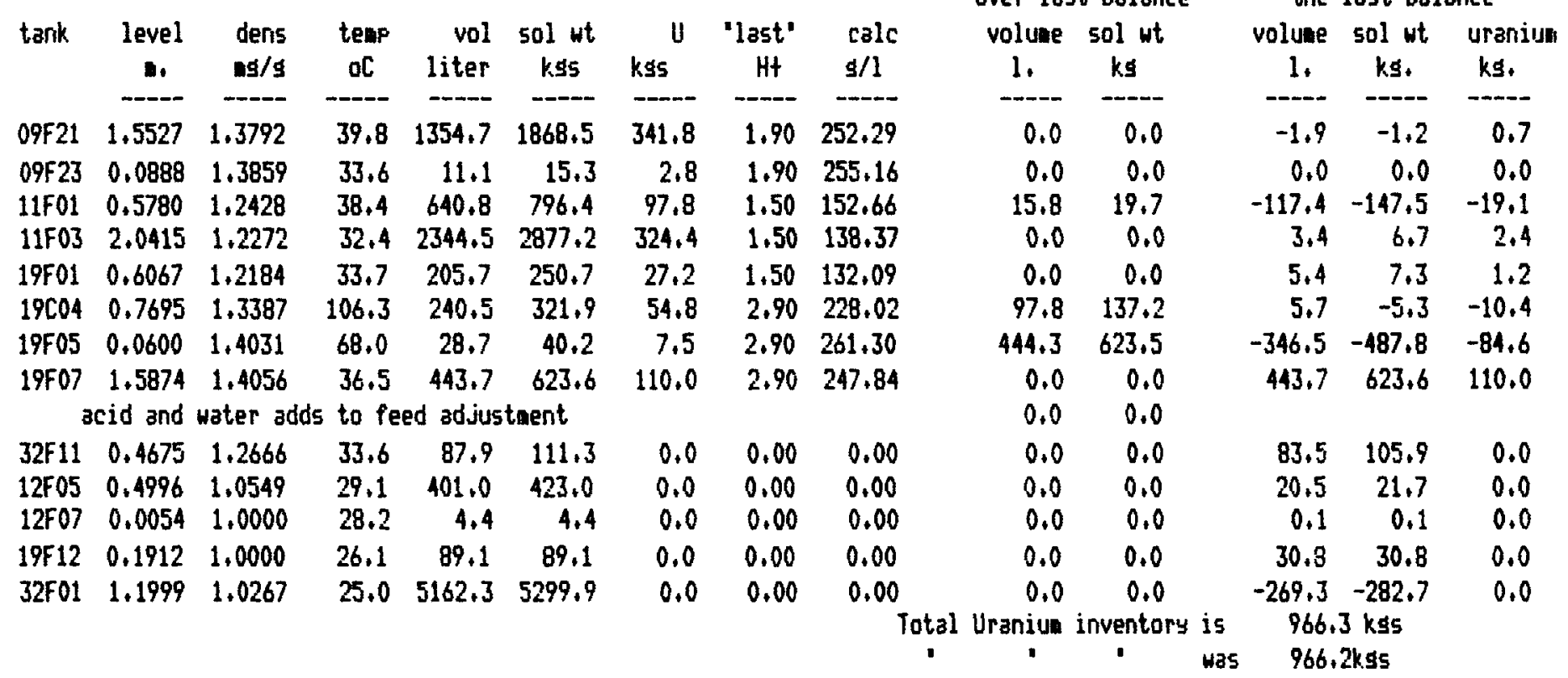

Fig. 6.10. In-process inventory summary from LSTIPI program. 
IET Facility Uranium Material Belance input is FROM O9F23, output is FROM $19 F 07$

ID = Besin Inv + Inputs - (Dutruts + Ending Iriv)

IET INV $=$ a hand calculated 'should be" inventor:

IET ID = IET INV - autonatic measured inventory

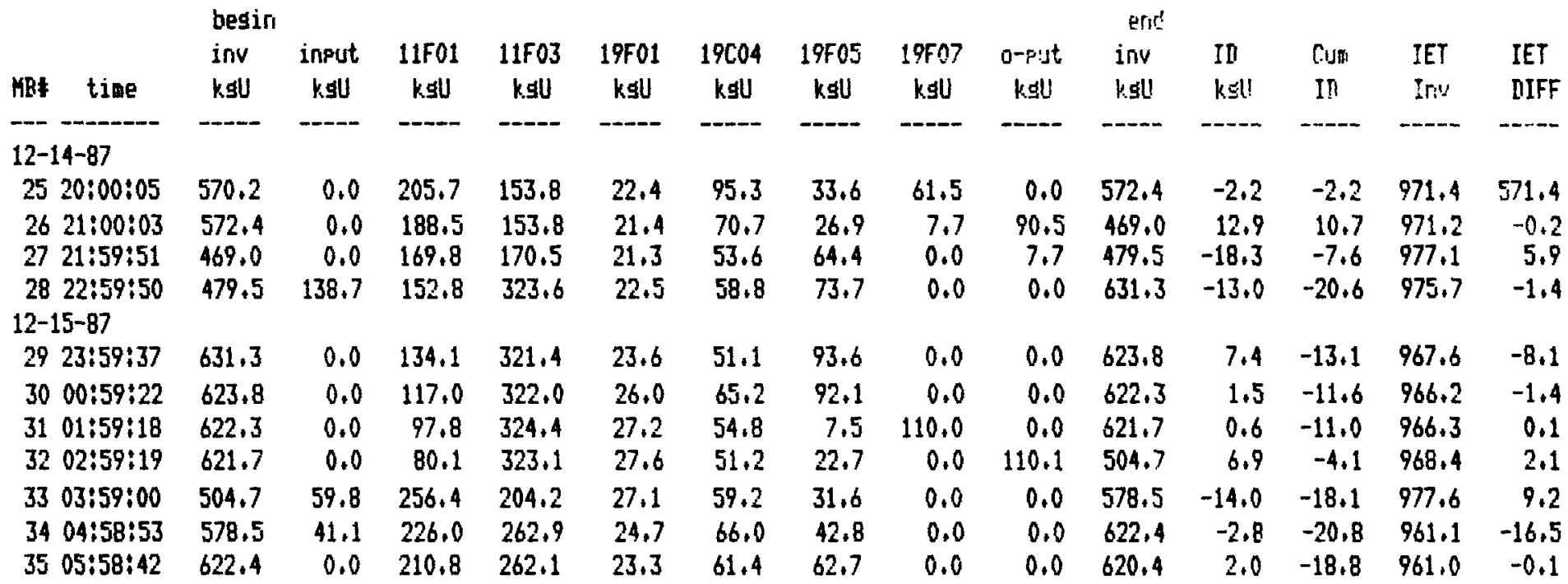

Fig. 6.11. NRTA balance summary - TOTBAL program. 
SUKMARY FOR TANK $11 F 01$

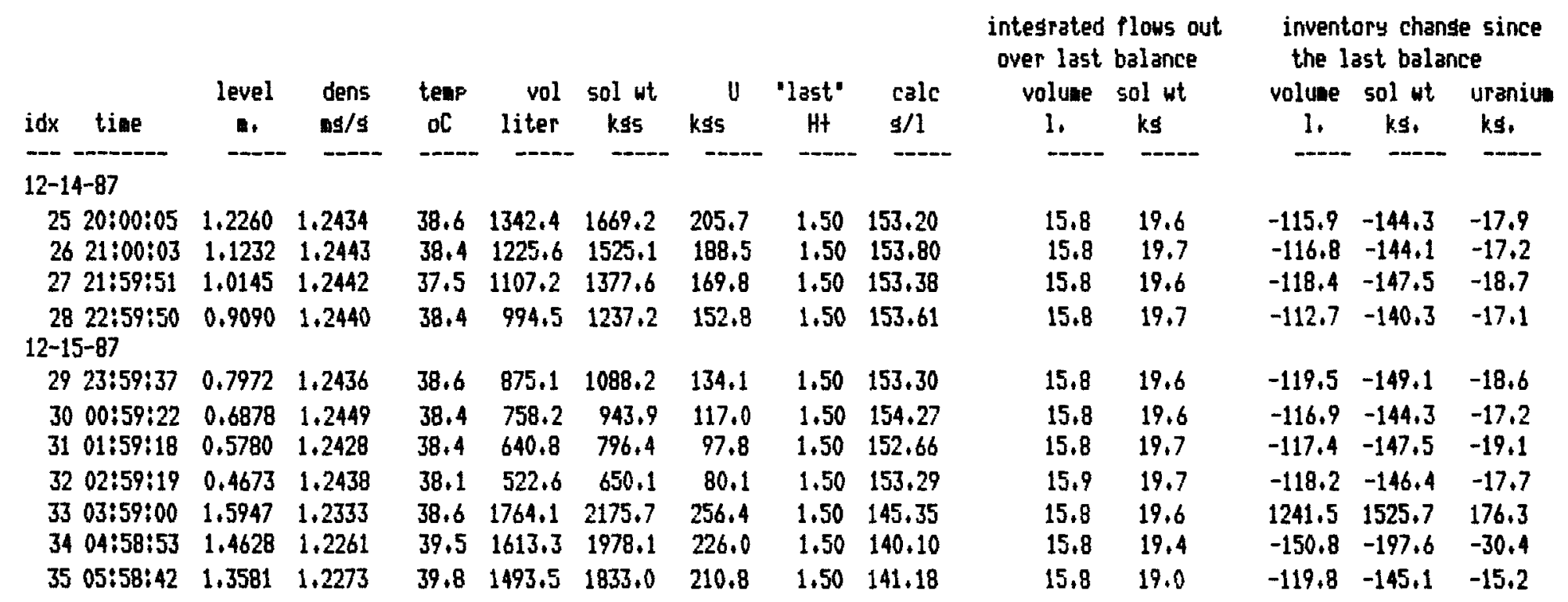

Fig. 6.12. Single tank data summary - ONETK program. 


\subsubsection{Program 13 - SCROL}

The SCROL program is used to obtain detailed listings of the process monitoring data base. The program makes use of virtually all of the process control data collected by the system and, in this sense, goes beyond the capabilities likely to be available with a limited set of information given to inspectors. However, the program has been useful for safeguards program development in the IET facility and was presented to the participants for their use to investigate the wealth of information that is available within a modem, computerized control system.

Figure 6.13 shows the commands necessary to use the SCROL routine. There are 24 different groupings for process information, dealing primarily with various plant systems and equipment. Participants used a number of different system reports in their analyses. Space does not permit inclusion of examples from each system. However, in the example given in Fig. 6.13, the user chose the feed tank system (11F01).

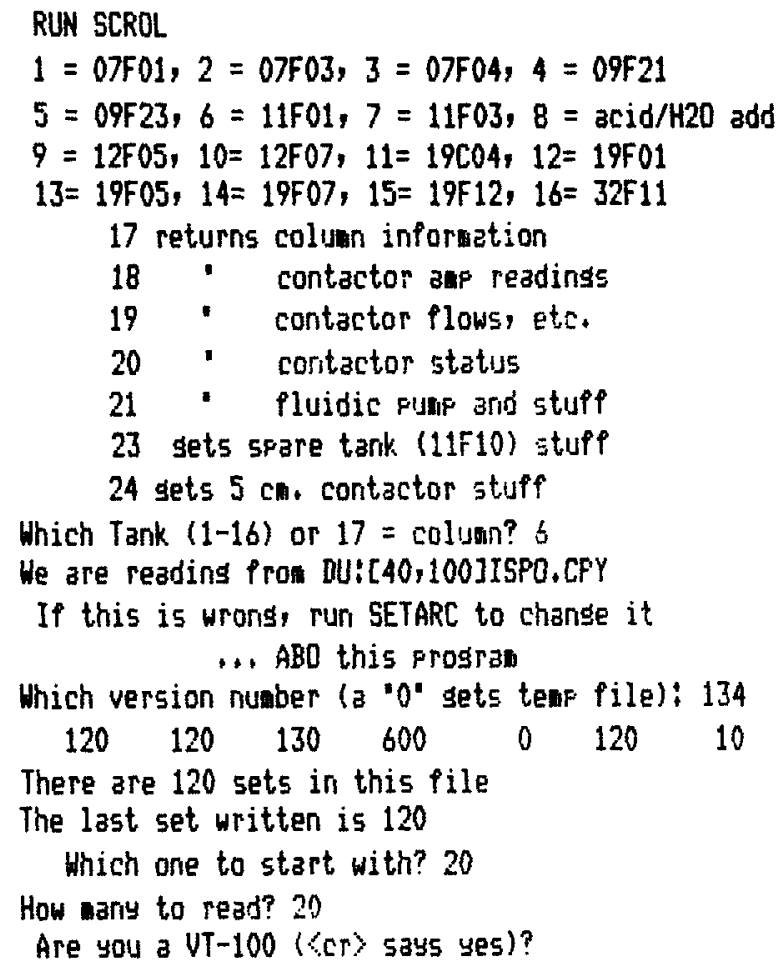

Fig. 6.13. Procedure to initiate SCROL program (data summary).

Use of the SCROL routine requires some knowledge of the data in the process monitoring 4-min data files. This information is obtained from other programs such as the reference program discussed in Sect. 6.2.10. In the example presented, the user chose version 134 of the process control data files. As discussed in Sect. 5.4, this can be considered volume 134 of the data volumes, containing 120 pages of process control data sets. The user went on to choose 20 pages starting with page 20 to be displayed. The output resulting from this selection is shown in Fig. 6.14. 
HA FEED (11FO1) TANK SUMMARY

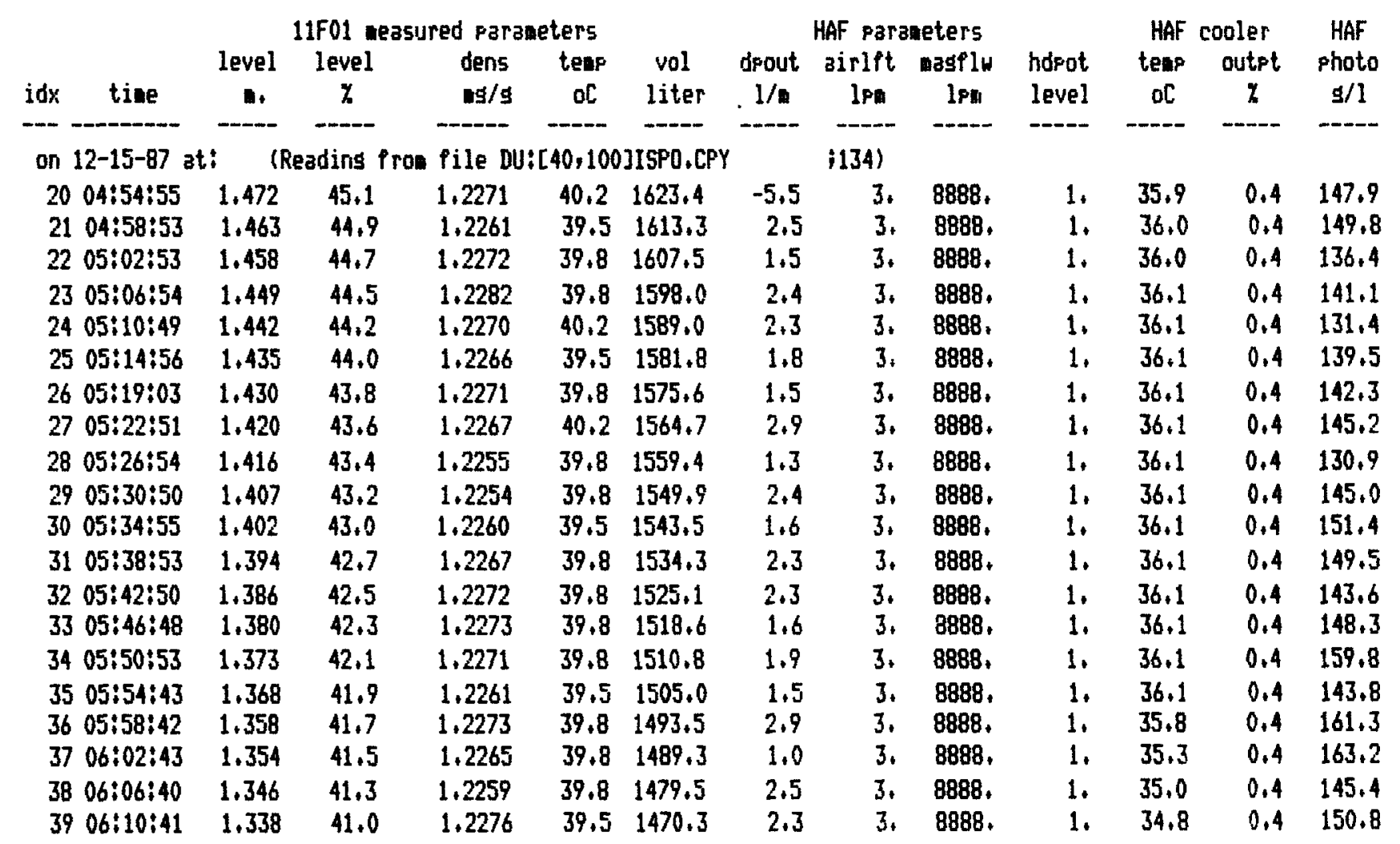

Fig. 6.14. Example of SCROL program (HA feed tank summary). 


\subsubsection{Program 14-REF}

As noted in the discussions for a number of programs, the NRTA balance files contain pointers to the source of the in-process inventory data in the process monitoring data files. The program REF allows the participants to read the references. Section 6.2 .9 discusses the necessity for this information when using the SCROL program. During an investigation of an alarm indication from any of the routines keyed to the NRTA balance files, the inspector finds the reference and uses the SCROL program or other routines to investigate the raw recorded data. An example of the use of the REF program is included in Fig. 6.15.

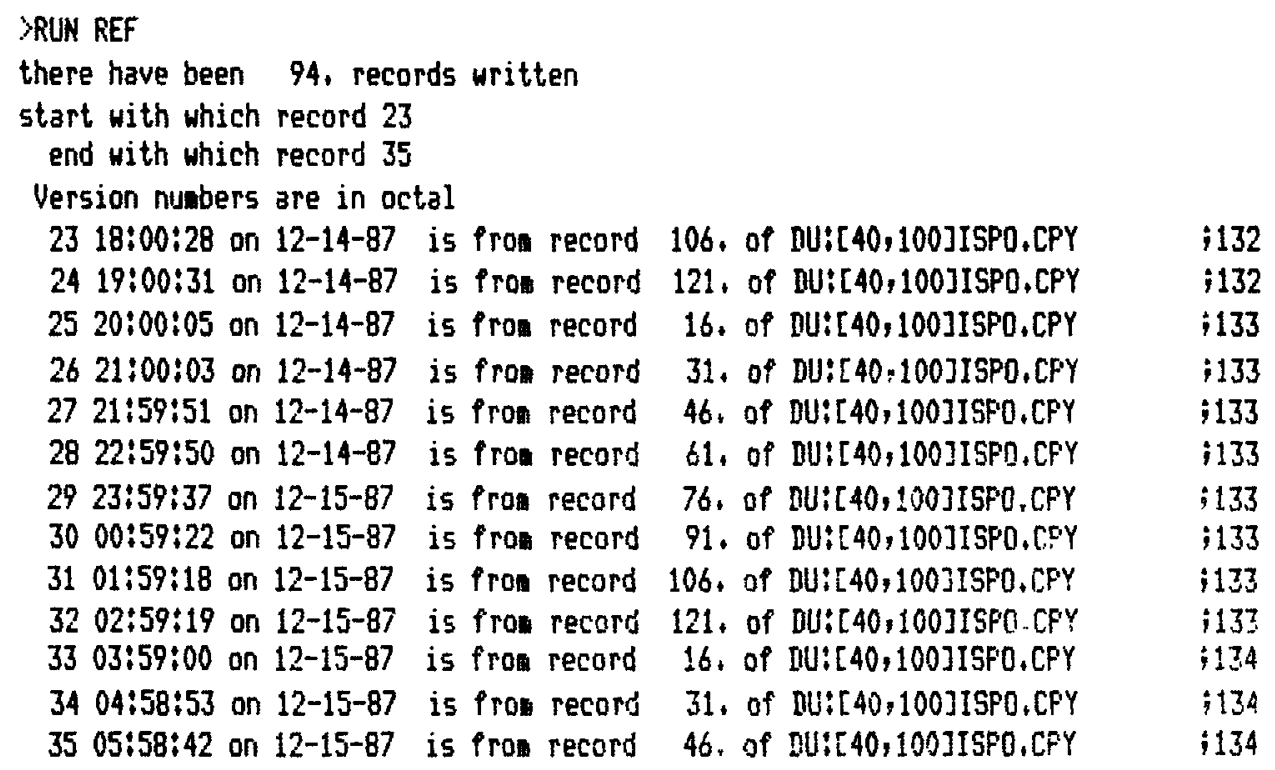

Fig. 6.15. REF program - NRTA dates and times.

\subsubsection{Program 15 - TRSUM}

Event logging is a role that can be of value to international safeguards and is easily implemented. Event logging with respect to the product area of the Tokai Reprocessing Plant was the subject of Task I of the TASTEX ${ }^{*}$ program and was a part of the package developed under Task E for electromanometer demonstration. TRSUM is a program that expands on the concepts of event logging for the IET safeguards system.

The process monitoring routine discussed in Sect. 6.1.2 analyzed the process monitoring data base and provides information to the inspector on significant process events throughout the facility. Cumulative quantities associated with transfers are calculated and stored in the NRTA data base. These cumulative data are used by the TRSUM program.

\footnotetext{
*Tokai Advanced Safeguards Technology Exchange (TASTEX) was a cooperative program between the IAEA, France, Japan, and the U.S. to explore advanced concepts for safeguards in reprocessing plants.
} 
Figure 6.16 is an example of the TRSUM program output. This program uses the NRTA balance file numbers for reference. The program provides summary information on process batch transfers. This is the event-logging function described as one of the appropriate applications. It was noted in discussions during the demonstration, and as recommended by participants, that this routine would be more useful if it showed receipt quantities in the summary as well.

\subsubsection{Program 16 - MICROT}

Process data associated with tank transfers provide valuable safeguards information. The program MICROT is provided in the safeguards inspectors tool bag to be used to confirm or resolve indications of safeguards problems from other software programs such as MONITR, or the solution balance routines.

The program MICROT also uses the NRTA balance files as reference. The user enters the number of the balance file of interest and enters the identification numbers of the tanks involved in the transfer. The programs find the key into the process monitoring data base. It returns a detailed summary of the process monitoring data for each tank for two hours before and one hour after the time of interest. As an example, based on the information shown in Fig. 6.16, period 31 was selected to analyze the transfer of product from the catch tank to the accountability tank. Figure 6.17 shows initiation of the routine with the user selecting the product collection tank (19F05) and the product accountability tank (19F07) as involved in the transfer. The data provided are shown in Fig. 6.18.

During the testing that involves actual removals in the IET facility, this program is useful in isolating the time and location of removals. The program has another valuable use in detection and quantification of measurement biases.

In the case of an operating reprocessing plant, the accountability tank measurements are carefully made with accurate and precise instruments. The measurements are usually verified by an inspector. The process monitoring routine (MONITR) provides a continuity of knowledge on the location and movement of accountability batches. The details of the MICROT routine can qualify in-process tank measurements with traceability to verified accountability measurements. 
VOLUME TRAMSFER SUMMARY

Cuaulative voluaes (11ters) transferred during each period

\begin{tabular}{|c|c|c|c|c|c|c|c|c|c|c|}
\hline Idx tine & $09 F 21$ & $09 F 23$ & $11 F 01$ & $11 F 03$ & 19701 & $19 C 04$ & $19 F 05$ & $19 F 07$ & $\begin{array}{l}\text { acid } \\
\text { add }\end{array}$ & $32 F 11$ \\
\hline \multicolumn{11}{|l|}{$12-14-87$} \\
\hline $2520: 00: 05$ & 0.0 & 0.0 & 15.8 & 0.0 & 0.0 & 77.9 & 268.6 & 0.0 & 0.0 & 160.0 \\
\hline $2621: 00: 03$ & 0.0 & 0.0 & 15.8 & 0.0 & 0.0 & 133.2 & 171.7 & 410.7 & 0.0 & 0.0 \\
\hline $2721: 59: 51$ & 1.8 & 0.0 & 15.8 & 0.0 & 0.0 & 143.0 & 0.0 & 34.7 & 0.0 & 0.0 \\
\hline $\begin{array}{l}28 \quad 22: 59: 50 \\
12-15-87\end{array}$ & -538.9 & 538.9 & 15.8 & 0.0 & 0.0 & 43.7 & 0.0 & 0.0 & 656.0 & 0.0 \\
\hline $2923: 59: 37$ & 0.0 & 0.0 & 15.8 & 0.0 & 0.0 & 68.5 & 0.0 & 0.0 & 0.0 & 0.0 \\
\hline $\begin{array}{l}3000: 59: 22 \\
31 \quad 01: 59: 18\end{array}$ & $\begin{array}{l}0.0 \\
0.0\end{array}$ & $\begin{array}{l}0.0 \\
0.0\end{array}$ & $\begin{array}{l}15.8 \\
15.8\end{array}$ & $\begin{array}{l}0.0 \\
0.0\end{array}$ & $\begin{array}{l}0.0 \\
0.0\end{array}$ & $\begin{array}{r}2.6 \\
97.8\end{array}$ & $\begin{array}{r}0.0 \\
444.3\end{array}$ & $\begin{array}{l}0.0 \\
0.0\end{array}$ & $\begin{array}{l}0.0 \\
0.0\end{array}$ & $\begin{array}{l}0.0 \\
0.0\end{array}$ \\
\hline $\begin{array}{ll}32 & 02: 59: 19 \\
33 & 03: 59: 00 \\
34 & 04: 58: 53\end{array}$ & $\begin{array}{l}0.0 \\
0.0 \\
0.0\end{array}$ & $\begin{array}{r}0.0 \\
224.6 \\
154.9\end{array}$ & $\begin{array}{l}15.9 \\
15.8 \\
15.8\end{array}$ & $\begin{array}{r}0.0 \\
1161.3 \\
0.0\end{array}$ & $\begin{array}{l}0.0 \\
0.0 \\
0.0\end{array}$ & $\begin{array}{l}88.1 \\
35.9 \\
34.6\end{array}$ & $\begin{array}{l}0.0 \\
0.0 \\
0.0\end{array}$ & $\begin{array}{r}444.1 \\
0.0 \\
0.0\end{array}$ & $\begin{array}{r}0.0 \\
0.0 \\
80.2\end{array}$ & $\begin{array}{r}221.1 \\
0.0 \\
304.2\end{array}$ \\
\hline $3505: 58: 42$ & 0.0 & 0.0 & 15.8 & 0.0 & 0.0 & 76.9 & 0.0 & 0.0 & 0.0 & 11.4 \\
\hline
\end{tabular}

Fig. 6.16. TRSUM program - event-logging summary.

\RUN MICRDT

Th1s prosian provides a 'nicro' analysis of process transfers. You should know the 'hourly' record number of concern and will enter the tanks involved in the transfer. Level, density and volunes for the tanks anvolved, recorded every four anutes for two hours before and ari hour after, will be showr.

Tank nuabers are as follows:

$1=07503,2=07 F 04$

$3=09521,4=09523,5=11 \mathrm{F01}, 6=11 \mathrm{F03}, 7=19 \mathrm{~F} 01$,

$8=19 \mathrm{CO}, 9=19 F 05,10=19 \mathrm{FO}, 11=11 \mathrm{~F} 10,1=32 \mathrm{~F} 11$

Enter sendins tank nuaber (1-12): ?

Enter receive tank nuaber $(1-12) ; 10$

Which record are we look 2 ns at? 31

are you a VT-100 ('cr) says yes):

Fig. 6.17. Initiation of MICROT program tank transfer summary. 
DATA FROY SAFEGUARDS 4-MINUTE ROUND FILES

For two hours before and an hour after BALANCE 31 analizins transfer from $19 F 05$ to $19 F 07$

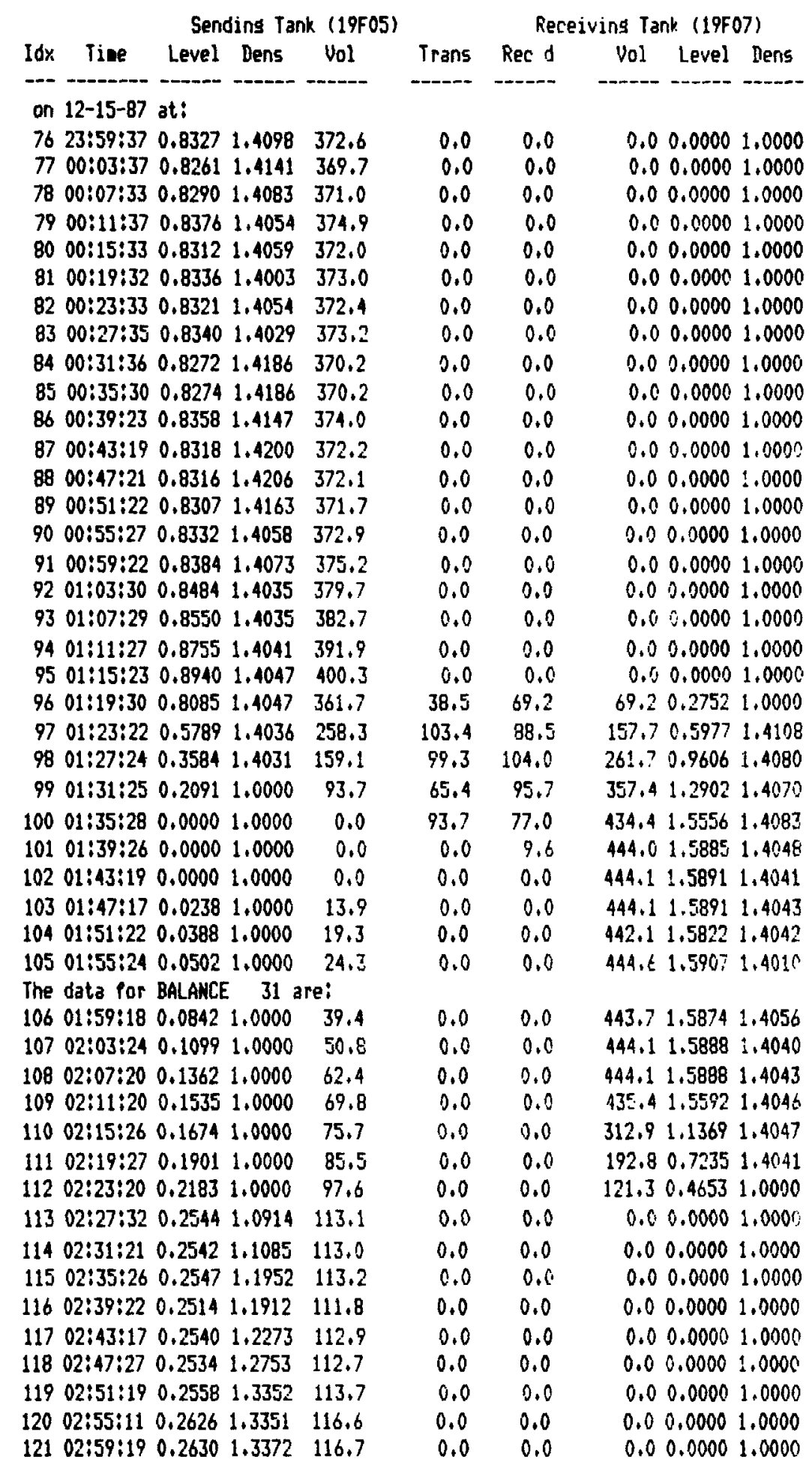

Fig. 6.18. MICROT program output - tank transfer summary. 


\section{REMOVAL DETECTION}

The process monitoring routines used in the IET facility safeguards system were described in Sect. 6. A goal of the December 1987 demonstration was to give participants the opportunity to play the role of inspectors and use the computerized process monitoring safeguards systems installed in the IET facility.

The benefit of testing and demonstration in the IET facility is that actual removals or other scenarios associated with safeguards can be created. During presentations on the use and philosophies of the IET safeguards systems, the IET facility operations staff implemented a series of material removal scenarios.

While the first part of the three-day meeting concentrated on discussions and practice with the tools of the IET safeguards system, the last portion allowed participants to use process monitoring. They used the system to detect and confirm real problems while experiencing problems and false alarms that are characteristic of process data from an operating plant. This section reviews some of the findings and conclusions.

\subsection{SOLVENT EXTRACTION FLOW}

It was noted in Sect. 3.3 that a special equipment change was implemented in the IET facility to accommodate testing with the smaller contactor units while operating the remainder of the system at the higher design flow sheet conditions. Recall that the higher flow sheet conditions were necessary to ensure frequent batch transfer activities for the demonstration and other tests conducted during the test run.

The process change involved the addition of a transfer line to move additional solutions from the feed tank (11F01) to the intercycle surge tank (19F01), bypassing solvent extraction. As a safeguards scenario, this operational change can be considered as an effort by a facility operator to "side-pocket" feed material, potentially in a location for later processing and recovery. In the case of the IET facility operations, the quantity involved was actually significantly larger than the process stream. However, it is interesting to consider this as a demonstration of process monitoring used for design verification.

The detection of this condition was alluded to in the discussion on the HEBAL program (see Sect. 6.2.2) and in the data shown in Fig. 6.6. Figure 7.1 is another example of the output from the HEBAL routine, showing another 10-h series of control unit balances. Every balance in the series produces an alarm. The consistent ID quantity suggests a continuous loss.

To confirm the loss, the inspector turns to the MINFLW software (see Sect. 6.2.4). This is a process monitoring routine directed at the detection of losses from the solvent extraction system. The routine opens the process monitoring data base. It calculates mass balances but also includes information to evaluate the measurements involved. It offers a summary option for the printout.

Figure 7.2 is the summary printout for several of the mass balance periods involved. Recall that the rate of increase in the HAW collection tanks should be equal to the feed rate plus any additions of scrub (HSS) solutions. The comparison of the wheel (see Sect. 3.2.3 for a description 
HEAD END TANK VOLUHE AND WEIGHT BALANCE

Solution weight i's volune $X$ density

inputs are 09F23, acid adds, and jet dilution effects

Infut

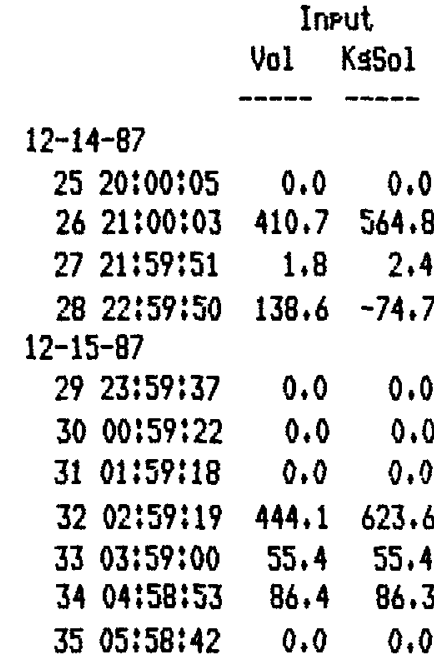

$09 F 23$

$428.0 \quad 596.9$

$571.4 \quad 792.8$

$542.7 \quad 757.7$

$10.9 \quad 15.2$

$10.7 \quad 14.8$

$11+1 \quad 15.3$

$11,1 \quad 15,3$

$444.2 \quad 626.5$

$220.3 \quad 308.0$

$0.0 \quad 0.1$

$0.0 \quad 0.1$
Vol KsSol
Vol KsSol

1047.11296 .9

1046.71296 .5

1105.61379 .6

$2347+52878+8$

2348.72877 .5

2341.12870 .4

2344.52877 .2

2346.22877 .2

1215.81537 .3

1741.82164 .7

1742.22164 .4
Vol Ks5ol

1342.41669 .2

$1225.6 \quad 1525.1$

1107.21377 .6

994.51237 .2

$875.1 \quad 1088.2$

$758.2 \quad 943.9$

$640.8 \quad 796.4$

$522.6 \quad 650.1$

1764.12175 .7

1613.31978 .1

1493.51833 .0
Printed at $12: 11: 36$

on $03-N O U-88$

Vol KsSol

Vol Kssol

$\begin{array}{llll}15.8 & 19.7 & 368.7 & 493.8\end{array}$

$\begin{array}{llll}15.8 & 19.6 & 74.2 & 82.3\end{array}$

$\begin{array}{lll}15.8 & 19.7 & -474.7-710.8\end{array}$

$\begin{array}{llll}15.8 & 19.6 & 102.7 & 131.2\end{array}$

$\begin{array}{llll}15.8 & 19.6 & 108.3 \quad 131.2\end{array}$

$\begin{array}{llll}15.8 & 19.7 & 98.2 & 121.1\end{array}$

$\begin{array}{llll}15.9 & 19.7 & 111.5 & 139.1\end{array}$

$\begin{array}{llll}15.8 & 19.6 & 152.4 \quad 168.6\end{array}$

$\begin{array}{llll}15.8 & 19.4 & -84.3 & -55.0\end{array}$

$\begin{array}{llll}15.8 & 19.0 & 103.6 & 126.4\end{array}$

the following periods exceed our investigetion heuristic: futher investisation is needed!

(1) for period 25 voluae ID is 99,9 and the solution weisht in is 123,8

(2) for period 26 volume In is 368.7 and the solution weisht In is 493.8

(3) for period 27 volues ID is 74.2 and the solution weisht In is 82.3

(4) for feriod 28 volune III is -474.7 and the solution weisht II is -710.8

(5) for period 29 voluse In is 102.7 and the solution weisht In is 131.2

( b) for period 30 voluwe III is 108.3 and the solution weight In is 131.2

(7) for period 31 volune In is 98.2 and the solution weight In is 121.1

(8) for feriof 32 volume IV is 111.5 and the solution weisht In is 137.1

(9) for period 33 volume In is 152.4 and the solution weisht In is 168.6

(10) for geriod 34 volune III is -84.3 and the solution weisht III is -55.0

(11) for period 35 volume ID is 103.6 and the solution weight ID is 126.4

Fig. 7.1. Alarm summary with HEBAL program. 


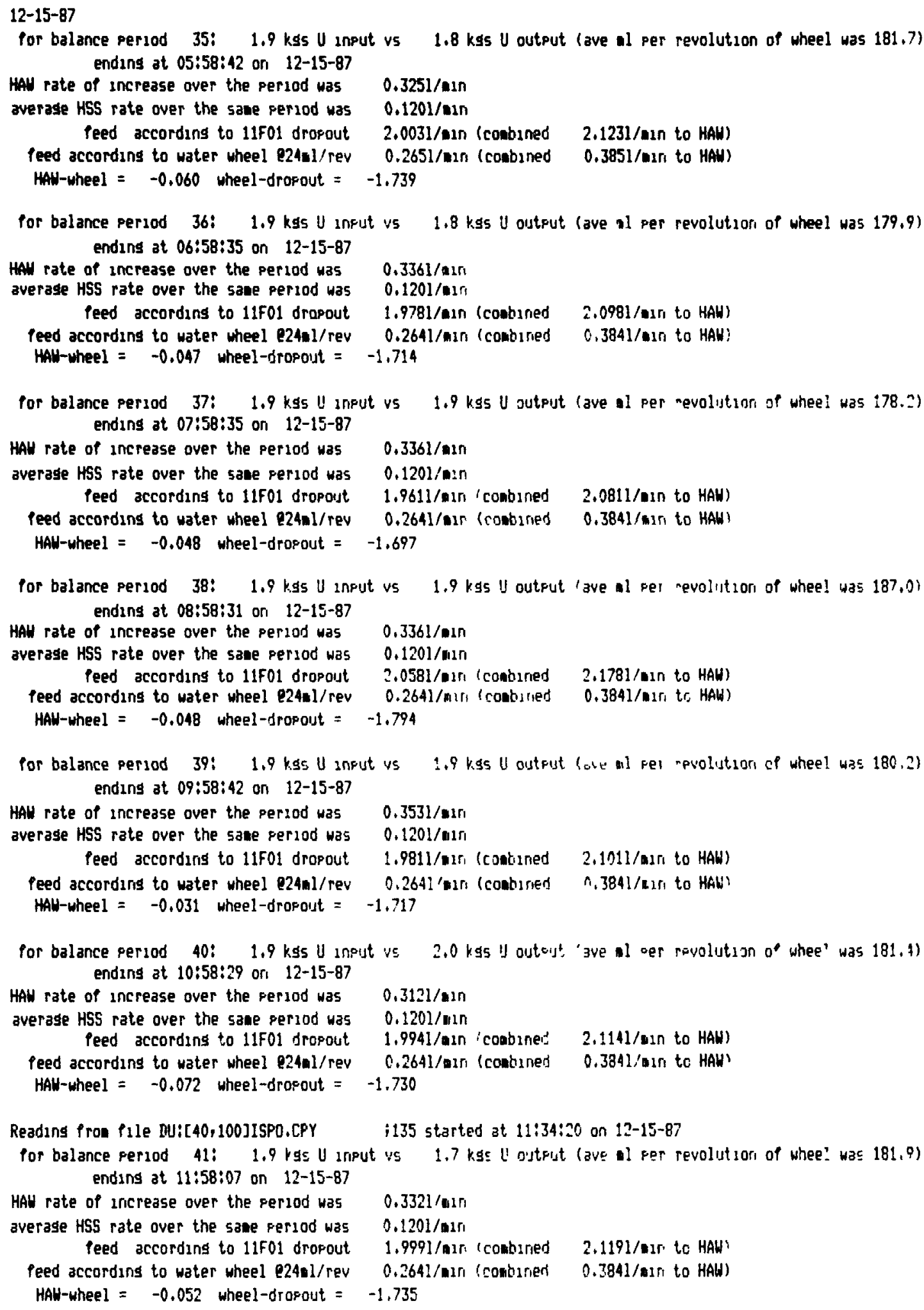

Fig. 7.2. MINFLW summary to confirm now bypass. 
of the flow control wheel device) calculated rate to HAW and the tank (11F01) dropout rate to HAW are shown. Over the period involved, the wheel measured flow to HAW difference averages about $50 \mathrm{~mL} / \mathrm{min}$. The difference between the dropout and HAW averages about $1.73 \mathrm{~L} / \mathrm{min}$.

Confidence in the wheel measured value is gained by comparison of the calculated mass flow into solvent extraction to the calculated mass output. This comparison is shown on the first line of the summary for each period in Fig. 7.2. This summary shows the output and input (calculated from the wheel value) to be close (about 1.8-1.9 $\mathrm{kg}$ per balance period of $1 \mathrm{~h}$ ).

The concentration for the output is measured in the separator pot as product and is delivered to the intercycle surge tank (19F01). The actual bypass line enters downstream of the product measurement. The summary in Fig. 7.2 confirms the wheel and product measurements and confirms the removal detected by the control unit balance analysis in Fig. 7.1. While not a part of the safeguards tool bag used by the participants, a control unit balance routine from the surge tank (19F01) to the product collection tank (19F05), including the product concentrator, can also be used. This routine involves heavy metal balance. It also has a volume balance that considers the condensate recycle as HCX in the calculation.

The loss detection analysis involving the solvent extraction mass flow may seem rather elementary because the removal scenario involves a quantity that exceeds the process rate by more than a factor of 6 . However, it is important to recognize the relationships between the data involved and how they are used. These relationships are exploited to provide the safeguards indications.

Also, note the apparent bias of $50 \mathrm{~mL} / \mathrm{min}$ in the wheel flow calculation. In this case, is was quantified by comparison to the HAW increase. During other test runs, even smaller biases were detected and confirmed. In the absence of a removal, the dropout rate (tank depletion rate calculation) can usually be used as a comparison, and the combination of three measurements (wheel, dropout, and HAW) give confidence to all three.

In this section, the relationships between the two control unit mass balance techniques were explored. The value of analysis of differences between redundant or related measurements was also explored. The problem detected was a bypass of solvent extraction. Detection of this activity can be related to scenarios that remove material from process equipment, or scenarios where process changes are made after design and construction verification activities.

\subsection{PRODUCT TANK MEASUREMENT BIAS DETECTION}

Process operations were steady during the period of time covered by the data shown in Fig. 7.1. The calculated IDs for the control unit balances during the period were fairly constant with the exception of period 41 recorded at 11:58:07. For this balance, the ID was $117 \mathrm{~L}$ which is different than the typical 100-104. This discrepancy should draw the attention of the inspector, even among the other alarm indications discussed in Sect. 7.1. The inspector should investigate any special activity associated with this balance to isolate the problem. He should note the measured input quantity of $455.3 \mathrm{~L}$ during the period. He should also make use of the process monitoring tools to resolve alarms or confirm a safeguards problems.

In this case, the first step is to review the analysis of the process monitoring routine, MONITR, which is shown in Fig. 7.3. The data show that the material was transferred directly from the product transfer tank. Also, note by comparison of the data in Figs. 7.1 and 7.3 that the summary in the HEBAL routine uses the measurements from the product tank (19F07) as the input quantity. 


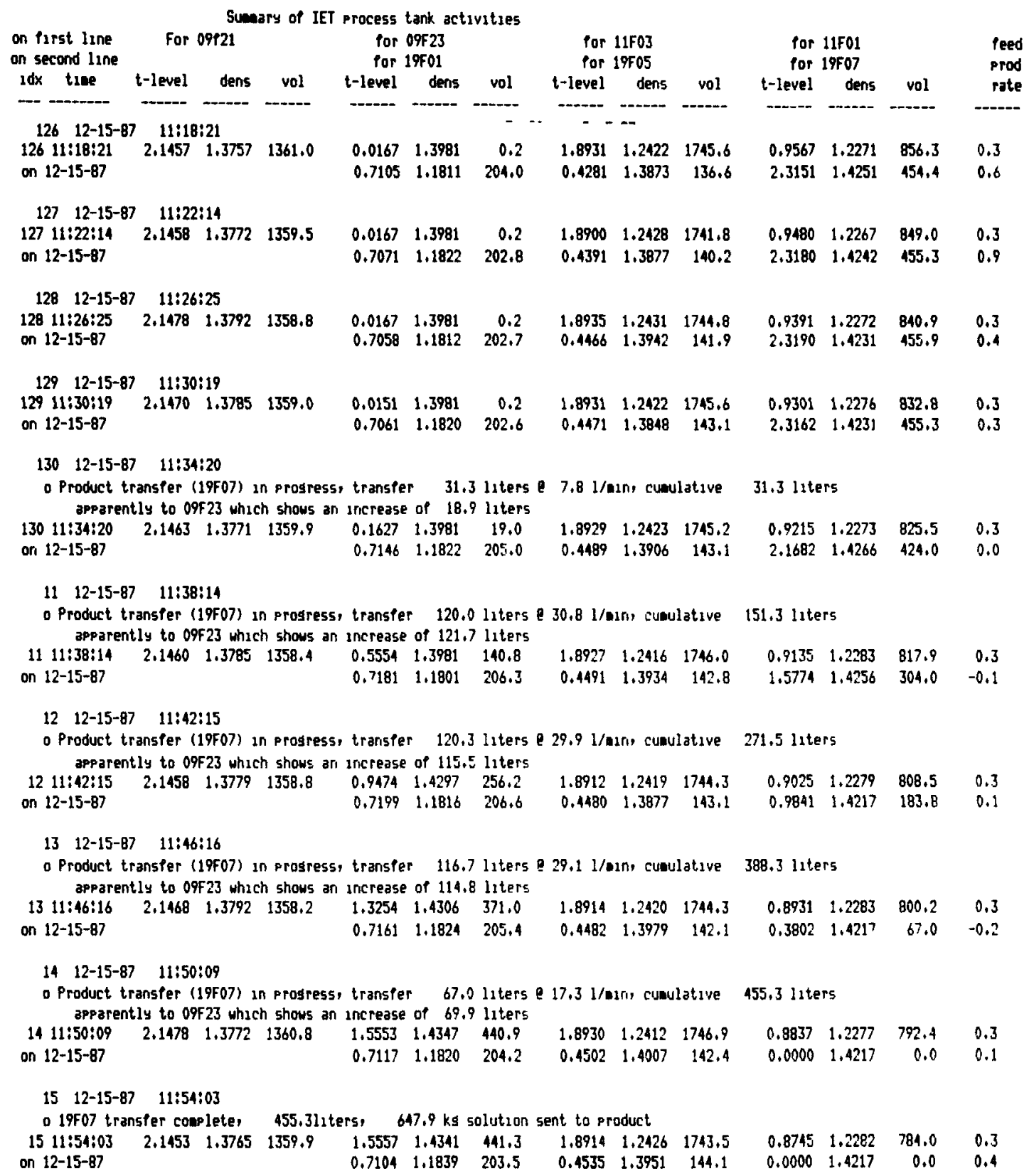

Fig. 7.3. MONITR program output showing product transfer. 
The inspector should be drawn immediately to the batch transfer comparisons. He should notice the progress of the transfer with each 4-min data set. Extracting the data from Fig. 7.3 for a summary gives the following:

\begin{tabular}{ccccc} 
& \multicolumn{2}{c}{ sent } & \multicolumn{2}{c}{ received } \\
\hline time & volume & density & volume & density \\
\hline $11: 34: 20$ & 31.3 & 1.4266 & 18.9 & 1.3981 \\
$11: 38: 14$ & 120.0 & 1.4256 & 121.7 & 1.3981 \\
$11: 42: 15$ & 120.3 & 1.4217 & 115.5 & 1.4297 \\
$11: 46: 16$ & 116.7 & 1.4217 & 114.8 & 1.4306 \\
$11: 50: 09$ & 67.0 & 1.4217 & 69.9 & 1.4347
\end{tabular}

From the HEBAL summary, 15-17 L are apparently missing. From the above data, the majority of the missing material (10-12 L) became apparent at the start of the transfer. The other $5 \mathrm{~L}$ show as missing midway through the transfer. There are subtle effects involved.

At the start of the transfer, the receiving tank (09F23) was empty and the liquid level was below the density measurement probe. With the logic built into the MONITR program, the density in the receiving tank is estimated as $1.3981 \mathrm{~g} / \mathrm{mL}$ based on the last batch in the tank. The differences are larger if actual, unadjusted measurements are used.

Figure 7.4 presents the output from the MICROT program, which uses unadjusted readings in the comparison calculation. When a tank is empty, or the density instrument is out of service, the instrument shows a density of 1.0 .

The error of the density estimate accounts for most of the initial difference of 10-12 L. At 11:42, the density probes in the receiving tank are covered. The summary reflects an actual measurement. The change from a density estimate to a measured value in the volume calculations results in the apparent $5 \mathrm{~L}$ discrepancy at 11:42, shown in the data presented in Fig. 7.3. The difference is larger in the uncorrected data presented in Fig. 7.4. Incidentally, the sending tank probes become uncovered, and the last measurement is carried forward as the estimate in the logic of the MONITR program.

These subtle density measurement effects are the cause of the discrete differences that are apparent in the progression of the transfer. However, the more important point is that the density in the receiving tank at the conclusion of the transfer is $1.4347 \mathrm{~g} / \mathrm{mL}$. The density measured in the sending tank was $1.4217 \mathrm{~g} / \mathrm{mL}$. There is a bias involved. If the final volume in the receiving tank is recalculated with the density of the sending tank, the final volume increases by $15 \mathrm{~L}$. If the correction is made, the inventory measurement for tank 09F23, shown in the HEBAL analysis, increases by the same amount and the ID in the HEBAL analysis is in line with the others.

It is concluded that the density of the product measurement tank is biased by about $2 \%$ and results in the problem apparent in the HEBAL analysis. The bias is confirmed in this case by a similar analysis of transfers and comparisons as the material was moved into the product tank. A similar bias was detected, but this analysis is not presented here. 
DATA FROM SAFEGUARDS 4-MINUTE ROUND FILES

For two hours before and an hour after BALANCE 41 analizing transfer fron $19 F 07$ to $07 F 04$

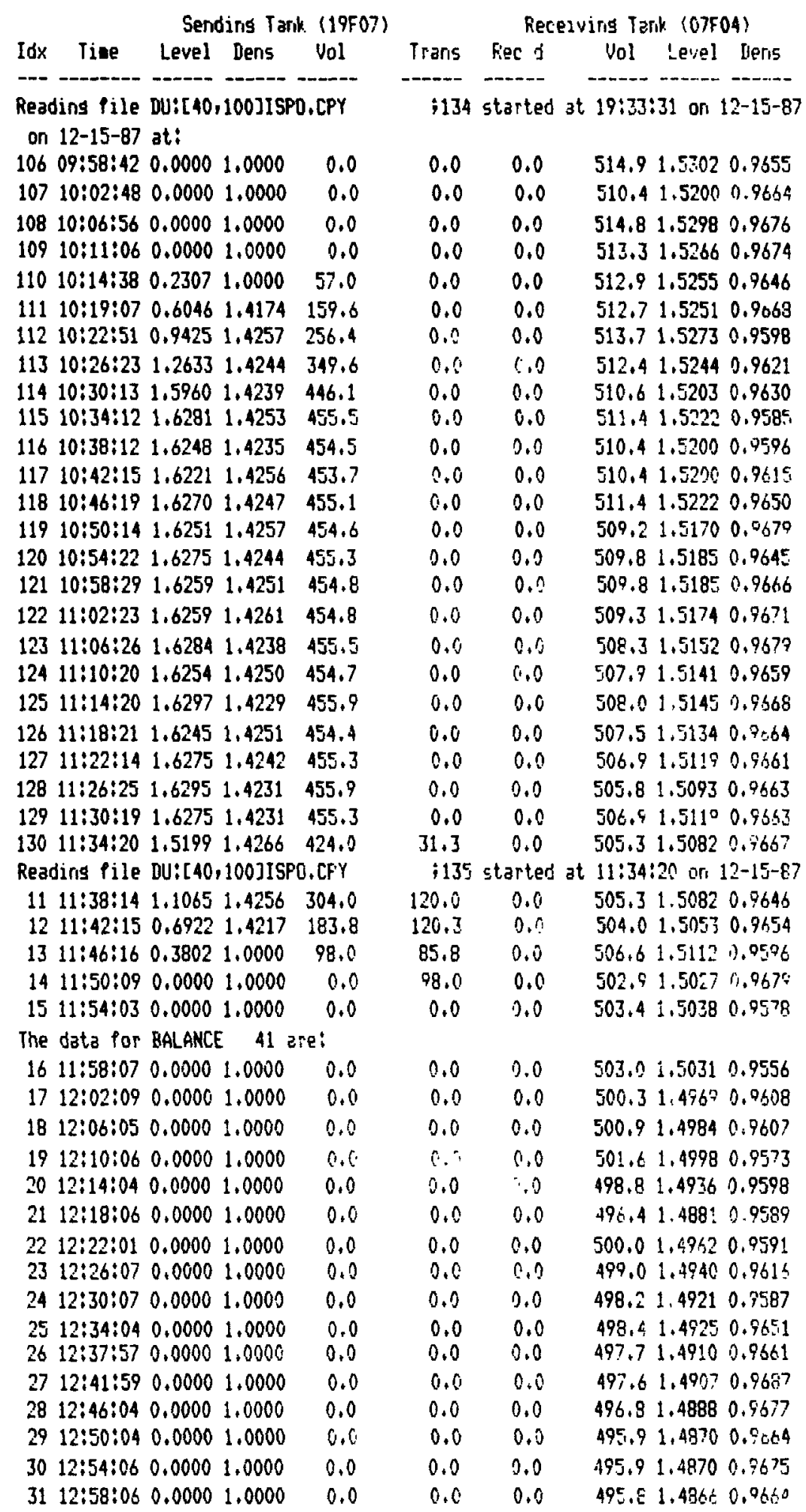

Fig. 7.4. Detail summary of product transfer from MICROT program. 
The IET facility is a test facility and, as noted previously, high accuracy accountability measurement equipment and laboratory analyses are not available. In an actual facility, the $2 \%$ bias would not be present in an accountability measurement. Capabilities exist for density measurements in an operating facility with an accuracy of $0.25 \%$ or less. Small biases can be detected.

The importance of this analysis with respect to an operating facility is that the same comparisons can be made and related backward (or forward) to an accountability measurement. These comparisons can serve to qualify process control measurements with traceability to a verified accountability standard. Process measurements are important to inventory measurements in conventional accounting or NRTA. The method of qualifying measurement systems to verified accountability measurements can qualify (verify) NRTA in-process inventory and conventional accounting inventory measurements. This is an example of process monitoring in a role of qualifying these measurements.

In the case presented here, the anomaly is resolved as due to a measurement bias. The results of this analysis can be incorporated into subsequent analyses to resolve anomalies before alarm. We have used the process monitoring analysis and tools, not only to resolve an alarm, but to qualify data for subsequent analysis.

\subsection{INPUT ACCOUNTABILITY MEASUREMENT ALARMS}

The previous two examples were derived from analysis of one of the control unit balance routines (HEBAL) in the process monitoring tool bag. Those analyses assume that the process monitoring routine MONITR had already been run to calculate the quantities transferred. However, there are a number of safeguards tests that are built into MONITR that alert the inspector to problems.

Figure 7.5 shows another segment of the output from MONITR. There are three events detected in the data shown in the figure that relate to scenarios expressed as concerns for safeguards. They involve attempts to bypass the accountancy tank with material.

The data recorded at 21:31:57 on December 14, 1987, produced an alarm that $56.8 \mathrm{~L}$ were missing from the input accountability tank (09F23). At the same time, an unexplained increase was noted in the feed adjust tank (11F03). The IET facility operator actually transferred a small amount of material into the system, making the transfer over a short time interval so that the system would not log the event. This action amounts to an undeclared transfer of material.

This analysis seems rather elementary when all the data are available. However, without process monitoring, on both the accountability tank and downstream tanks, this event would be difficult to detect. If this were actual feed in an LWR plant, about $50 \mathrm{~g}$ of plutonium would be involved. In a breeder fuel plant, it would be about one kilogram. This analysis and detection is made with volume measurement data only, readily available from a process control system. The data are easily verified by cross check to the input accountability tank measurements that are routinely monitored by the inspectors.

The data in Fig. 7.5 show a very small amount of material added to the accountability tank at 21:43:56. This is just prior to the start of the announced accountability transfer. This could be interpreted as an attempt to add material after sampling.

The actual transfer of the accountability batch started during the time period before 22:03:56. It is obvious from the start that material is being transferred from the surge tank (09F21) at the same time that the accountability tank (09F23) is being transferred to the feed adjust tank (11F03). In the first interval, $8 \mathrm{~L}$ are shown as transferred from tank 09F21. The 


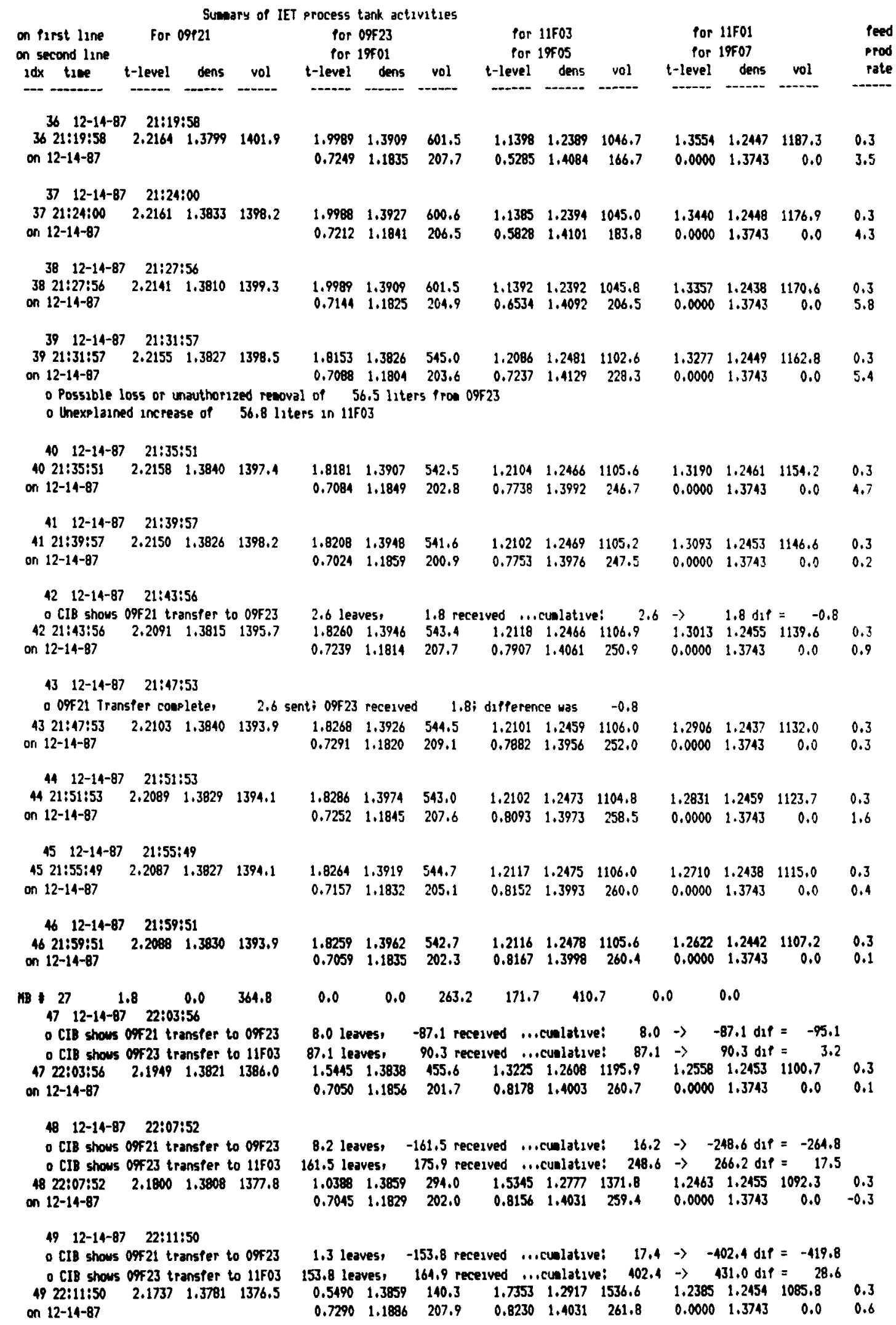




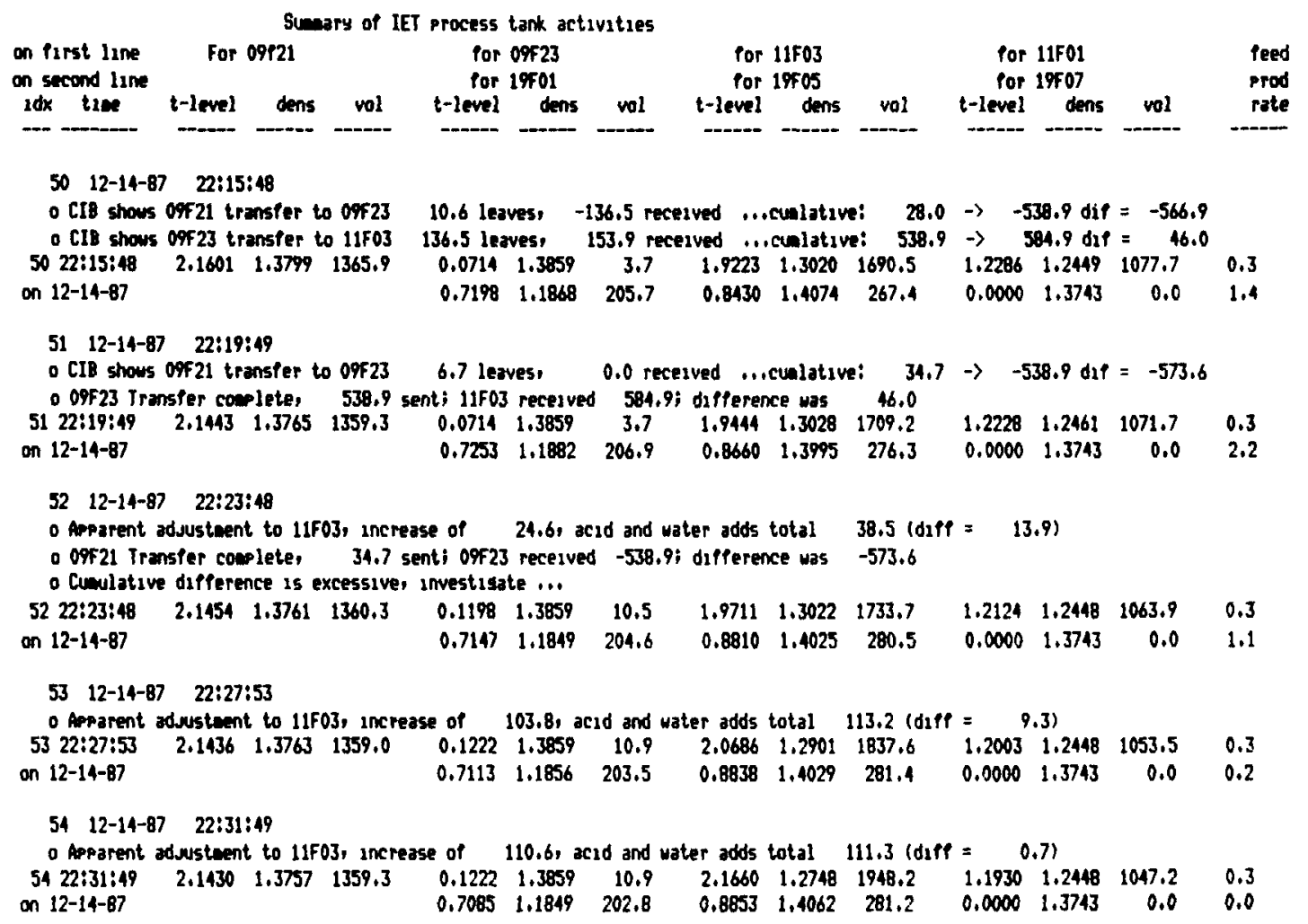

Fig. 7.5. MONITR program - detection of accountability tank bypass.

accountability transfer is completed at $22: 15: 48$. The comparison shows $538.9 \mathrm{~L}$ transferred and 584.9 received. MONITR calls the difference excessive and suggests the need for additional investigation. Notice also that an additional $6.7 \mathrm{~L}$ is transferred into the accountability tank after the transfer.

The MONITR routine calculated $34.7 \mathrm{~L}$ total transferred from tank 09F21. Adjusting for the amount sent after the transfer, $28 \mathrm{~L}$ was transferred into tank $09 \mathrm{~F} 23$ while the transfer was in progress. MONITR calculated $538.9 \mathrm{~L}$ sent. The transfer from tank $09 \mathrm{~F} 23$ to tank $11 \mathrm{~F} 03$ is a steam jet, and a jet dilution effect of about $4 \%$ can be expected. Thus the $538.9 \mathrm{~L}$ sent to tank $11 \mathrm{~F} 03$ should increase to $560.5 \mathrm{~L}$ by this effect alone. The additional $28 \mathrm{~L}$ makes the total $588.5 \mathrm{~L}$ compared to the $584.9 \mathrm{~L}$ observed.

In summary, the MONITR routine was effective at detection of three different scenarios that attempt to bypass the accountancy measurement tank:

1. undeclared transfers to process

2. additions after sampling and measurement

3. undeclared additions during accountability transfer

The routine achieved these sensitivities using only process monitoring data available from the process control computer system. 


\subsection{PRODUCT TANK REMOVALS}

Process monitoring routines can be very sensitive to product tank removals. The product tank monitoring task of the TASTEX experiments was an early example of this application. Product tank monitoring is part of the IET safeguards system. The difference between the IET application and other earlier applications is in the extent of the logic developed and implemented to evaluate the process data. IET facility testing has been extensive in this particular area in order to understand the influences of process variations and characteristics of process measurements on the sensitivities achievable.

Figure 7.6 is another example of the output from the MONITR routine. Three indications of loss from tank 19F07 are found in these data. In the first example (02:34) there is a caution that the status of the mixing equipment changed. The other two (03:03 and 03:26) simply indicate a loss or removal.

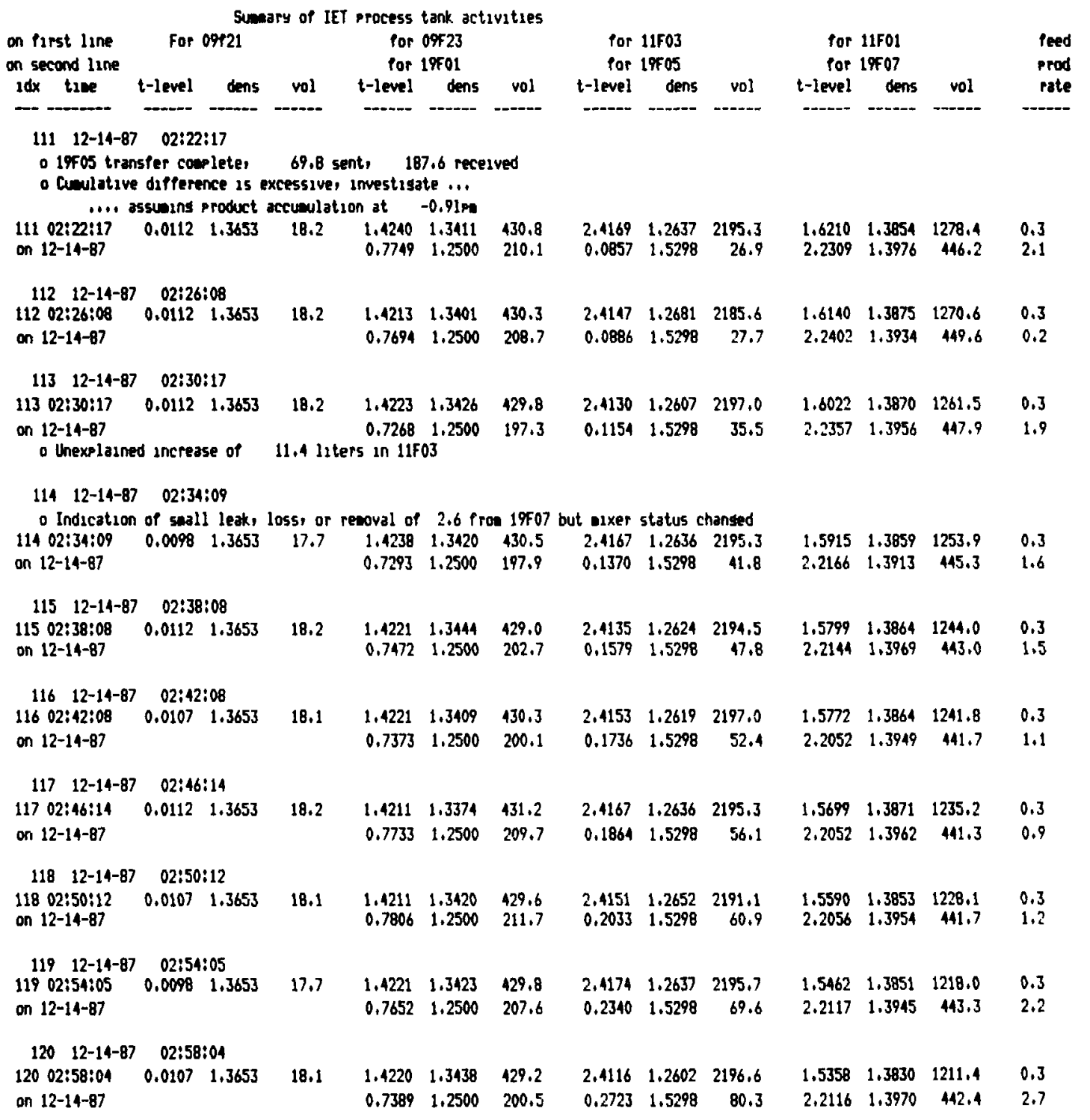




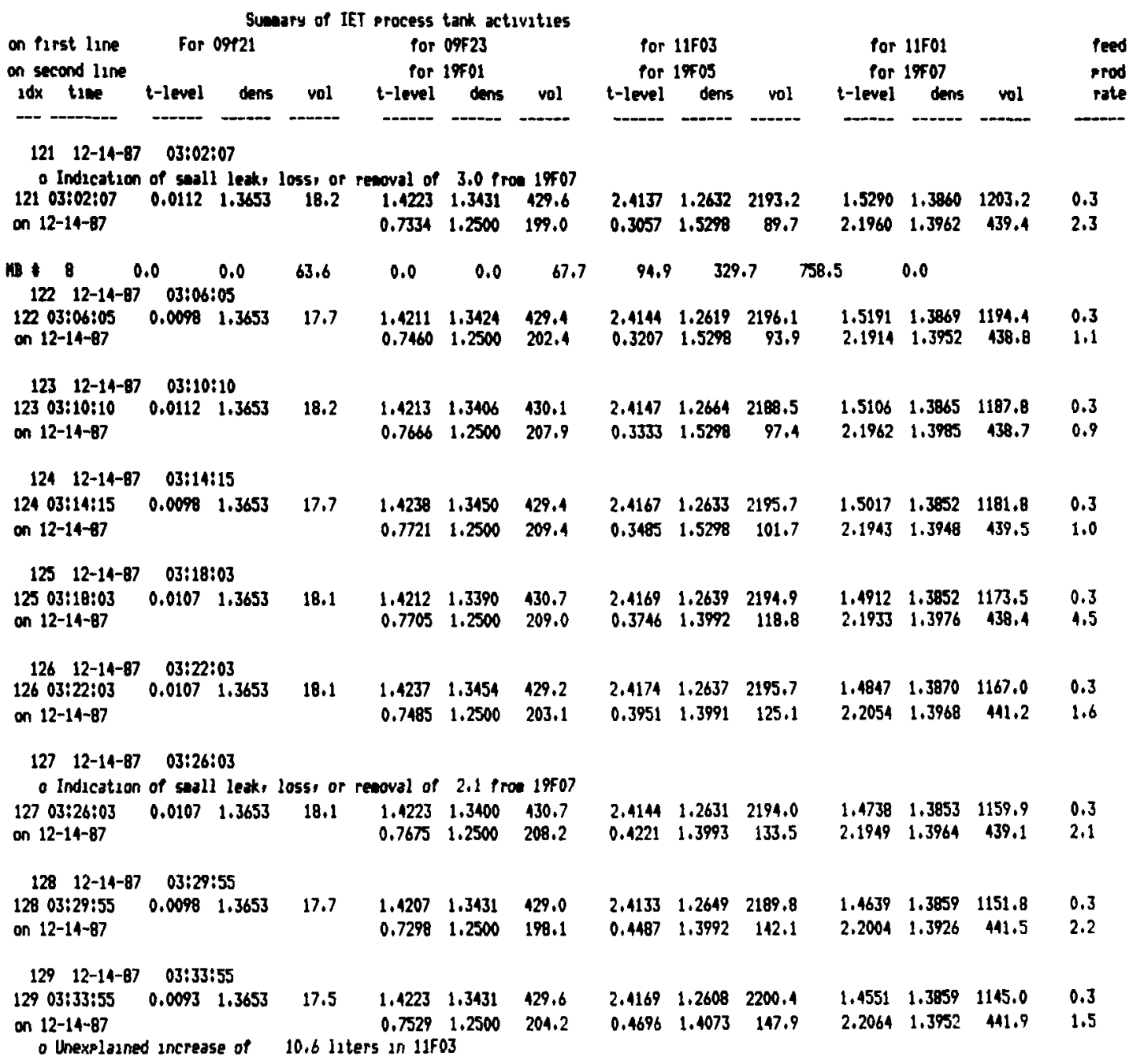

Fig. 7.6. MONITR program - detection of product tank removals.

The SCROL program is pulled from the process monitoring tool bag and is used here for confirmation of the alarm. This program presents detailed data for a selected process system. In this case, the program is used to present data for the product accountability tank. The detailed data shown in Fig. 7.7 include those used by MONITR.

The detailed data of Fig. 7.7 show the tank being filled from $02: 02$ to $02: 18$. Notice that the calculated volume changed from 446.2 to 449.6 to 447.9 between $02: 22$ and $02: 30$. There were no alarms generated by MONTTR until 02:34 (see Fig. 7.6). Testing at the IET facility has shown that a detailed look at a combination of variables can be more sensitive to removals than monitoring a single variable. In the case of the product tank, MONITR contains intelligence to use a combination of tests involving apparent level changes, density changes, temperature changes, mixing status indicators, and volume changes. Alarm sensitivity is set to $0.5 \mathrm{~L}$ during the IET facility tests. Only when there is a combination of removal indicators does MONITR generate an alarm. 
SUMARAY FOR TANK 19F07

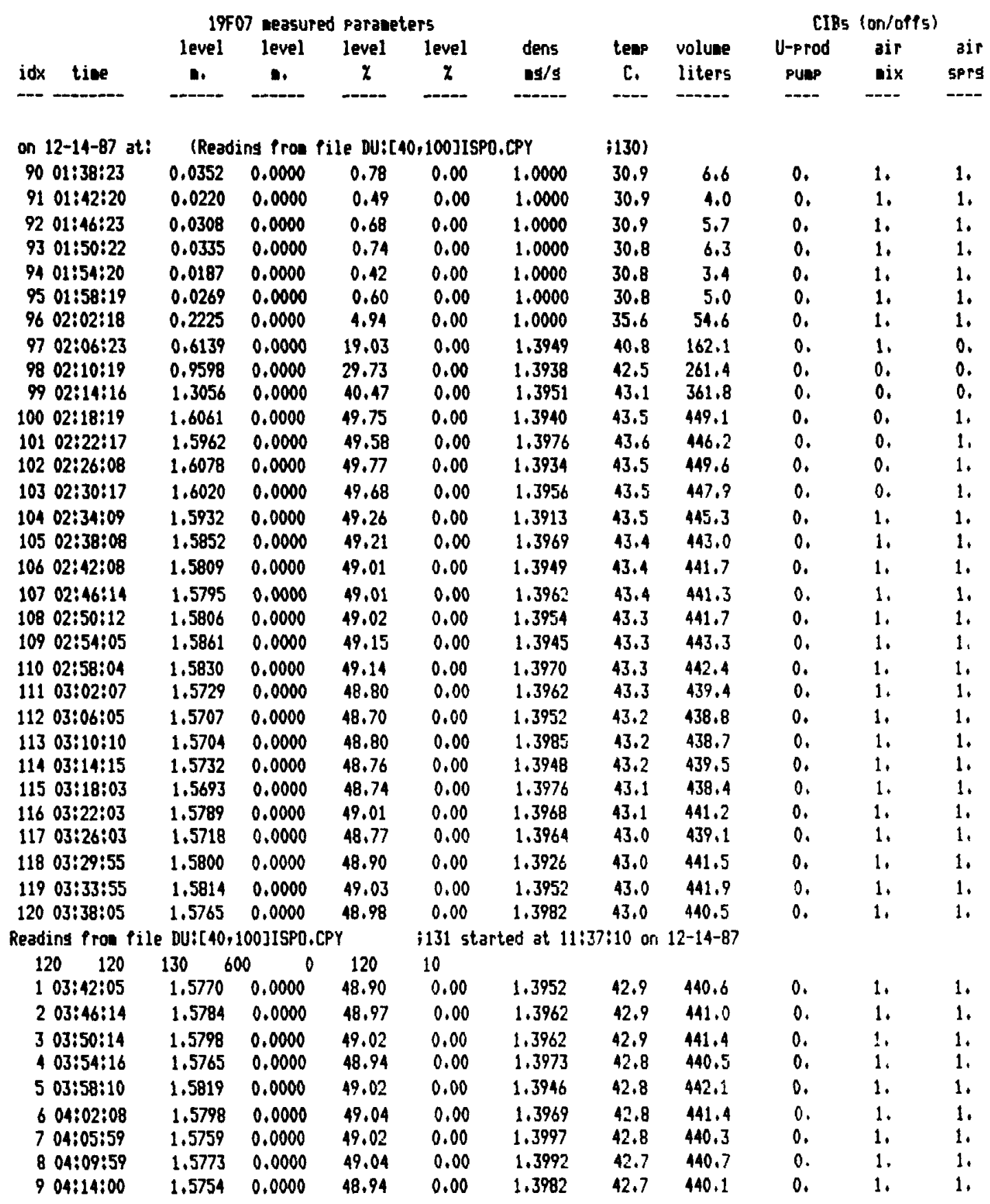

Fig. 7.7. Confirmation of product tank removals with SCROL program. 
While calculated volumes change by more than $0.5 \mathrm{~L}$ during the period between $02: 22$ and 02:30, there is no alarm until 02:34. As shown in Fig. 7.7, the air mixers in the tank were turned off at that time. This change in status results in the qualifier added to the alarm message shown in Fig. 7.6. These data are still suspicious. Using the data from Fig. 7.6, the volume decreases to 441-442 $\mathrm{L}$ after 02:42 and stays somewhat stable until almost 03:00. There is a spike to $443 \mathrm{~L}$ at 02:54, but this seems to be a single measurement anomaly. The analysis and alarm logic in MONITR does not detect a problem after 02:34.

The alarm of MONITR shown in Fig. 7.6 and the additional analysis of data from the SCROL program lead to a conclusion that a removal occurred. It seems to involve a volume change from about 447 to $441 \mathrm{~L}$ or 5-6 L. The IET operations staff reported that they actually removed $5 \mathrm{~L}$ during this time period. The MONITR alarm only calculated $2.6 \mathrm{~L}$ as the loss in the alarm message. It seems that the removal was taking place over the time interval when the data at 02:34 were being recorded. That is, some of the $5 \mathrm{~L}$ were removed in the interval between 02:30 and 02:34 and was detected. The rest was removed between $02: 34$ and $02: 38$ and did not produce an alarm. This is an indication of the importance of timing of safeguards tests and practical implications of removal detection.

The alarm shown in Fig. 7.6, which occurred at 03:02, is a little harder to resolve. Examination of the data provided by the SCROL program shows the calculated volumes ranging from 438.7 to $442.1 \mathrm{~L}$ prior to the alarm. There is an alarm at 03:02, and another alarm at 03:26. In this case the volume spiked up to 441.2 at 03:22 from 438.4 four minutes before. The volume then fell back to 439.1 at $03: 26$, which produced the alarm. The measured volume then went back to 441.5 in the four minutes later. It is tempting to conclude that the alarms at 03:02 and 03:26 are both false alarms.

Resolution requires a broad look at the data from the time after the first removal to the end of the data set shown in the SCROL program output of Fig. 7.7. The data from 02:38 to 02:58 average 442.1 L. For the time from 03:06 to the end, the average is 440.4 The operations staff actually did remove $2 \mathrm{~L}$ from the tank at 03:05. The MONITR program did alarm the removal. This apparent sensitivity must be considered in relation to the false alarm generated at 03:26. A thorough analysis was able to isolate the alarm at about $1.7 \mathrm{~L}$ using some averaged volume measurements taken around the time of concem.

The process monitoring routines available in the IET safeguards system include those directed at the product area. These can be compared to simpler routines that have been implemented and tested in other programs like TASTEX. Development of the IET process monitoring system has included evaluation of process data and the characteristics. The IET work has allowed development of complex logic routines like those used to screen volume changes for alarm in the data discussed in this section. The knowledge about process data behavior, gained from extensive testing, has been incorporated in the analysis routine for use by the participants (inspectors) in the demonstration.

The MONITR routine did detect two removals at 02:34 and 03:05, but produced a false alarm at 03:26. Analysis of the data was provided by MONITR, but resolution/confirmation required the use of the SCROL program as well. This exercise further demonstrates a sensitivity of process monitoring but shows the necessity of having the tool bag of analysis routines available to the inspector. 


\subsection{REMOVAL FROM SOLVENT EXTRACTION FEED TANK}

The IET safeguards system is a test system and is still under development. For this demonstration, the intention was to concentrate on those aspects of the safeguards system and process monitoring that have particular significance to international safeguards. That is, the removal tests and method of detection were focused on those plant activities and scenarios that are often discussed as concerns for international safeguards. Process monitoring can be sensitive to a broader range of potential problems. One such scenario was encountered during the demonstration. As it turned out, a removal of material was planned by the operations group. They inadvertently carried out the removal at the time when an instrument failure occurred. In terms of international safeguards, this particular event can be viewed as an attempt to cover a removal with an apparent instrument failure.

Figure 7.8 gives the output from MONITR for a series of data recorded between 04:11 and 04:58. There is notice of an accountability waste transfer and a feed adjustment activity in the data, showing process monitoring in a data logging function. More significant is the alarm recorded by the routine at 04:42. An unexplained increase of $84.8 \mathrm{~L}$ was detected in the feed adjustment tank (11F03). The alarm is due to a real increase, not just an instrument spike because the volume increase persists. The experienced safeguards analyst also notices the density decrease, indicating that the addition was a low density solution.

The next logical step in the safeguards resolution process is to examine tanks that could deliver solutions to tank 11F03. There is no change in tanks 09F23 or 09F21 and no indication of an attempt to bypass the accountancy measurement. A curious observation is noted in the feed tank, however. Recall that Sect. 7.1 presented an analysis of feed rates and discovered a bypass around the solvent extraction system. With the bypass, the nominal feed rate is about $2 \mathrm{~L} / \mathrm{min}$. There is normally a volume change in tank $11 \mathrm{F03}$ of about $8 \mathrm{~L}$ in a 4-min data set. Between 04:35 and 04:38, there was a change of $27.4 \mathrm{~L}$. During the next interval, the change is 27.1. Between $04: 42$ and $04: 46$, the change is again normal at $7.8 \mathrm{~L}$.

The next logical step is for the inspector to pull the SCROL program from his tool bag and select the acid and water add system for closer examination (making selection 8 as shown in Fig. 6.13 and described in Sect. 6.2.9). The data for the time period in question are shown in Fig. 7.9. In the IET facility, acid and water additions are measured by integrating flowmeters, the output of which is shown under columns FQ90F29 and LQ90F17 in Fig. 7.9. We observe the water addition for adjustment at 04:31 and 04:35. The output from the flowmeter, the integrated flow, increases to 3000 and stays. This particular instrument has a maximum of 3000 . At that point the integrator needs to be manually reset. In effect, the flowmeter became inoperative at 04:35.

Volume measurements for the recovered water tank (90F17) are also among the data shown in Fig. 7.9. The water tank feeds many systems in addition to feed adjustment needs. There are continuous volume changes. The normal volume change is about $15 \mathrm{~L}$. There are significantly larger volume changes during the periods between 4:31 and 4:38. These correspond to the water additions to tank 11F03, but are not indicated in the MONITR analysis because of the failure of the flowmeter instrument.

The actual differences can be computed. However, it is resolved that the flowmeter has failed to indicate the addition. The inspector now knows the reason for the unexplained increase, but he has also found the problem of excessively large, unexplained decreases in the feed tank (11F01). There is no alarm in the MONITR program output to call attention to this particular problem. As noted at the start of this section, the IET facility safeguards system is developmental. 


\begin{tabular}{|c|c|c|c|c|c|c|c|c|c|c|c|c|}
\hline $\begin{array}{l}\text { on first line } \\
\text { on second line } \\
\text { Idx tive }\end{array}$ & \multicolumn{5}{|c|}{$\begin{array}{l}\text { Sumary of IET process tank octivities } \\
\text { O9f21 }\end{array}$} & \multicolumn{2}{|c|}{$\begin{array}{c}\text { for } 11503 \\
\text { for } 19605 \\
\text { t- }\end{array}$} & vol & \multicolumn{2}{|c|}{ or $11 F 01$} & vol & $\begin{array}{l}\text { pe } \\
\text { pp } \\
\text { pa }\end{array}$ \\
\hline 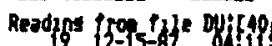 & 180015 & PO.CPY & 11345 & started a & $11: 34: 2$ & on $12-15$ & 5-87 & & & & & \\
\hline $\begin{array}{ll}1904: 11: 04 & 2.1528 \\
\text { on } 12-15-87 & \end{array}$ & 1.3750 & 1366.2 & $\begin{array}{l}0.0048 \\
0.7309\end{array}$ & $\begin{array}{l}1.3981 \\
1.2135\end{array}$ & 204.2 & $\begin{array}{l}1.6292 \\
0.4634\end{array}$ & $\begin{array}{l}1.2868 \\
1.3598\end{array}$ & $\begin{array}{r}1447.2 \\
151.2\end{array}$ & $\begin{array}{l}1.9395 \\
0.0000\end{array}$ & $\begin{array}{l}1.2298 \\
1.4041\end{array}$ & $\begin{array}{r}1744.0 \\
0.0\end{array}$ & $\begin{array}{l}0.3 \\
0.0\end{array}$ \\
\hline $\begin{array}{cc}20 & 12-15-87 \\
2004: 15: 02 & 2.1517 \\
\text { on } 12-15-87 & \end{array}$ & 1.3728 & 1367.7 & $\begin{array}{l}0.0056 \\
0.7306\end{array}$ & $\begin{array}{l}1.3981 \\
1.2123\end{array}$ & 204.4 & $\begin{array}{l}1.6308 \\
0.4666\end{array}$ & $\begin{array}{l}1.2869 \\
1.3626\end{array}$ & $\begin{array}{r}1448.5 \\
151.9\end{array}$ & $\begin{array}{l}1.9307 \\
0.0000\end{array}$ & $\begin{array}{l}1.2288 \\
1.4041\end{array}$ & $\begin{array}{r}1737.3 \\
0.0\end{array}$ & 0.3 \\
\hline $\begin{array}{rrr}21 & 12-15-87 & 04: 19 \\
0 & \text { Accountability } \\
21 & 0419: 03 & 2.1526 \\
\text { on } 12-15-87 & \end{array}$ & $\begin{array}{l}: 03 \\
\text { te trans } \\
1.3730\end{array}$ & $\begin{array}{l}\text { ster en pr } \\
1368.1\end{array}$ & $\begin{array}{l}\text { osiress - c } \\
0.0048 \\
0.7305\end{array}$ & $\begin{array}{l}\text { cumulativ } \\
1.3989 \\
1.2114\end{array}$ & $\begin{array}{l}\text { transfer } \\
0.0 \\
204.5\end{array}$ & $\begin{array}{r}\text { red } 153 \\
1.6308 \\
0.4652\end{array}$ & $\begin{array}{l}34.8 \text { 12te } \\
1.2869 \\
1.3600\end{array}$ & $\begin{array}{r}1448.5 \\
151.7\end{array}$ & $\begin{array}{l}1.9229 \\
0.0000\end{array}$ & $\begin{array}{l}1.2289 \\
1.4041\end{array}$ & $\begin{array}{r}1730.1 \\
0.0\end{array}$ & $\begin{array}{l}0.3 \\
0.0\end{array}$ \\
\hline 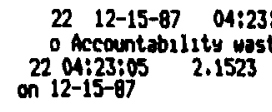 & Le trans & $\begin{array}{l}\text { sfer } 2 n \text { pr } \\
1366,8\end{array}$ & $\begin{array}{l}0.0071 \\
0.7312\end{array}$ & $\begin{array}{l}\text { sueviativ } \\
1.39 \% 1 \\
1.2092\end{array}$ & $\begin{array}{l}\text { transfer } \\
0.0 \\
205.0\end{array}$ & $\begin{array}{r}\text { red } 1511 \\
1.6293 \\
0.4710\end{array}$ & $\begin{array}{l}13.6 \text { 11te } \\
1.2864 \\
1.3644\end{array}$ & $\begin{array}{r}147.6 \\
153.1\end{array}$ & $\begin{array}{l}1.9120 \\
0.0000\end{array}$ & $\begin{array}{l}1.2266 \\
1.4041\end{array}$ & $\begin{array}{r}1723.1 \\
0.0\end{array}$ & $\begin{array}{l}0.3 \\
0.3\end{array}$ \\
\hline 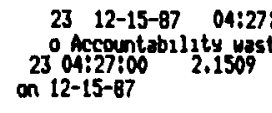 & $\begin{array}{l}: 00 \\
\text { te tr } \\
1.37\end{array}$ & 13 & $\begin{array}{c}\text { ofress }-\mathrm{Cl} \\
0.0071 \\
0.7236\end{array}$ & $\begin{array}{l}\text { Euevulativ } \\
1.3991 \\
1.2043\end{array}$ & $\begin{array}{l}\text { transft } \\
0.0 \\
203.8\end{array}$ & $\begin{array}{l}\text { red } 1515 \\
1.6302 \\
0.4749\end{array}$ & $\begin{array}{l}30,0 \text { lited } \\
1.2864 \\
1.3664\end{array}$ & $\begin{array}{r}1448.5 \\
154.2\end{array}$ & $\begin{array}{l}1.9004 \\
0.0000\end{array}$ & $\begin{array}{l}1.2255 \\
1.4041\end{array}$ & $\begin{array}{r}1713.9 \\
0.0\end{array}$ & 0.3 \\
\hline 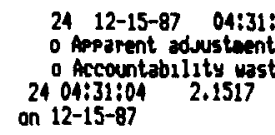 & $\begin{array}{l}: 04 \\
\text { to } 11 F \\
\text { te trans } \\
\text { t. tran } \\
3.720\end{array}$ & $\begin{array}{l}003, \\
\text { sfer } \\
136\end{array}$ & $\begin{array}{l}\text { ase of } \\
0.5 r e 55-c \\
0.0079 \\
0.7336\end{array}$ & $\begin{array}{l}2.5, \text { a } \\
\text { cuvulativ } \\
1.3981 \\
1.2111\end{array}$ & $\begin{array}{l}20 \text { and we } \\
\text { transfer } \\
0.0 \\
205.4\end{array}$ & $\begin{array}{l}\text { ter adds } \\
\text { red } 1524 \\
1.6330 \\
0.4776\end{array}$ & $\begin{array}{l}\text { total } \\
\begin{array}{l}18.6 \text { I1te } \\
1.2864 \\
1.3634\end{array}\end{array}$ & $\begin{array}{l}7.0 \text { ldof } \\
1451.0 \\
155.4\end{array}$ & $\begin{array}{l}=4 \\
1.8943 \\
0.0000\end{array}$ & $\begin{array}{l}\text { 1.4) } \\
1.2276 \\
1.4041\end{array}$ & $\begin{array}{r}1705.2 \\
0.0\end{array}$ & $\begin{array}{l}0.3 \\
0.3\end{array}$ \\
\hline $\begin{array}{ccc}25 & 12-15-87 & 04135: \\
0 \text { Apparent } & \text { adjustevent } \\
25 \text { 04:35:-0 } & 2.1533 \\
\text { on } 12-15-87 & \end{array}$ & $\begin{array}{l}00 \\
\text { to } 115 \\
1.3726\end{array}$ & 136 & $\begin{array}{l}\text { ase of } \\
0.0079 \\
0.7266\end{array}$ & $\begin{array}{l}93.7,{ }^{2} \\
1.3981 \\
1.2082\end{array}$ & $\begin{array}{r}\text { Id and } \\
0.0 \\
203.9\end{array}$ & $\begin{array}{r}\text { ter adds } \\
1.7746 \\
0.4847\end{array}$ & $\begin{array}{l}\text { total } \\
1.2771 \\
1.3714\end{array}$ & $\begin{array}{l}73.3 \text { (diff } \\
1544.7 \\
156.8\end{array}$ & $\begin{array}{l}=-20 \\
1.6896 \\
0.0000\end{array}$ & $\begin{array}{l}.41 \\
1,2266 \\
1.4041\end{array}$ & $\begin{array}{r}1701.3 \\
0.0\end{array}$ & \\
\hline $\begin{array}{ccc}26 & 12-15-87 & 04: 38: \\
26 & 04: 38: 59 & 2.1517 \\
\text { on } 12-15-87 & \end{array}$ & $\begin{array}{l}539 \\
1.3743\end{array}$ & 1366.2 & $\begin{array}{l}0.0056 \\
0.7321\end{array}$ & $\begin{array}{l}1.3981 \\
1.2071\end{array}$ & 205.7 & $\begin{array}{l}1.8219 \\
0.4869\end{array}$ & $\begin{array}{l}1.2597 \\
1.3671\end{array}$ & $\begin{array}{r}1655.7 \\
158.1\end{array}$ & $\begin{array}{l}1.8608 \\
0.0000\end{array}$ & $\begin{array}{l}1.2276 \\
1.4041\end{array}$ & $\begin{array}{r}1673.9 \\
0.0\end{array}$ & .3 \\
\hline 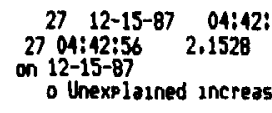 & $\begin{array}{l}156 \\
1.3731 \\
\text { se of }\end{array}$ & $\begin{array}{l}1368.1 \\
84.8 \text { lit }\end{array}$ & $\begin{array}{r}0.0079 \\
0.7227 \\
\text { ers in 11F }\end{array}$ & $\begin{array}{l}1.3981 \\
=03\end{array}$ & $\begin{array}{r}0.0 \\
203.2\end{array}$ & $\begin{array}{l}1.8927 \\
0.5011\end{array}$ & $\begin{array}{l}1.2455 \\
1.3682\end{array}$ & $\begin{array}{r}1740.5 \\
162.6\end{array}$ & $\begin{array}{l}1.8290 \\
0.0000\end{array}$ & $\begin{array}{l}1.2257 \\
1.4041\end{array}$ & $\begin{array}{r}1646.8 \\
0.0\end{array}$ & $\begin{array}{l}0.3 \\
1.1\end{array}$ \\
\hline $\begin{array}{ccc}28 & 12-15-87 & 04: 46: \\
2804: 46 ; 58 & 2,1524 \\
\text { on } 12-15-87 & \end{array}$ & $\begin{array}{l}58 \\
1.3731\end{array}$ & 1367.9 & $\begin{array}{l}0.0071 \\
0.7257\end{array}$ & $\begin{array}{l}1.3981 \\
1.2041\end{array}$ & $\begin{array}{r}0.0 \\
204.4\end{array}$ & $\begin{array}{l}1,8905 \\
0.5259\end{array}$ & $\begin{array}{l}1.2426 \\
1.3766\end{array}$ & $\begin{array}{r}1742.6 \\
169.7\end{array}$ & $\begin{array}{l}1.8244 \\
0.0000\end{array}$ & $\begin{array}{l}1.2283 \\
1.4041\end{array}$ & $\begin{array}{r}1639.0 \\
0.0\end{array}$ & $\begin{array}{l}0.3 \\
1.8\end{array}$ \\
\hline $\begin{array}{ll}29 & 12-15-87 \\
29 & 04: 50: 50: 53 \\
\text { on } 12-15-87 & 2.1524\end{array}$ & 153 & 1368.1 & $\begin{array}{l}0.0079 \\
0.7292\end{array}$ & $\begin{array}{l}1.3981 \\
1.2049\end{array}$ & $\begin{array}{r}0.0 \\
205.2\end{array}$ & $\begin{array}{l}1.8905 \\
0.5424\end{array}$ & $\begin{array}{l}1.2426 \\
1.3711\end{array}$ & $\begin{array}{r}1742.6 \\
175.8\end{array}$ & $\begin{array}{l}1.8094 \\
0.0000\end{array}$ & $\begin{array}{l}1.2249 \\
1.4041\end{array}$ & $\begin{array}{r}1629.8 \\
0.0\end{array}$ & $\begin{array}{l}0.3 \\
1.6\end{array}$ \\
\hline $\begin{array}{ll} & 30 \quad 12-15-87 \\
3004: 54: 55: 54: & 2.1523 \\
\text { on } 12-15-87 & \end{array}$ & $\begin{array}{l}55 \\
1.3741\end{array}$ & 1366.8 & $\begin{array}{l}0.0071 \\
0.7292\end{array}$ & $\begin{array}{l}1.3981 \\
1.2023\end{array}$ & $\begin{array}{r}0.0 \\
205.7\end{array}$ & $\begin{array}{l}1.8908 \\
0.5633\end{array}$ & $\begin{array}{l}1.2425 \\
1.3818\end{array}$ & $\begin{array}{r}1743.1 \\
181.3\end{array}$ & $\begin{array}{l}1.8058 \\
0.0000\end{array}$ & $\begin{array}{l}1.2271 \\
1.4041\end{array}$ & $\begin{array}{r}1623.4 \\
0.0\end{array}$ & 1.3 \\
\hline $\begin{array}{ll}31 & 12-15-87 \\
31^{04: 59: 53} & 04: 58: \\
\text { on } 12-15-87 & \end{array}$ & $\begin{array}{l}53 \\
1.3717\end{array}$ & 1368.7 & $\begin{array}{l}0.0079 \\
0.7321\end{array}$ & $\begin{array}{l}1.3981 \\
1.2020\end{array}$ & $\begin{array}{r}0.0 \\
206.5\end{array}$ & $\begin{array}{l}1.8900 \\
0.5825\end{array}$ & $\begin{array}{l}1.2428 \\
1.3835\end{array}$ & $\begin{array}{r}1741.8 \\
187.3\end{array}$ & $\begin{array}{l}1.7936 \\
0.0000\end{array}$ & $\begin{array}{l}1.2261 \\
1.4041\end{array}$ & $\begin{array}{r}1613.3 \\
0.0\end{array}$ & $\begin{array}{l}0.3 \\
1.5\end{array}$ \\
\hline$A B \neq 34$ & & 94.6 & 1161.3 & 0.0 & 71.8 & 0.0 & & .0 & & 8.6 & & \\
\hline
\end{tabular}

Fig. 7.8. MONITR program alarm on feed adjust tank (11F03).

The MONITR program does not presently contain logic to compare solvent extraction feed flow indications to generate this alarm, but this is easily added. The inspector does get an alarm indication from the HEBAL routine shown in Fig. 7.10. As discussed in Sect. 7.1, every period in the HEBAL analysis in alarm because of the solvent extraction bypass activity. However, note the different magnitude of the calculated ID statistics shown in Fig. 7.10 for periods 33 and 34 . The problems noted by the MONITR routine are in the time period 34. The inspector has confirmed the water addition measurement problem. There is now a strong indication of an actual removal from the feed tank (11F01). 
RECYCLE ACID and WATER ADDITIONS

\begin{tabular}{|c|c|c|c|c|c|c|c|c|c|c|}
\hline \multirow[b]{2}{*}{$i d x$} & \multicolumn{4}{|c|}{$90 F 29$ (recycle acid) } & \multicolumn{2}{|c|}{$90 \mathrm{~F} 17$ (recycle H2O) } & \multicolumn{2}{|c|}{$\begin{array}{c}\text { acid flow } \\
\text { FQ9OF29 F90F17 }\end{array}$} & water & $\begin{array}{l}\text { flow } \\
\text { F90F17B }\end{array}$ \\
\hline & \% & m. & $3 / 5$ & liters & . & liters & 1. & 1/min & 1. & $1 /$ min \\
\hline $12-15-87$ & & & & & & & ;134) & & & \\
\hline $103: 39: 10$ & 41.57 & 0.6983 & 1,3425 & 1901.6 & 2.0140 & 4562.1 & 389.70 & 0.00 & 2918.69 & 26.82 \\
\hline $\begin{array}{ll}2 & 03: 43: 07 \\
3 & 03: 47: 09\end{array}$ & $\begin{array}{l}41.57 \\
41.56\end{array}$ & $\begin{array}{l}0.6995 \\
0.7003\end{array}$ & $\begin{array}{l}1.3401 \\
1.3382\end{array}$ & $\begin{array}{l}1905.3 \\
1907.5\end{array}$ & $\begin{array}{l}1.9902 \\
1.9928\end{array}$ & $\begin{array}{l}4506.4 \\
4510.8\end{array}$ & $\begin{array}{l}390.06 \\
390.06\end{array}$ & $\begin{array}{l}0.00 \\
0.00\end{array}$ & $\begin{array}{l}2918.69 \\
2919.06\end{array}$ & $\begin{array}{l}26.83 \\
26.83\end{array}$ \\
\hline $403: 51: 04$ & 41.53 & 0.6979 & 1.3418 & 1902.3 & 1.9946 & 4516.7 & 389.70 & 0.00 & 2918.69 & 26.84 \\
\hline 5 03:55:04 & 41.50 & 0.6994 & & & 1.9873 & 4501.3 & 389.70 & & 19.06 & 26.83 \\
\hline $603: 59: 00$ & 41.51 & 0.6992 & 1.3387 & 1904.5 & 792 & 4480.8 & 390.06 & & & 7 \\
\hline 7 04:03:00 & 41.51 & 0.6986 & 1.3398 & 1902.3 & 1.9719 & 4466.9 & 390.06 & 0.00 & 2919.06 & 26.82 \\
\hline $\begin{array}{l}804: 07: 06 \\
904: 11: 04\end{array}$ & $\begin{array}{l}41.50 \\
41.52\end{array}$ & $\begin{array}{l}0.6994 \\
0.6992\end{array}$ & $\begin{array}{l}1.3382 \\
1.3392\end{array}$ & $\begin{array}{l}1904.5 \\
1904.5\end{array}$ & $\begin{array}{l}1.9639 \\
1.9580\end{array}$ & $\begin{array}{l}4451.5 \\
4436.8\end{array}$ & $\begin{array}{l}389.70 \\
389.70\end{array}$ & $\begin{array}{l}0.00 \\
0.00\end{array}$ & $\begin{array}{l}2919.42 \\
2919.06\end{array}$ & $\begin{array}{l}26.82 \\
26.79\end{array}$ \\
\hline $\begin{array}{ll}10 & 04: 15: 02 \\
11 & 04: 19: 03 \\
12 & 04: 23: 05\end{array}$ & $\begin{array}{l}41.51 \\
41.51 \\
41.51\end{array}$ & $\begin{array}{l}0.6995 \\
0.6997 \\
0.6992\end{array}$ & $\begin{array}{l}1.3380 \\
1.3377 \\
1.3389\end{array}$ & & $\begin{array}{l}1.9510 \\
1.9445 \\
1.9375\end{array}$ & $\begin{array}{l}4420.7 \\
4409.0 \\
4392.1\end{array}$ & $\begin{array}{l}390.06 \\
390.43 \\
390.06\end{array}$ & 0.00 & $\begin{array}{l}2919.79 \\
2919.42 \\
2918.69\end{array}$ & $\begin{array}{l}26.78 \\
26.79 \\
26.79\end{array}$ \\
\hline $1304: 2$ & 41.51 & 0.6997 & 1.3375 & 1906.0 & 1.9316 & 4379.0 & 390.43 & 0.00 & 2919,42 & 26.80 \\
\hline 14 04: & 41.46 & 0.6979 & 1.3396 & .1 & 1.9206 & 4360.6 & 389.70 & 0.00 & 12 & 26.80 \\
\hline $1504: 35: 00$ & 41.51 & 0.6983 & 1.3403 & 1901.6 & 1.8646 & 4234.6 & 390.06 & 0.00 & 3000.00 & 26.82 \\
\hline $1604: 38: 59$ & 41.50 & 0.6994 & 1.3392 & 1904.5 & 1.8060 & 4107,2 & 389.70 & 0.00 & 3000.00 & 26.83 \\
\hline $1704: 42: 56$ & 41.50 & 0.6986 & 1.3395 & 1902.3 & 1.7661 & 4023.7 & 390.06 & 0.00 & .00 & 26.86 \\
\hline $1804: 46: 58$ & 41.50 & 0.6992 & 1.3385 & 1904.5 & 1.7584 & 4006.8 & 389.70 & 0.00 & .00 & 26.87 \\
\hline $1904: 50: 53$ & 41.47 & 0.6994 & 1,3372 & 1904.5 & 1.7525 & 3991.5 & 389.70 & 0.00 & .00 & 26.86 \\
\hline $\begin{array}{ll}20 & 04: 54: 55 \\
21 & 04: 58: 53\end{array}$ & $\begin{array}{l}41.46 \\
41.52\end{array}$ & $\begin{array}{l}0.6986 \\
0.6992\end{array}$ & $\begin{array}{l}1.3382 \\
1.3390\end{array}$ & & $\begin{array}{l}1.7448 \\
1.7361\end{array}$ & $\begin{array}{l}3976.1 \\
3957.0\end{array}$ & $\begin{array}{l}390,06 \\
389,70\end{array}$ & $\begin{array}{l}0.00 \\
0.00\end{array}$ & $\begin{array}{l}3000.00 \\
3000.00\end{array}$ & $\begin{array}{l}26.85 \\
26.84\end{array}$ \\
\hline $2205: 02: 53$ & 41.52 & 0.6984 & 1.3406 & 1901.6 & 1.7273 & 3936.5 & 389.70 & 0.00 & 3000.00 & 26.82 \\
\hline $\begin{array}{l}2305: 06: 54 \\
2405: 10: 49\end{array}$ & $\begin{array}{l}41.52 \\
41.47\end{array}$ & $\begin{array}{l}0.7005 \\
0.6988\end{array}$ & $\begin{array}{l}1.3366 \\
1.3382\end{array}$ & $\begin{array}{l}1908.2 \\
1903.1\end{array}$ & $\begin{array}{l}1.7177 \\
1.7100\end{array}$ & $\begin{array}{l}3917.5 \\
3899.9\end{array}$ & $\begin{array}{l}390.43 \\
390.06\end{array}$ & $\begin{array}{l}0.00 \\
0.00\end{array}$ & $\begin{array}{l}3000.00 \\
3000.00\end{array}$ & $\begin{array}{l}26.82 \\
26.80\end{array}$ \\
\hline $2505: 14: 56$ & 41.52 & 0.7001 & 1,3373 & 1906.7 & 1.7009 & 3879,4 & 389.70 & 0.00 & 3000.00 & 26.78 \\
\hline $26 \quad 05: 19: 03$ & 41.44 & 0.6999 & 1.3348 & 1906.0 & 1.6921 & 3860.3 & 389.70 & 0.00 & 3000.00 & $26.7 ?$ \\
\hline $2705: 22: 51$ & 41.47 & 0.6994 & 1.3370 & 1904.5 & 1,6833 & 3842.8 & 390.06 & 0.00 & 3000.00 & 26.76 \\
\hline $2805: 26: 54$ & 41.45 & 0.6983 & 1.3385 & & 1.6771 & 3828.1 & 390.06 & 0.00 & 3000.00 & 26.76 \\
\hline $2905:$ & 41.46 & 0.6984 & 1.3386 & 1901.6 & 1.6698 & 3812.0 & 390.06 & 0.00 & 3000.00 & 26.80 \\
\hline $30 \quad 05: 34: 55$ & 41,45 & 0.6975 & 1.3398 & 1898.7 & 1.6610 & 3792.9 & 390.06 & 0.00 & 3000.00 & 26.82 \\
\hline
\end{tabular}

Fig. 7.9. Confirmation of instrument fallure with SCROL program.

For additional confirmation on the apparent removal, the inspector turns to the MINFLW program. This program has a number of options. In this case, the inspector uses the detailed data option (as discussed in Sect. 6.2.4). The output is shown in Fig. 7.11. The feed rate to solvent extraction, based on the depletion rate (dropout) in the feed tank, is shown in the column labeled "dout L/min." At 04:38 and 04:42, the rates are calculated at 6.87 and $6.86 \mathrm{~L} / \mathrm{min}$, respectively. In the summary for this period, the comparisons of the wheel measured flow to the HAW increases are typical (see Sect. 7.1). The comparison of dropout to HAW and dropout to wheel are not typical (see typical comparisons discussed in Sect. 7.1). This is the confirmation on the removal. 
HEAD END TANK VOLUME AND WEIGHT BALANCE

Solution weisht is volune $X$ derisity

inputs are 09F23, acid adds, and jet dilution effects

Vol Kaso

Vol Kasol

$0.0 \quad 0.0$

$30 \quad 00: 59: 22 \quad 0.0 \quad 0.0$

$3101: 59: 18 \quad 0.0 \quad 0.0$

$32 \quad 02 \div 59: 19 \quad 444.1 \quad 623.6$

$3303: 59: 00 \quad 55.4 \quad 55.4$

$\begin{array}{llll}34 & 04: 58: 53 & 86.4 & 86.3\end{array}$

$3505: 58: 42$

$3606: 58: 35$

$3707: 58: 35$

$38 \quad 08: 58: 31$

$3909: 58: 42$

$4010: 58: 29$

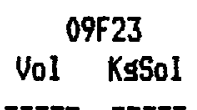

$11.1 \quad 15.3$

$11,1 \quad 15,3$

$444.2 \quad 626.5$

$220,3308,0$

$0.0 \quad 0.1$

$0.0 \quad 0.1$

0.10 .1

0.10 .1

0.10 .2

0.10 .2

$0.1 \quad 0.2$

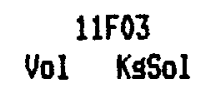

Vol KsSol

2341.12870 .4

$2344,52877,2$

2346.22877 .2

$1215.8 \quad 1537.3$

1741.82164 .7

$1742,22164,4$

1744.32166 .2

1743.52165 .8

1741.82165 .0

1743.12163 .8

1743.12165 .7

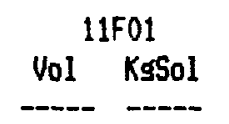

$758.2 \quad 943.9$

$640.8 \quad 796.4$

$522.6 \quad 650.1$

1764.12175 .7

1613.31978 .1

1493.51833 .0

1375.11687 .2

1257.41544 .0

1134.11392 .3

$1014.9 \quad 1245.5$

$895.71099,3$

\begin{tabular}{cc}
\multicolumn{2}{c}{ 0-put } \\
Vol & Kssol \\
\hline & $-\cdots$ \\
& \\
15.8 & 19.6 \\
15.8 & 19.7 \\
15.9 & 19.7 \\
15.8 & 19.6 \\
15.8 & 19.4 \\
15.8 & 19.0 \\
15.8 & 19.0 \\
15.8 & 19.0 \\
15.8 & 19.0 \\
15.9 & 19.1 \\
15.8 & 19.0
\end{tabular}

$15.8 \quad 19.0$

the following periods exceed our investisation heuristic:

futher investisation is needed!

(1) for period 30 volune ID is 108.3 and the solution weight In is 131.2

(2) for period 31 voluse ID is 98.2 and the solution weisht ID is 121.1

(3) for period 32 volune ID is 111.5 and the solution weisht ID is 139.1

(4) for period 33 volune ID is 152,4 and the solution weisht In is 168,6

(5) for period 34 volume ID is -84.3 and the solution weisht ID is -55.0

( 6) for period 35 volune In is 103.6 and the solution weitht In is 126.4

(7) for period 36 volume ID is 100.5 and the solution weisht ID is 125.0

(8) for period 37 volune IV is 102.6 and the solution weight III is 124.5

(9) for period 38 volume ID is 109.2 and the solution weisht ID is 133.5

(10) for period 39 volune ID is 102.0 and the solution weisht In is 128.9

(11) for period 40 volume ID is 103.4 and the solution weisht In is 125.3

Fig. 7.10. Removal detection with HEBAL program. 
The operations personnel actually removed $35 \mathrm{~L}$ from the feed tank during this period. Alarm mechanisms using comparisons of feed rate determinations are not included in the process monitoring routine MONITR, so a specific alarm was not generated. An alarm for this removal was generated in the HEBAL routine. With the continuous bypass and constant alarm status, this alarm was not readily apparent. The alarm on the removal was in combination with effects due to instrument problems as well.

The purpose of this example is to show that process data always reflect process activities in some way. The problem is to identify the kinds of activities that should produce alarms. In this example, a simple test that compares the various solvent extraction flow determinations, included in the MONITR routine, would have simplified the detection. This specific test was not a part of the routine. It can be easily implemented. Likewise, the IET testing has found that virtually any scenario, identified as concem, can be checked. It is a matter of specifying the concem and identifying the minimum data set needed to implement.

\subsection{FALSE ALARM INDICATIONS}

Next to intrusiveness, the false alarm rate is probably the biggest concem voiced in opposition to applications of process monitor for safeguards. During the demonstration, participants experienced a number of false alarm indications. Most false alarm indications are simply the result of "spikes" or "blips" in instrument signals that are characteristic of process control data. The causes are not well understood, but resolution is very easy because the measurements return to normal in the next data set. Ideally, a well developed software system would resolve many of these internally without the alarm generation.

Experience with the IET safeguards system, at the level of development that existed at the time of the demonstration, has shown a false alarm rate of about $2 \%$ for those type alarms that relate to process instrument characteristics. This $2 \%$ rate is in the MONITR program alone, analyzing data that are collected on a 4-min basis. There has not been enough experience to estimate a rate for unresolvable false alarms, using the broad range of tests and analysis routines. However, the examples presented in this chapter were chosen to show the interaction of a number of routines to explore the relationships between measurements and process indications that can be used to give the sensitivity and false alarm capabilities desired. As an example, the alarms limit on static product storage tanks is $0.1 \%$ (expressed as a percent of tank capacity) using process control instruments and volume relationships that have stated uncertainties on the order of $1-5 \%$. 
HA FLOW HEASUREMENT STUDY

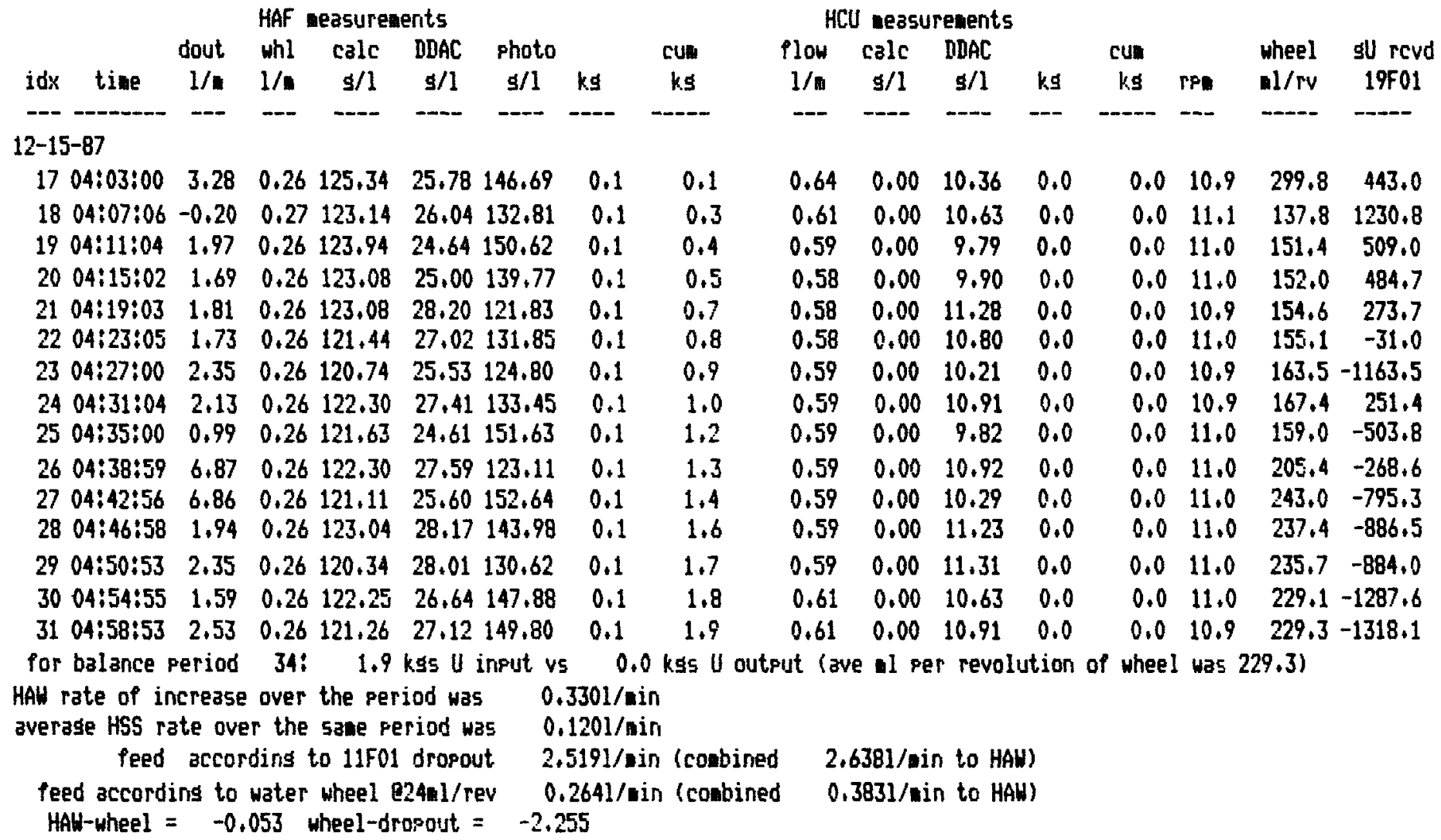

Fig. 7.11. Confirmation of removal with MINFLW program. 


\section{ARTIFICIAL INTELLIGENCE IN SAFEGUARDS}

The demonstration and the examples of removal detection and alarm resolution presented in this report show the extent of the data base and the number of analysis methods that are needed to make safeguards process monitoring work. Along with intrusiveness and false alarm concems, there is a concem that inspectors in the field, or even the plant operator's own safeguards personnel, will not have the expertise in analysis and knowledge of plant operations and measurement systems to effectively use process monitoring.

Discussions during the demonstration and examples presented in this report try to show that there is a procedure that a person, familiar with process monitoring and the plant data involved, will follow in use of the various analysis methods. The MONITR routine is usually used as the basic process monitoring tool to give preliminary indications. In the IET application, this program also calculates a number of parameters and expands the data base for use by a number of other routines such as mass flow balances, volume balances, and solution balances. There are certain indications from the MONITR routine that should lead the inspector to apply these other analysis routines. There is a generally effective hierarchy for application of the process monitoring analyses that starts with the MONITR routine. Based upon results and alarm indications, other routines are invoked. It does, however, generally take a knowledge of the chemical process systems involved to make efficient use of the available software.

Artificial intelligence is an emerging field of computer science that offers the opportunity for helping inexperienced personnel to have the benefit of the knowledge of experts in making decisions. The topic of artificial intelligence in safeguards is one of the more important topics to the future of process monitoring in safeguards. Expert systems, as a part of Al, are being developed as a method of capturing the knowledge and experience of experts in logic within computer systems. This knowledge can usually be reduced to a complex set of rules that guide the decision process. Expert system shells are now commercially available that offer flexible software that allows the expert to document and implement a rule base to guide the decision process for others. Expert systems have been successfully developed for medical diagnostics, computer system ordering, and even airline seating pricing activities. There are recent efforts to control plant operations with expert systems. The logic and decision structure that go into other successful expert system applications is similar to the uses that apply to process monitoring.

With the power of small computer systems and the availability of commercial expert system software, it is easy to see an application for $\mathrm{AI}$ in safeguards. The inspector can be sent to a site with software developed by agency experts with access to facility information at headquarters. The expert system can guide the less experienced inspector through the analysis.

Artificial Intelligence applications that are at the forefront of the technology are experimenting with learning. Examples were shown during the demonstration where the process monitoring routines were used to quantify instrument biases. Intelligence built into process monitoring routines and analysis expert systems can learn and monitor these biases. This may be the basis to improve NRTA data. 
There have been some efforts in application of expert systems for safeguards. These have been principally in the area of qualification of operator entered data based on expected values and some quality control checks. At ORNL, there has been an effort to use an expert system language to recognize safeguards significant events such as batch transfers and instrument failures by analysis of process data. This effort was described to participants as part of the discussion on AI. An effort is needed to apply these principles to the inspector's task of reviewing process monitoring data. AI can be used to help guide the inspector through the various analyses available. 


\section{PROCESS MONITORING FOR INTERNATIONAL SAFEGUARDS}

The initial phase of Task C.59, a literature search to summarize previous activities in the area of process monitoring for safeguards (reported in ISPO-255, ORNL/TM-1015), found a number of programs that accomplished various parts of a process monitoring application. None of these programs seemed to be complete. Furthermore, concepts of process monitoring for international safeguards continue to evolve with advancements in computer technology and availability. Opinions on possibilities and capabilities of process monitoring are often rooted in these past activities.

The definition of process monitoring and the role it can play in future large-scale plants under international safeguards were active topics for discussion during the final sessions of the demonstration.

\subsection{DEFINITIONS OF PROCESS MONITORING}

Data handling and process monitoring capabilities are improving with computer technology. Because this is a rapidly emerging technology, there is limited experience with these systems in operating reprocessing plants. Safeguards process monitoring is tied to the technology of computerized process control. Concepts for safeguards process monitoring are evolving with the advancement of commercial process control technology.

Because of this evolution, a consensus on the definition of process monitoring is elusive. The ambiguity in definition was well reported in STR-235, "Current Status of Process Monitoring for IAEA Safeguards." This ambiguity and confusion was discussed as part of Task C.59. It is worthwhile to reconsider the definition in view of currently available computer technology and capabilities and current activities in the area of process monitoring for safeguards.

As a modern definition offered during the demonstration, process monitoring for safeguards is the use of a broad range of process data and analysis tools to make timely and sensitive judgments on the location and movement of nuclear materials throughout the processing plant and to make timely and sensitive judgments on the status and performance of equipment and instruments used for nuclear material accounting measurements.

In order to recognize the implications of such a broad definition, it is helpful to consider an evolution of the definition in safeguards. It is somewhat unfortunate that the words process monitoring were chosen to describe a safeguards program when the words also have a strong connotation in terms of plant control. A first step in defining safeguards process monitoring is to distinguish between the safeguards application and the more conventional definition associated with operations monitoring and control. For the sake of this discussion, refer to the process application as operations monitoring and the safeguards application as safeguards process monitoring.

Operations monitoring is a broad range of operational activities typically associated with operation of a process or manufacturing plant. Operations monitoring has traditionally been the responsibility of facility operators who use their knowledge and judgment to observe process 
conditions and run the plant in a safe and efficient manner. As operations monitoring activities take advantage of modem computer and data processing capabilities, the experience, judgment, and knowledge of operators are translated to software and control systems for better plant performance. As these control systems are implemented, more information and analysis routines become available for safeguards use (i.e., safeguards process monitoring).

Capabilities for operations monitoring have evolved rapidly in recent years. As late as the end of the 1970s, operation monitoring still involved operators watching strip charts in the control room. Operations monitoring now involves commercially available software and hardware interfaced to plant equipment. Today, it means console filled control rooms where many of the operations activities are automated and plant information is collected, digested, and organized for logical presentation to operations personnel.

Safeguards process monitoring has evolved similarly. In the early stages of development (described in ISPO-255, ORNL/TM-1015), process monitoring experiments involved selection and installation of instruments and computers (TASTEX). Simple computer systems collected data, and analysis was usually limited to data plots. With availability of modem process control systems, process monitoring now involves complex analysis routines and decision software, moving into the fields of AI.

With the changing nature of process control and information systems and the changing process monitoring concepts that try to use these capabilities, the ambiguity of definitions noted in STR-235 is not inappropriate. The broad definition in this report and in discussions during the demonstration tries to consider modem capabilities of process control systems as they can contribute to the safeguards program for modem plants.

\subsection{PROCESS MONITORING, THE BROAD RANGE OF TOOLS}

At several times during the discussions, participants agreed that process monitoring is a valuable tool. The question explored during the discussions was whether it is valuable only to the facility operator or whether it can be adapted to the international safeguards program. Process monitoring might better be described as a set of analysis tools rather than a tool.

Remember that safeguards process monitoring has grown out of operations monitoring. The experienced operator focuses his attention on a few key instruments to control specific operations. When he notices an anomaly, his mind invokes a hierarchy of analysis algorithms, involving a broader set of instruments and information to confirm the operations anomaly, isolate the cause, and initiate corrective action.

The earliest control systems used simple hardware controllers to emulate an experienced operator. Computer control systems continue the effort, using computer software to implement control logic. The most modem systems are moving to AI and expert systems that contain a basic software capability to implement the complex decision logic that an experienced operator uses. These latest systems analyze conditions and decide on implementation of the appropriate control logic.

Safeguards process monitoring, in the broadest context, is similar. There are a few useful overview routines. These indicate potential safeguards problems and a considerable number of false alarms. An effective safeguards approach uses a hierarchy of analysis routines to resolve false alarms, or to confirm and isolate the problem.

Safeguards has traditionally involved calculation and analysis of a single decision statistic, the material balance (ID) statistic. There has been considerable research and a lot of experience with this single statistic analysis. Process monitoring, with a reliance on multiple tests and a 
hierarchy of decisions producing a rather fuzzy conclusion, is adverse to accepted principles of safeguards. There is an understandable reluctance to accept process monitoring as an intemational safeguards tool.

There is a reluctance to accept process monitoring as a tool for international safeguards because it does not use the traditional ID statistic. It does not lend itself to the traditional statistical analysis techniques applied to ID calculations. It requires the broad range of tools and the ability to handle the fuzzy conclusions. Participants were given the opportunity to apply this broad range of tools to operations data generated during the IET facility test runs. They experienced false alarms resulting from characteristic uncertainties and spurious signals inherent in process data. They were exposed to resolution techniques involving the hierarchy of tests. This was done with a modem data acquisition system, not yet available in most plants throughout the world, applied to a plant that is characteristic of an operating reprocessing facility.

The IET facility safeguards system represents an effort to implement a total safeguards package applicable to an operating, next generation large-scale reprocessing plant. As such, it contains elements that go beyond those that might be appropriate for international safeguards applications. Some of the elements are directed at helping the facility operator implement a safeguards program in a cost effective and efficient manner. The goal of the demonstration was to introduce the participants to the capabilities that do exist and allow them the opportunity to anticipate a role for perhaps a limited subset in international safeguards.

\subsection{THE ROLE OF PROCESS MONITORING FOR INTERNATIONAL SAFEGUARDS}

During the Task C.59 demonstration, there was considerable discussion on the role of process monitoring and where it fits in the overall safeguards hierarchy, including operator, national, and international safeguards groups. There was a general consensus among participants in the demonstration that process monitoring should and would be adapted and serve a valuable role in safeguards, but probably only for the operator. There were also discussions on whether process monitoring could be included in international safeguards.

The two specific roles for process monitoring in international safeguards that were discussed are event logging and mass flow balances. During the demonstration, adaptations of these and other process monitoring tools were available. They all serve to detect anomalies indicative of loss or removal of very small quantities of materials. These tools can be directed at detection of specific removal scenarios of concem to international safeguards. This was the role of process monitoring discussed. However, the majority of the discussion was directed more at whether these tools can be applied.

Process monitoring for safeguards probably cannot fit within the current context of safeguards, which is essentially pencil and clipboard data handling with some subsequent computerized data processing. Along with concerns for verification, this is a part of the problem with acceptance. Process monitoring requires collection and analysis of huge quantities of data. Acceptance will require adjustments in the fundamentals of the safeguards approaches (i.e., reliance on the ID statistic) and a significant increase in the use of computers for data collection and analysis. Availability of modem computer systems is a recent phenomenon. There is not a base of experience within IAEA and the safeguards community to have confidence in these data collection and analysis systems. These concerns were expressed by participants.

The lack of experience and confidence in the use of computers may be the cause of negative reactions when discussing the applicability of process monitoring. Two such reactions were that process monitoring is too intrusive and requires too much knowledge of plant 
operations. Inspectors will never have the depth of knowledge to make valid judgments from the data and test results. These objections were often stated during discussions on applications of process monitoring.

Is process monitoring too intrusive? It was noted that there are few, if any, secrets in reprocessing plant processes, only slight variations in flow sheet. The IAEA deals with reprocessing plant process design information. This is provided in the design information questionnaire as part of the negotiations for the subsidiary agreements for each facility under provisions of INFCIRC/153 and implementing documents. NRTA involves much of the same process data as a minimum data set for process monitoring. Process monitoring only involves more frequent, and thus, automated data collection. Is process monitoring significantly more intrusive than existing or pending (NRTA) requirements? These issues were discussed, but participants continued to express concerns over intrusions and the ability to verify the process monitoring data.

Is too much knowledge required? It was noted by participants that the very small plants being safeguarded today present a problem for inspectors. Significant training efforts are being implemented to prepare inspectors for plant assignments. Plant coverage is already almost $100 \%$. NRTA is being considered for most plants and lends a new dimension to the expertise required of inspectors. Task C.59 investigators noted that process monitoring implies computers interfaced to plant measurement and information systems. The engineering sciences of AI and expert systems will reduce knowledge requirements. These new sciences compile the knowledge of the safeguards expert and incorporate that knowledge in computer-based software. Powerful and inexpensive hardware is available that can be deployed in the field. The IET system used in the demonstrations is a limited example of this capability. Current computer systems can handle the expert system software and bring the expert capabilities to the aid of the on-site inspector. It was suggested that these capabilities could result in more expertise in the field for conventional accounting, and NRTA data collection, as well as process monitoring.

This part of the discussion concluded with participants recognizing that they were able to use the installed safeguards system in the IET facility with a minimum of training and involvement. They were able to make judgments about false alarms and actual removals. However, they continued to express concerns about the ability of IAEA to train inspectors and deploy hardware and software in operating plants within constraints of current IAEA operations. 


\section{SUMMARY}

Computer-based process control systems are being used in virtually all modem plants, whether chemical processing or mechanical assembly, to provide timely information on the location and movement of material throughout the plant. This timely information on location and movement of materials is also the goal of an effective safeguards system for nuclear fuel handling facilities. This compatibility leads to the question of how process monitoring can play a role in safeguards in the future large-scale nuclear fuel reprocessing plants.

The evolution of process monitoring in safeguards was presented in ISPO-255. Early efforts focused on selection and installation and testing of hardware. During these efforts, computer systems were very expensive, and equipment to interface to plant instrumentation was just becoming available. Computerized process control systems, with software and hardware easily adaptable to specific plants, later became commercially available. Efforts in the area of process monitoring expanded and began to focus on specific tests and applications. ISPO-255 presented a list of elements that must be considered for a process monitoring application to be fully developed. Few, if any, of these early efforts fully developed the concepts and requirements to implement process monitoring for safeguards. ISPO-275 was the second report prepared as part of Task C.59. This document selected two specific process monitoring applications and developed all the requirements of a system to implement them.

The final phase of Task C.59 was to implement these and other process monitoring applications in the IET facility and demonstrate them to representatives of IAEA. This was done in December 1987. This document reported on the demonstration and results of tests.

The demonstration involved operation of the IET facility. The facility is a full-scale reprocessing plant demonstration facility. It uses depleted uranium solutions to simulate feed material and includes prototypical processing systems and equipment. The process monitoring routines were used to detect a number of removals and other problems induced by the IET operating staff to simulate certain diversion scenarios identified in agency documents such as STR-140, "An Advanced Safeguards approach for a Model 200 T/A Reprocessing Facility," and STR-152, "Nuclear Material Safeguards for Reprocessing Plants," as concerns for reprocessing plants. There was considerable success in detecting activities that are aimed at bypassing the accountancy tank with dissolver solutions. There was also success in identifying and isolating removals of material from the process. Participants also used process monitoring as an event-logging tool. The monitoring routines identify and automatically record batch transfers. This $\log$ of events can serve the inspector in a comparison to reported accountability transfers.

In discussions early in the demonstration, IAEA participants expressed considerable skepticism for applicability of process monitoring in international safeguards. They expressed concerns about intrusiveness and the ability of the agency and inspectors to handle the volumes of data. At the conclusion of the demonstration, a record of meeting was jointly prepared by the participants and ORNL staff. This record (presented in Sect. 11) reflects the participants opinions at the conclusion. Skepticism remained, but IAEA participants generally felt that process 
monitoring does have potential for application. Participants suggested that given other priorities within IAEA, the priority of process monitoring research is probably low. They do not face the problem of safeguards in large reprocessing plants in the immediate future, and the applications for process monitoring are in these facilities. The record of meeting reflected IAEA participants opinions on the future direction of research in process monitoring. They generally agreed that the research should not stop. 


\section{RECORD OF MEETING}

As a final step, participants and the IET staff developed a record of meeting describing the general consensus as a conclusion of Task C.59. This record states the following:

Process Monitoring is one of several advanced techniques being studied as candidates for enhancing the intemational safeguards in large-scale reprocessing plants. For the past several years, the U.S. Program of Technical Assistance to the International Atomic Energy Agency (IAEA) Safeguards has sponsored development of process monitoring at ORNL. The IAEA representatives met at ORNL December 14-16, 1987 to review the status of this work. The computational tools developed by this task were demonstrated as part of a uranium run in the Integrated Equipment Test (IET) facility.

The first day of the meeting included an introduction to the IET facility and a review of past process monitoring test runs and analysis. Fifteen computer programs were briefly described, demonstrated, and exercised. The second day consisted of a more detailed description and illustration of each computer code, with specific application to data currently being generated. Three mass removals during the IET demonstration run were detected utilizing these computational tools. The day ended with a round table discussion of the strengths and weaknesses of various safeguards methodologies: conventional methods, near-real-time accounting (NRTA), and especially process monitoring. The third day continued with conducting hands-on testing to identify heavy metal removals from the previous night. The data concluded with a general discussion of how process monitoring might be applied with IAEA member states and future activities of Task C.59.

The IAEA representatives agree that the process monitoring technique is not suitable for intemational safeguards inspections of whole facilities as it now exists. However, it may have limited applications around specific unit operations. Some present shortcomings are as follows:

- Too much data are accessed in this version. Data requirements should be kept to a minimum (e.g., level/volume, density/concentration, etc.). Minimizing the amounts of data required will make it more likely that member nations will provide it.

- The computer programs identify to many operations activities that result in false alarms (e.g., instrument error). The inspector ought to be able to manually correct this data in order to smooth the time flow of information and to highlight actual material losses. Computer programs ought to be improved to aid the inspector in how to interpret and resolve alarms.

The computer program should be as friendly as possible to the user by identifying problem solving patterns (e.g., if this situation presents itself, then follow steps 1 then 2, etc.). Graphical displays would be useful. Finally, the computer program ought to provide a summary of all inconsistencies once apparent false alarms are removed. There are no resources within IAEA to develop software. 
- The system should be developed to take into account safeguards criteria. However, the development of such criteria (e.g., the timeliness of material balances) is input that must be provided by IAEA.

- Efforts must continue to establish ways of verifying the authenticity of data input to mass balance calculations. This problem is perhaps solvable if the inspector can have confidence that a certain few points have not been tampered.

- The links and commonality between process monitoring and conventional accounting safeguards techniques and NRTA techniques should be investigated. The best features and unique capabilities of each determined to obtain an overall, best capability for future large-scale plants.

There was some discussion that the data base obtained from IET demonstration runs and the process monitoring computer codes for analyzing that data would be useful as a training tool for safeguards inspectors. These are easily transported to other locations.

The role and resources of IAEA were discussed. The IAEA is an administrative and implementing organization with a budget that is not likely to increase in the near term, yet the demands for safeguards are increasing. At the present time, too much of the inspector's time is spent in facilities, manually reviewing data. Computerization of data collection and evaluation must occur to increase the effectiveness and efficiency of the safeguards effort. Artificial intelligence and knowledge-based expert systems incorporated into advanced safeguards techniques, such as process monitoring, are ways to improve inspector effectiveness and efficiency.

In summary, the IAEA representatives feel that as a result of this demonstration, the process monitoring technique shows sufficient potential to justify further development for specific applications. However, the representatives call attention to the need to examine process monitoring in terms of relative priorities and limited resources. It is expected that these decisions will be made at the IAEA headquarters during early 1988. 


\section{APPENDIX A AGENDA OF MEETING \\ Topic Outline for Process Monitoring Demonstration ISPO Task C.59}

\section{DAY 1-FACILITY AND COMPUTER FAMILIARIZATION}

1.1 IET Layout and Facility Description

1.2 Equipment Descriptions

1.3 Instrument and Computer System Description

1.4 Introduction to Computer Use

\section{DAY 2-PROCESS MONITORING DISCUSSIONS}

1.2 Process Monitoring and NTRA Descriptions

2.2 Introduction to Analysis Routines

2.3 Review of Previous Test Runs with Data Analysis Routines

2.4 Test Removals in Progress in the IET During the Day

\section{DAY 3-PROCESS MONITORING IN REMOVAL DETECTION}

3.1 Test for Previous Day Removals

3.2 General Discussion on Process Monitoring and Applications for International Safeguards

3.3 Develop Some Additional Test Procedures with IET Systems

3.4 Artificial Intelligence Application in Safeguards 


\section{AGENDA TOPIC DESCRIPTIONS}

\section{DAY 1-FACILITY AND COMPUTER FAMILIARIZATION}

The first day will be devoted to discussions and presentations to familiarize participants with the IET facility, the processing equipment, instrumentation, and computer systems.

\subsection{IET Layout and Facility Description}

This will be a general discussion of history and purpose of the IET facility. This will include discussion on how the facility relates to a typical reprocessing plant in terms of equipment and flow sheet.

\subsection{Equipment Description}

A more detailed discussion on IET equipment and normal operating modes as they relate to safeguard process monitoring concerns will be presented. This will include details of measurement systems (dip-tube) in the IET that are typical of reprocessing plants. This section of the presentations will include a tour of the facility to provide attendees with the opportunity to see in-cell type equipment and installations typical of an operating plant.

\subsection{Instrument and Computer System Description}

The IET facility is equipped with a modern, commercial computer control system. The computer system is interfaced to typical process instruments and control equipment. Participants will be introduced to principles of measurements (dip-tube system), the instruments involved in measurements, and mechanisms for computer interface as they relate to safeguards measurement concerns.

\subsection{Introduction to Computer Use}

During this session, participants will be given details on the use of the computer systems. The IET facility uses Digital PDP-11 series computers. Participants will be given accounts and passwords on the safeguards computer. This section of the demonstration will deal with log-on procedures and general system concerns to allow the participants to proceed with "hands-on" use of the IET safeguards system. 


\section{DAY 2-PROCESS MONITORING DISCUSSIONS}

The second day is devoted to specific discussions on process monitoring as a safeguards tool and the installed safeguards system in the IET facility. While discussions are in progress, the IET facility will be operating and the IET operations staff will make several removals of material.

\subsection{Process Monitoring and NRTA Descriptions-Introduction to Analysis Routines}

The specifics of the process monitoring application installed in the IET safeguards system will be discussed. These discussions will include goals and sensitivities of the various tests and how they relate to the IET flow sheet. Relationships of process monitoring and NRTA will be discussed.

\subsection{Introduction to Analysis Routines}

All safeguards tests that use process data, whether process monitoring or NRTA, have to deal with spurious signal characteristics of these data and resulting false alarm indications. The IET safeguards system uses a series of data analysis and alarm resolution routines to deal with false alarm indications. These have been described as a "tool kit" for analysis of safeguards data. These tools will be discussed along with the role in relation to the process monitoring and NRTA tests.

\subsection{Review of Previous Test Runs with Data Analysis Routines}

Several test runs of the IET facility have been conducted over the past few years. Some of these runs have included actual removals. Participants will be given the opportunity to "practice" with the safeguards system by review of these past runs. Specific examples of removals and "false alarms" will be demonstrated and discussed.

\subsection{Test Removals in Progress in the IET During the Day}

During the discussions on the second day, the IET operating staff will make several actual removals. They will be general guidelines for possible removals, but the specifics of the removals will not be known to the participants or the safeguards staff involved in the demonstration. 


\section{DAY 3-PROCESS MONITORING IN REMOVAL DETECTION}

The final phase of the demonstration allows participants the opportunity to use the system to detect removals. An opportunity is presented to discuss specifics of the IET system and possible role for this approach in international safeguards.

\subsection{Test for Previous Day Removals}

Participants will actually try to identify removals, quantify them, and isolate the location. Participants will work in teams of 2 to 3, using computer terminals and installed software. Each team will summarize results and compare with other teams. As a group, participants will develop a report and compare findings with actual removals which will be reported by the operators group.

\subsection{General Discussions on Process Monitoring and Applications for International Safeguards}

This will be an opportunity for participants to discuss process monitoring and its role in international safeguards. There are many questions on applicability, minimum data requirements, and the ability of regulatory agencies to deal with large quantities of process data. This will be an opportunity for agency personnel, with the benefit of some fresh experiences in process monitoring applications, to exchange views.

\subsection{Develop Some Additional Test Procedures with IET Systems}

The IET facility is equipped with a modem, computerized process control system. A minimum set of available data is used in the installed process monitoring routines. With the experiences gained during the previous session, participants will discuss additional applications and uses of the data acquisition capabilities to try to implement some new routines.

\subsection{Artificial Intelligence Applications in Safeguards}

Participants will have been exposed to a large amount of data and a number of safeguards analysis routines. They will use a variety of safeguards data analysis routines to resolve alarms or confirm removals. The final session will expose them to some aspects of the expert systems area of artificial intelligence and explore the role of these advanced computer applications in safeguards. 
ORNL/TM-10912

ISPO-293

Dist. Category UC-526

\section{INTERNAL DISTRIBUTION}

\author{
1. D. E. Benker \\ 2. W. D. Bond \\ 3-5. W. D. Burch \\ 6. D. A. Costanzo \\ 7. S. F. DeMuth \\ 8-17. M. H. Ehinger \\ 18. R. E. Eversole \\ 19. M. J. Feldman \\ 20. R. K. Genung \\ 21. R. W. Glass \\ 22. W. S. Groenier \\ 23-27. M. J. Haire \\ 28. J. E. Hardy \\ 29. R. T. Jubin \\ 30. R. K. Kibbe \\ 31. L. N. Klatt \\ 32. E. H. Krieg, Jr. \\ 33. B. E. Lewis
}
34. S. A. Meacham
35. C. F. Metz, III
36. D. R. Moser
37. R. E. Norman
38. W. W. Pitt
39. K. E. Plummer
40. W. Reich
41. J. H. Shaffer
42. S. P. Singh
43. B. B. Spencer
44-45. J. G. Stradley
46. J. W. Wachter
47. C. R. Weisbin
48-49. Laboratory Records
50. Laboratory Records ORNL-RC
51-52. FRD Publications Office
53. ORNL Patent Section

\section{EXTERNAL DISTRIBUTION}

54. D. E. Bailey, Director, Division of Fuels and Reprocessing, Office of Facilities, Fuel Cycle, and Test Programs, NE-471, U.S. Department of Energy, Washington, DC 20545.

55. F. P. Baranowski, 657 Fairfax Way, Williamsburg, VA 23185.

56. J. E. Dunn, ORNL/CFRP On-Site Representative, USDOE/PNC Collaboration Program, Reprocessing Technology Development Division, Tokai Works, Power Reactor and Nuclear Fuel Development Corporation, Tokai-mura, Ibaraki-ken, Japan, Post No. 319-11.

57-58. C. W. Emeigh, USNRC, MS 88-1SS, Washington, DC 20555.

59. R. W. Foulkes, BNFL, PLC, Risley, Warrington WA36AS, United Kingdom.

60. L. Green, International Safeguards Project Office, Brookhaven National Laboratory, Upton, NY 11973.

61-65. E. A. Hakkila, Los Alamos National Laboratory, Los Alamos, NM 87545.

66-67. R. Hawkins, Lamb Associates, Inc., 1684 E. Gude Drive, \#303, Rockville, MD 20850.

68. B. J. Jones, BNFL, PLC, Risley, Warrington WA36AS, United Kingdom.

69. M. J. Ohanian, Associate Dean for Research, College of Engineering, 300 Weil Hall, University of Florida, Gainesville, FL 32611. 
70. M. J. Rohr, Program Manager, Consolidated Fuel Reprocessing Program, Energy Programs Division, Energy Technology Branch, Oak Ridge Operations Office, U.S. Department of Energy, P.O. Box 2001, Oak Ridge, TN 37831.

71. K. E. Sanders, DOE, Office of Safeguards and Security, DP342.2, GTN, Washington, DC 20545.

72-73. B. W. Smith, Battelle Pacific Northwest Laboratory, P.O. Box 999, Richland, WA 99352.

74-148. A. Waligura, International Safeguards Project Office, Brookhaven National Laboratory, Upton, NY 11973.

149-150. R. Weh, DWK, Hamburger Allec 4, Postf.14 07, D-300 Hannover 1, Federal Republic of Germany.

151. Office of Assistant Manager for Energy Research and Development, DOE-ORO, Oak Ridge, TN 37831.

152-223. Given distribution as shown in TIC-4500 under UC-526, Consolidated Fuel Reprocessing Category. 